MARCEL RODAS CEZARETTI

BRASIL E AS NORMAS DOS ACORDOS INTERNACIONAIS

EM MATÉRIA COMERCIAL

DISSERTAÇÃO DE MESTRADO

ORIENTADOR: PROFESSOR DOUTOR MASATO NINOMIYA

UNIVERSIDADE DE SÃO PAULO

FACULDADE DE DIREITO

SÃO PAULO - SP

2017 

MARCEL RODAS CEZARETTI

\section{BRASIL E AS NORMAS DOS ACORDOS INTERNACIONAIS EM MATÉRIA COMERCIAL}

Dissertação de Mestrado, apresentado à Banca Examinadora do Programa de Pós-Graduação em Direito, da Faculdade de Direito da Universidade de São Paulo, na área de concentração Direito Internacional, sob a orientação do Professor Doutor Masato Ninomiya.

\section{UNIVERSIDADE DE SÃO PAULO \\ FACULDADE DE DIREITO SÃO PAULO - SP \\ 2017}


Autorizo a reprodução e divulgação total ou parcial deste trabalho, por qualquer meio convencional ou eletrônico, para fins de estudo e pesquisa, desde que citada a fonte.

\section{Catalogação da}

Publicação

Serviço de Biblioteca e Documentação

Faculdade de Direito da Universidade de São Paulo

\section{Cezaretti, Marcel Rodas}

Brasil e as Normas dos Acordos Internacionais em Matéria Comercial. / Marcel Rodas Cezaretti; orientador Masato Ninomiya -- São Paulo, 2017.

$421 \mathrm{p}$

Dissertação (Mestrado - Programa de Pós-Graduação em Direito Internacional) - Faculdade de Direito, Universidade de São Paulo, 2017.

1. Normas dos Acordos Internacionais em Matéria Comercial. 2. Bilaterais. 3. OMC. 4. ALADI. 5. MERCOSUL. I.

Ninomiya,Masato, orient. II. Título. 
Nome: CEZARETTI, Marcel Rodas

Título: Brasil e as normas dos acordos internacionais em matéria comercial.

Dissertação apresentada à Faculdade de Direito Internacional da Universidade de São Paulo para obtenção do título de Mestre em Direito Internacional.

Aprovado em:

Banca Examinadora

Prof. Dr.

Instituição:

Julgamento:

Prof. Dr(a).

Instituição:

Julgamento:

Prof. Dr(a).

Instituição:

Julgamento: 



\section{RESUMO}

O objeto da presente dissertação é estudar o comércio no Brasil desde sua independência até os dias atuais, sob a ótica dos tratados internacionais, de natureza comercial, concluídos pelo País. Primeiramente, são resumidos aspectos teóricos fundamentais, imprescindíveis para embasar, cientificamente, o trabalho: tratados internacionais, organizações internacionais, direito do comércio internacional, ministérios e órgãos ligados ao comércio. A seguir apresenta-se o fruto de pesquisa, que reuniu quatrocentos e trinta tratados, que constituem a quase totalidade dos tratados comerciais brasileiros. Eles são divididos em: (i) bilaterais; (ii) concluídos sob a égide do GATT/OMC, (iii) da ALADI, (iv) do MERCOSUL e (v) principais tratados vigentes e operantes; e tratados em negociação. Após, são estudados, um a um, todos os tratados reunidos e preenchidas fichas individuais de cada um.

Após exame de cada categoria de tratado, formulam-se conclusões técnico-jurídicas e político-econômicas. Além dessas conclusões parciais, ao longo do trabalho, há, no final, conclusões gerais.

Palavras-chave: direito comercial, direito dos tratados, tratados concluídos pelo Brasil em matéria de comércio, GATT/OMC, ALALC, ALADI e MERCOSUL 


\begin{abstract}
The proposed dissertation is to examine trade in Brazil from its Independence Day, on September 7, 1822, to the present day. Highlighting the nature of commercial activities from the insight of international treaties concluded during this period, the purpose of this study is to expand research on trade in Brazil. First, basic theoretical aspects are summarized, essential to give a scientific basis to the work: International Treaties, International Organizations, International Trade Law, Ministries, and Trade-related Entities. The following is the true essence of this research, bringing together four hundred and thirty treaties, which constitute almost all Brazilian trade agreements. They are divided into: (I) bilateral treaties; (II) treaties concluded under the watch of the GATT/WTO; (III) ALADI treaties; (IV) MERCOSUR treaties; and (V) main, current, and operating treaties under negotiation. Afterwards, one by one, all the collected treaties are filled and individual aspects of each are studied.
\end{abstract}

After the examination of categories from each treaty, Technical, Legal, Political, and Economic conclusions are formulated. In addition to the partial conclusions made, there are also general conclusions made at the end.

Keywords: Trade Law, Treaty Law, Trade Agreements concluded by Brazil, GATT/WTO (General Agreement on Tariffs and Trade/World Trade Organization), ALALC (LAFTALatin-American Free Trade Association), ALADI (LAIA- Latin-American Integration Association), MERSOSUL (MERCOSUR- Southern Common Market) 


\section{SUMÁRIO}

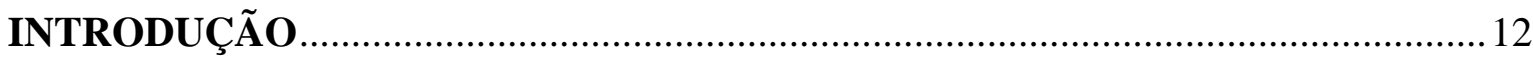

PRIMEIRA PARTE - FUNDAMENTAÇÃO TEÓRICA …………………………..... 14

1. CAPÍTULO PRIMEIRO - TRATADOS INTERNACIONAIS. .......................... 14

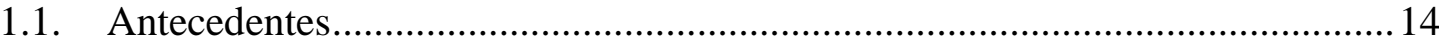

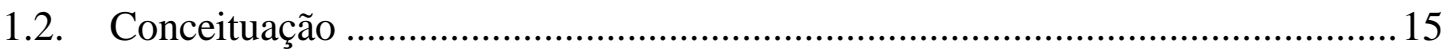

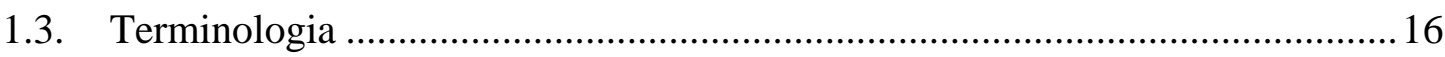

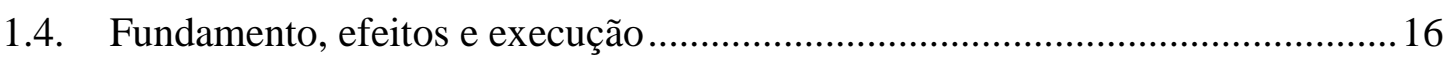

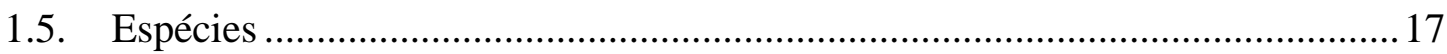

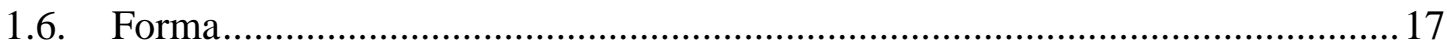

1.7. Processo de conclusão dos tratados solenes ……………………………….......... 18

1.8. Processo de conclusão dos acordos em forma simplificada ................................. 19

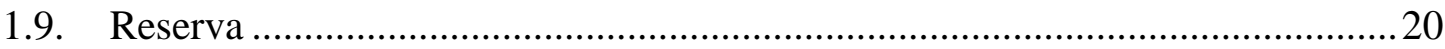

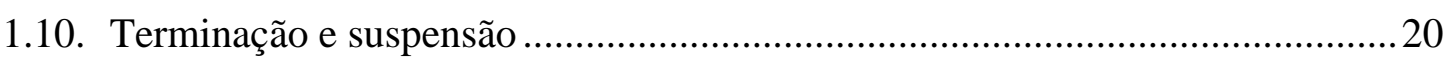

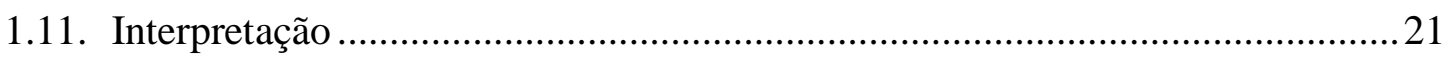

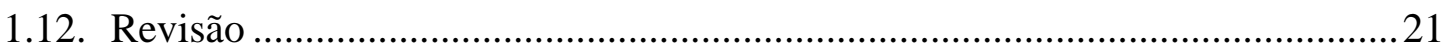

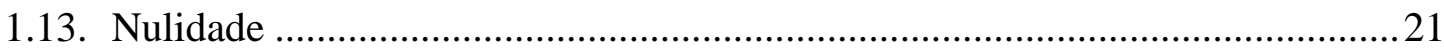

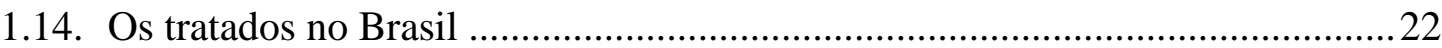

2. CAPÍTULO SEGUNDO: ORGANIZAÇÕES INTERNACIONAIS..................23

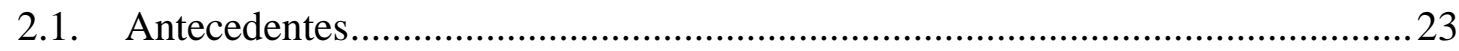

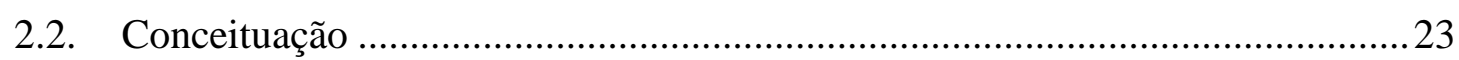

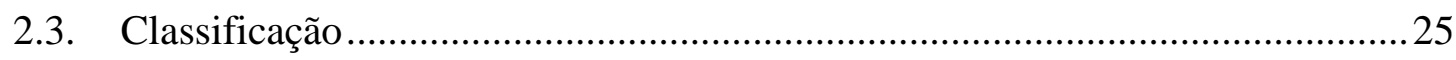

2.4. Organizações com finalidades econômica e comercial e Organizações Regionais

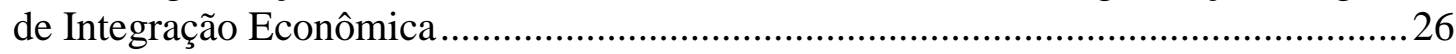

2.5. Organização Mundial do Comércio (OMC) ………........................................ 27

2.6. Conferência das Nações Unidas sobre Comércio e Desenvolvimento (UNCTAD)

2.7. Associação Latino Americana de Livre Comércio (ALALC)................................33

2.8. Associação Latino-Americana de Integração (ALADI) ………………………...... 34

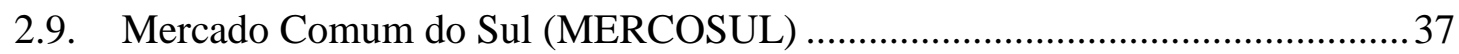

2.10. Organizações Internacionais Não Governamentais (ONG's )............................4 40

2.11. O Brasil e as Organizações Internacionais ......................................................... 41

3. CAPÍTULO TERCEIRO: DIREITO DO COMÉRCIO INTERNACIONAL. 42

3.1. Evolução do Direito do Comercio Internacional e Acordos de Comercio .........42

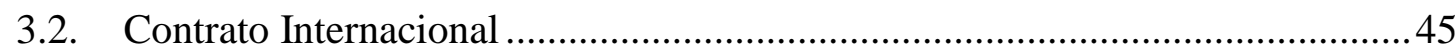

4. CAPÍTULO QUARTO: MINISTÉRIOS, COMISSÕES E INSTITUIÇÕES BRASILEIROS RELACIONADOS AO COMÉRCIO INTERNACIONAL...........47 


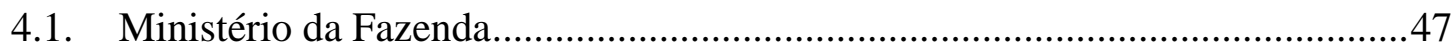

4.2. Ministério da Justiça e Cidadania ....................................................................48

4.3. Ministério das Relações Exteriores. .................................................................48

4.4. Ministério da Indústria, Comércio Exterior e Serviços ....................................50

4.5. Câmara de Comércio Exterior (CAMEX) .......................................................52

4.6. Agência de Promoção de Exportações do Brasil (Apex- Brasil)........................53

4.7. Confederação Nacional da Indústria (CNI) .....................................................54

SEGUNDA PARTE - TRATADOS CONCLUÍDOS PELO BRASIL, TENDO O COMÉRCIO POR OBJETO. PESQUISA E EXEGESE .........................................56

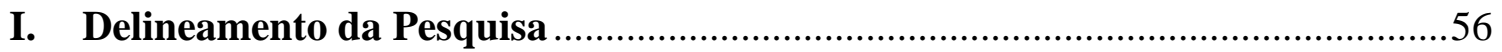

5. CAPÍTULO QUINTO: TRATADOS BILATERAIS CONCLUÍDOS PELO

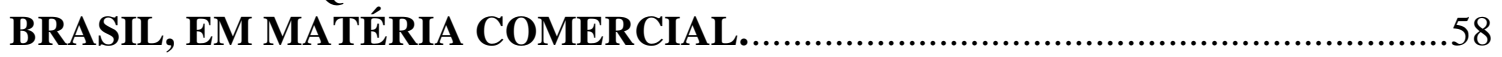

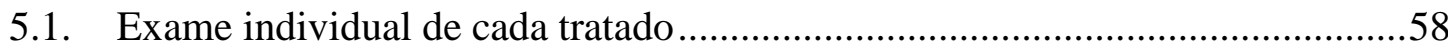

5.2. Considerações técnico-jurídicas e político-econômicas sobre os tratados

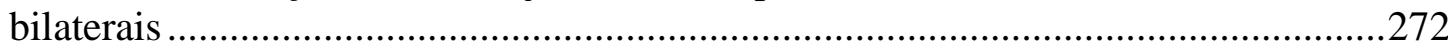

6. CAPÍTULO SEXTO: TRATADOS DA ORGANIZAÇÃO MUNDIAL DO

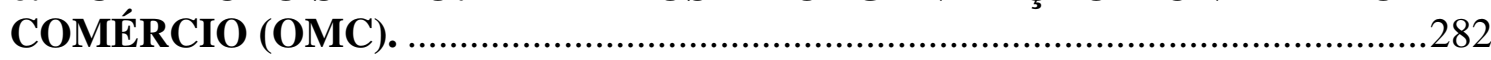

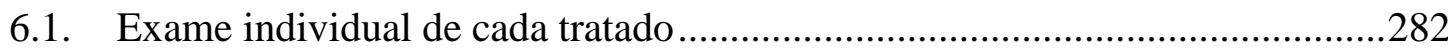

6.2. Considerações técnico-jurídicas e político-econômicas sobre os tratados da OMC .287

7. CAPÍTULO SÉTIMO: TRATADOS DA ASSOCIAÇÃO LATINO-

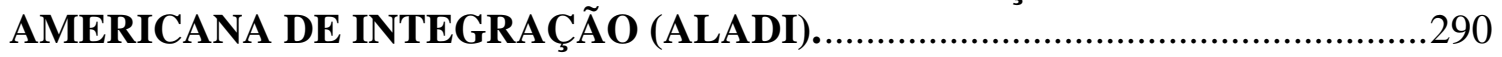

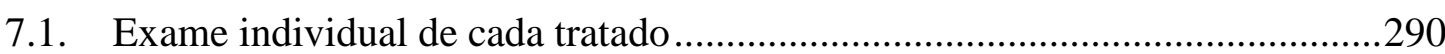

7.2. Considerações técnico-jurídicas e político-econômicas sobre os tratados da

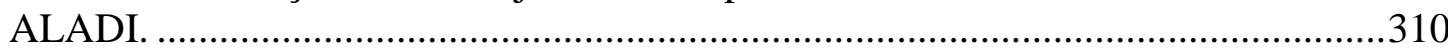

8. CAPÍTULO OITAVO: TRATADOS DO MERCADO COMUM DO SUL

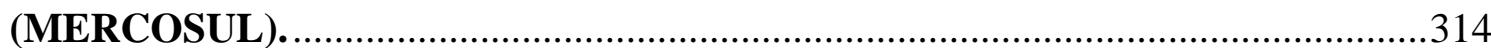

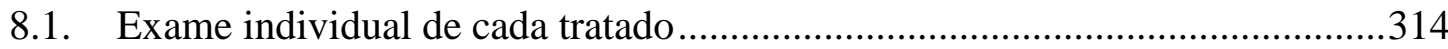

8.2. Considerações técnico-jurídicas e político-econômicas sobre os tratados do

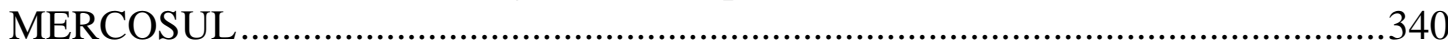

9. CAPÍTULO NONO: PRINCIPAIS TRATADOS VIGENTES EM MATÉRIA

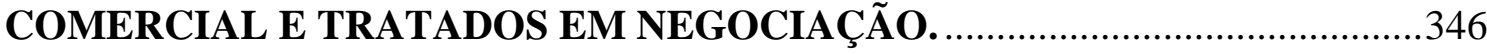

9.1. Principais tratados vigentes em matéria comercial concluídos pelo Brasil desde

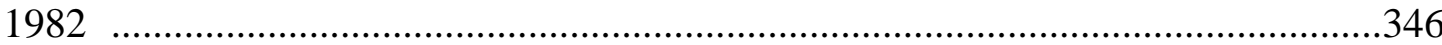

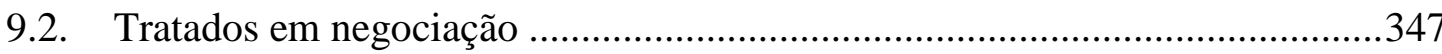

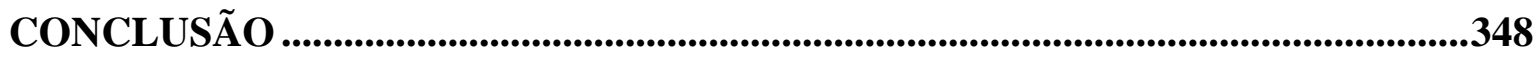

REFERÊNCIAS ....................................................................................................356

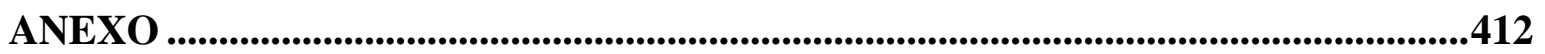





\section{INTRODUÇÃO}

Muitas são as variáveis, econômicas, jurídicas etc., que influem no aumento e na agilidade do comércio internacional de um país. Dentre elas, há variáveis de cunho instrumental, como os instrumentos internacionais utilizados para normatizar os acordos de vontade entre os Estados. Os tratados internacionais, desde a antiguidade, vêm servindo também a esse propósito.

Uma pesquisa, que reúna o maior contingente possível dos tratados concluídos pelo Brasil em matéria comercial e os analise, certamente ajudará a esclarecer a mecânica do comércio internacional. Por essa razão, a presente dissertação propõe-se a reunir tais tratados, concluídos desde 1822, examiná-los com o intuito de verificar que espécies de tratados vêm sendo utilizado nesse contexto, bem como que papel os tratados internacionais tiveram e vêm tendo no comércio internacional do Brasil.

O trabalho divide-se em duas partes. Na primeira parte são estudados, de maneira sintética, instituições de direito internacional público, direito internacional privado e de direito do comércio internacional, que reúnam conhecimentos indispensáveis para embasar a análise dos tratados internacionais, com a profundidade que o conhecimento científico exige. Para possibilitar boa compreensão, explana-se também sobre ministérios e órgãos brasileiros, públicos e privados, com ingerência no comércio.

A segunda parte contém pesquisa própria, feita junto à Presidência da República; ao Ministério das Relações Exteriores (Departamento de Atos Internacionais); Ministério da Indústria, Comércio Exterior e Serviços; Associação Latino Americana de Integração - ALADI; Mercado Comum do Sul - MERCOSUL, à Organização Mundial do Comércio - OMC, Conferência das Nações Unidas sobre Comércio e Desenvolvimento - UNCTAD e Conselho Nacional da Indústria. Tal pesquisa reuniu 430 tratados que o Brasil, desde sua independência, em 1822, vem concluindo em matéria comercial. A seguir é feita análise dos tratados coletados durante a pesquisa, à luz dos conceitos teóricos deduzidos na primeira parte do trabalho. Com o intuito de obter subsídios para o trabalho, ademais da pesquisa realizada, foram feitas entrevistas com três personalidades - Embaixador Santiago Irazabal Mourão, Subsecretário-Geral de Cooperação Internacional, Promoção Comercial e Temas Culturais do MRE; Doutor Fernando Magalhães Furlan, antigo secretário-executivo do MDIC e Professor Welber Barral, antigo Secretário de Comércio Exterior do MDIC- cujas respostas constam do ANEXO.

Finalmente, são traçadas as conclusões finais do trabalho. 


\section{CONCLUSÃO}

As normas dos acordos internacionais em matéria comercial constituem o tema desta dissertação. São de interesse, portanto de um lado, as características dos tratados utilizados (aspecto técnico de direito dos tratados); e, de outro, o respectivo conteúdo normativo.

O Brasil vem atuando, desde a independência por meio da conclusão de tratados bilaterais (diplomacia bilateral) e, após o surgimento das organizações internacionais, também nas organizações universais de comércio - máxime o GATT/OMC- e nas organizações regionais de integração econômica: ALALC, ALADI e MERCOSUL (diplomacia multilateral). No referente à essas organizações, o Brasil atua, tanto como membro da organização, com maior ou menor protagonismo e interesse; quanto, como signatário dos respectivos tratados negociados sob sua égide.

As conclusões referentes aos tratados bilaterais e à atuação brasileira no GATT/OMS, ALADI e MERCOSUL encontram-se no tópico 2, respectivamente, dos capítulos sexto, sétimo e oitavo; e integram as presentes conclusões finais.

Cabe agora, como conclusão, redundar sobre o papel do Brasil nas organizações referidas, que enfeixam a atuação brasileira no comércio a nível internacional; bem como elaborar visão geral sobre a situação passada e presente e fazer prognósticos.

O GATT/OMC teve papel fundamental na normatização das trocas internacionais, no estabelecimento das melhores práticas e na solução de controvérsias. O panorama atual da OMC, é de certa tensão quanto ao futuro, entre os países-membros desenvolvidos e os em desenvolvimento. Estes insistem no aprofundamento da liberalização dos produtos agrícolas; enquanto aqueles preferem tratar de "novos temas": obrigações relacionadas a propriedade intelectual, comércio eletrônico etc.

A Rodada Doha, iniciada a mais de quinze é ainda não concluída, faz alguns críticos falar no insucesso da OMC como instrumento de liberalização comercial. Tal observação é decorre de visão unilateral da Organização, pois seus outros dois pilares - monitoramento e solução de controvérsias - funcionam regularmente, com manutenção das obrigações avençadas e ganhos comerciais. Ademais, há aspectos positivos da Rodada: a recente conclusão do Acordo de Facilitação de Comércio, que entrará em vigor, assim que dado número de ratificações forem depositadas. 
Entretanto, como as negociações tradicionais, feitas conforme o método do single undertaking não avançaram, duas consequências são percebidas. A primeira, verificada no âmbito interno da OMC, fez com que os acordos de participação voluntária e de temática livre (exemplo: Trade in Services Agreement - TISA) tomassem a dianteira. Consoante a segunda, externamente à da Organização, importantes atores do comércio internacional passaram a investir em esquemas alternativos, como o Transatlantic Trade and Investment Partnership (TTIP), o Trans-Pacific Partnership - TPP) e o Regional Comprehensive Economic Partnership (RCEP).

O Brasil, signatário do GATT 1947 e membro-fundador da OMC, sempre defendeu as negociações comerciais multilaterais, sendo reconhecido tanto pelos demais membros da Organização, quanto pela sua burocracia interna, por seu protagonismo e apoio, para que países em desenvolvimento, negociassem, com força e realce, certos temas como fim de subsídios à exportação, acesso a mercados agrícolas e apoio interno; bem como por seu aporte para a solidificação do sistema de solução de controvérsias. O fato de o atual Diretor-Geral da OMC ser brasileiro - o embaixador Roberto Azevêdo - desde 2013 e forte candidato à reeleição para o triênio subsequente, atesta o reconhecimento do papel que o Brasil vem prestando à Organização.

O futuro da OMC depende da evolução da política internacional e de seu posicionamento frente à comunidade internacional. Certamente, ela manter-se-á como uma referência de melhores práticas internacionais, ponto de convergência em questões de conteúdo e órgão de solução de controvérsias.

As negociações da ALADI, desde a década de 90 do passado século, contrariamente ao método utilizado pela OMC, de amplas rodadas multilaterais, centram-se em acordos bilaterais ou plurilaterais de alcance parcial. Máxime nos chamados Acordos de Complementação Econômica (ACEs), que funcionam como guarda-chuva para esquemas de liberalização comercial entre alguns países membros, por meio de cronogramas de desgravação tarifária. Um dos exemplos foi o MERCOSUL surgido graças ao ACE $\mathrm{n}^{\circ} 18$.

O Brasil, sob a égide da ALADI, tem concluído, desde os últimos anos do século XX, acordos com Chile (1996), Bolívia (1996), México (2002), Colômbia (2004), Equador (2004), Venezuela (2004 e 2012), Peru (2005) e Cuba (2006), que o fizeram detentor, individualmente ou em conjunto com o MERCOSUL, de ampla rede de preferências comerciais na América Latina. Tarifa zero - 100\% de preferência tarifária - com Chile e Bolívia, para todo o universo 
de tarifas. Com exceção de Guiana e Suriname, estão em andamento com os países da América do Sul, cronogramas de desgravação tarifária, com o objetivo de conformar, até 2019, área virtual de livre comércio. Hoje, nas exportações do Brasil para os países da ALADI, tãosomente $5,9 \%$ do total do universo tarifário não possui tarifas preferenciais ou tarifa zero.

Novos temas passaram a interessar a ALADI, a partir da última década do passado século: cooperação aduaneira, integração física, serviços, facilitação do comércio e promoção comercial. Materialização disso é o acordo concluído entre Brasil e Peru, sobre investimentos, serviços e compras governamentais; a negociação corrente entre Brasil e México sobre coerência regulatória, facilitação do comércio e propriedade intelectual; bem como o projeto de Certificação de Origem Digital.

$\mathrm{O}$ aumento do número de membros é outra característica, relativamente recente da ALADI, que de onze membros passou para treze (Cuba, em 1999 e Panamá (2012); estando a Nicarágua em processo de adesão. Tal vem possibilitando a realização da EXPO ALADI, que, desde 2014, reúne empresários dos países membros, da América Central e do Caribe.

O MERCOSUL, além de projeto de integração econômica, integra, essencialmente, o projeto de desenvolvimento nacional brasileiro, em virtude de sua contribuição para a estabilidade, paz, cooperação e prosperidade regionais. Ademais, seu interesse econômico para o país é inegável. No período de 2006 a 2015, dos US\$ 224 bilhões de superávit comercial brasileiro, US\$ 87 bilhões derivaram-se do comércio com os membros do MERCOSUL.

Além da liberalização comercial intrabloco, o MERCOSUL negocia e executa projetos visando a diversificação produtiva e o desenvolvimento socioeconômico. O foco atual é a eliminação das barreiras não tarifárias restantes e o cuidado com compras governamentais e facilitação de investimentos.

Recente reavaliação do bloco econômico denotou consenso para a necessidade de revitalização da integração econômica e comercial, com maior liberalização e abertura, não somente do mercado interno, mas também do mercado externo. A finalidade é estimular a mobilidade de capitais entre os países do MERCOSUL, alocar eficientemente tais recursos, fazendo com que o ambiente negocial seja mais amigável aos empresários; assim como agilizar as negociações comerciais extra-regionais, para incrementar suas exportações e angariar capitais. 
Desde sua criação, o MERCOSUL toma decisões de maneira intergovernamental, ou seja, pelo voto afirmativo de todos os Estados-Membros. Essa modalidade não evoluiu com o passar do tempo, como seria de se esperar. Por outro lado, foram frequentes as crises econômicas, políticas e ideológicas, por que passaram, praticamente, todos os partícipes do bloco; bem como o relacionamento conturbado entre alguns de seus membros. Ademais, por força da Resolução GMC (Grupo Mercado Comum) n 32/00, os membros do MERCOSUL somente podem participar de negociações com terceiros países, em bloco. Em razão de tal pano de fundo, não é de se estranhar que haja quem se refira à estagnação institucional e à paralisia decisória, por que passaria o bloco, e que ainda não arrefeceu, apesar da melhora nas relações comerciais entre Brasil e Argentina, após 2015.

Recentemente, importantes mutações foram efetuadas com o objetivo de incrementar o comércio exterior brasileiro. Ainda sob a presidência Dilma Rousseff, em 2015 e 2016, o Plano Nacional de Exportações definiu mercados-alvos até 2018; veio a lume o Portal Único de Comércio Exterior, que permite a total digitalização das operações de exportação e importação, reduzindo o respectivo tempo em até 50\%; estabeleceu-se instrumento para proteção de investimento, o Acordo de Cooperação e Facilitação de Investimentos (ACFIs); e concluíramse acordos preferenciais de comércio com o Chile, Peru, Colômbia, Paraguai, Argentina etc., assim como o primeiro acordo bilateral de Compras Governamentais com o Peru. Sob a presidência Michel Temer, foram feitas mudanças estruturais, transferindo-se a Apex-Brasil e a Camex do MDIC para o MRE, e do BNDES para o Ministério de Planejamento e Gestão (MPOG), com o intuito de aproximar a diplomacia de Estado da diplomacia comercial ${ }^{524}$. Mesmo tendo em conta que a tendência majoritária dos países seja ter estruturas de comércio exterior e de política externa independentes, é cedo para se julgar os benefícios dessas mudanças.

Tanto é verdade que, presentemente, o peso dos interesses econômicos é razão fundamental para definir as estratégias externas, que das dez diretrizes formuladas pelo atual Ministro das Relações Exteriores, seis referem-se à política comercial. Relativamente ao MERCOSUL, há o intuito de renovar o agrupamento regional, fortalecendo o livre-comércio entre seus membros e eliminando barreiras, ainda altas dentro do bloco. Por outro lado, de

\footnotetext{
${ }^{524}$ Aspecto positivo da inclusão da Apex-Brasil no Itamaraty é possibilitar que os interesses nacionais se articulem, externamente, de maneira mais eficiente, além de possibilitar sinergias relativamente às estratégias de negócio.
} 
maneira pragmática, o multilateralismo da OMC fica um tanto relativizado, ressaltando-se a conveniência de progredir com os acordos preferenciais do comércio.

O MRE possui ampla estrutura de promoção comercial no exterior, tendo capacidade, entre outras coisas, para: produzir informações e estudos de inteligência comercial; organizar missões e eventos comerciais; e gestionar junto a governos estrangeiros. Entretanto, o MRE atua em conjunto com outros órgãos brasileiros, em particular o Ministério da Indústria, Comércio Exterior e Serviços (MDIC), na elaboração e na execução da estratégia de promoção comercial brasileira, na manutenção de ações de complementaridade entre os dois ministérios, revigorando as ações de política externa, mormente no âmbito das negociações dos tratados comerciais.

O fato é que a despeito de todas as mudanças, a economia brasileira mantémrelativamente fechada, não sendo alta a percentagem do resultado do comércio exterior em seu produto interno bruto total. A abertura comercial, decantada como objetivo por vários governos, esbarra, no plano interno, com a baixa competitividade de sua indústria, em razão dos altos custos, inclusive logísticos, alta tributação e burocracia excessiva; e, no externo, com crises econômicas e protecionismos internacionais.

O Brasil, historicamente, inseriu-se no comércio internacional valendo-se mais de suas vantagens comparativas, percebidas e exploradas desde o período colonial, no fornecimento de commodities agrícolas e minerais ao mundo do que, propriamente, pela negociação de tratados comerciais, que possuíram peso marginal no referente à inserção do Brasil no comércio internacional.

A partir da abertura comercial verificada na década de 90, do século XX, o Brasil priorizou as negociações comerciais no âmbito multilateral (OMC) e no âmbito regional (MERCOSUL). A prioridade concedida a esses dois fóruns justificava-se pela lógica de que, no plano multilateral, os países em desenvolvimento e de menor nível de desenvolvimento relativo possuem melhores condições de negociar, se o fizerem conjuntamente, em bloco.

No âmbito do MERCOSUL, o Brasil submeteu-se à restrição imposta pela Decisão 32/2000 do Conselho de Mercado Comum, que obriga os membros do bloco a negociar acordos de preferências tarifárias em conjunto. A excessiva priorização do bloco regional deu-se, certamente, pela ambição de consolidar o país como líder regional, muito embora tal condição seja ínsita ao Brasil, devido à sua inconteste superioridade econômica, comercial, territorial e populacional. Em que pese a exceção de negociar ACEs entre o MERCOSUL e países da 
ALADI, que não fazem parte do bloco comercial, abriu mão de negociar acordos comerciais mais efetivos fora do MERCOSUL. Além de tudo, o componente ideológico, de há muito, tem relativizado a importância do MERCOSUL no prisma comercial.

$\mathrm{Na}$ área da OMC, por seu turno, as negociações multilaterais encontram-se, praticamente, paralisadas, há mais de uma década.

Entretanto, os esforços verificados nos últimos anos, no sentido de serem concluídos ACFIs, além de acordos de serviços, compras governamentais e facilitação de comércio, aparentemente, sinaliza reação do Brasil no sentido de superar essa tendência histórica de ocupar posição secundária no comércio internacional, muito aquém do tamanho de sua economia.

Nesse contexto, a participação do Brasil no comércio internacional tem-se mantido marginal diante do tamanho de sua economia, fato comprovado pelos números sofríveis de seu comércio internacional $^{525}$. Críticas de especialistas e pressões de entidades representativas do setor privado, como a Confederação Nacional da Indústria (CNI) e Confederação Nacional da Agricultura, (CNA), tem levado o governo federal a inserir mais efetivamente o Brasil no âmbito das trocas comerciais internacionais, incrementando a atuação do governo federal (notadamente MDIC e MRE) nas negociações comerciais.

Foram firmados, nos últimos anos, sete Acordos de Cooperação e Facilitação de Investimentos $(\mathrm{ACFIs})^{526}$, estando dois pendentes de assinatura ${ }^{527}$. Embora não se trate de acordos comerciais stricto sensu, são relevantes como incentivadores de investimentos, em virtude de seu potencial como geradores de trocas comerciais. Lembre-se que os ACFIs representam um modelo elaborado pelo MDIC para substituir os antigos Acordos de Promoção e Proteção de Investimentos (APPIs), baseados no modelo internacional dos Bilateral Investment (BITs), que, assinado, em número de quatorze pelo Brasil, na década de 90, não chegaram a ser ratificados pelo Congresso brasileiro, por conta de questionamentos acerca da constitucionalidade de diversas de suas disposições.

\footnotetext{
${ }^{525}$ Embora a economia brasileira seja considerada, atualmente, a nona economia do mundo, a participação do Brasil no comércio internacional está na $25^{\mathrm{a}}$ posição.

${ }^{526}$ São eles: Angola, Chile, Colômbia, Maláui, México, Moçambique (assinados em 2015) e Peru (assinado em 2016).

527Jordânia e Índia (assinados em 2016).
} 
No âmbito do Mercosul, esforços têm sido feitos no sentido de fortalecer a rede de acordos vigentes entre os membros do bloco, por meio de negociações referentes a compras governamentais, investimentos e serviços.

Também merecem destaque a conclusão dos seguintes acordos, cuja implementação deve ocorrer no ano de 2017: Acordo de Ampliação Econômico Comercial Brasil-Peru; Antecipação de Cronogramas do Acordo de Bens com o Peru; Acordo Automotivo BrasilColômbia; Protocolo de Serviços Mercosul-Colômbia; Protocolo Têxtil e Siderúrgico com a Colômbia; Acordo Comercial Expandido Brasil-México; Acordo de Compras Governamentais Brasil-Chile; Acordo sobre Serviços Financeiros Brasil-Chile; Acordo Automotivo BrasilParaguai; e Acordo sobre Compras Governamentais Brasil-Colômbia; e Acordo MercosulAliança do Pacífico.

Espera-se para 2017, avanços nas negociações do Acordo Mercosul-União Europeia, Mercosul-Índia e Mercosul-EFTA (Associação Europeia de Livre Comércio, ou European Free Trade Association). Diálogos exploratórios entre o Mercosul e o Canadá, a Coreia do Sul e o Japão também devem ser empreendidos no decorrer de 2017.

No âmbito bilateral Brasil-EUA, por se tratar de temas fora dos limites estabelecidos pela mencionada Resolução GMC n 32/00, devem ser alcançados acordos em questões referentes à convergência regulatória, facilitação de comércio e propriedade intelectual.

Diante do contexto atual, do perfil dos acordos já firmados historicamente, dos acordos em negociação e dos prognósticos descritos, é possível identificar uma tendência de mudança no perfil do Brasil quanto à sua inserção no comércio internacional. Se por um lado, no cenário atual, o Brasil é signatário de uma rede de acordos concentrados na América Latina e com ênfase em acordos de natureza tarifária, é possível identificar uma estratégia do MRE e do MDIC, como resposta a pressões dos setores exportadores brasileiros, de estabelecer acordos com uma rede mais variada de países em termos geográficos, de perfil de desenvolvimento e de escopo (incluindo temas de investimentos, serviços, compras governamentais e propriedade intelectual).

Tendo em vista o cenário internacional sob uma perspectiva mais ampla, com o viés protecionista que se tem observado nos Estados Unidos da América (que se refletiu na eleição do Presidente Trump) e na União Europeia (que causou o Brexit); a intensa rejeição, por parte da opinião pública europeia, quanto ao acordo Acordo de Livre Comércio com o Canadá (UECETA); e a emergência de lideranças políticas conservadoras e populistas em diversos países, 
é possível antever retrocesso quanto a esquemas já estabelecidos de acordos comerciais, como os mencionados TTIP, TPP e a própria União Europeia.

Embora essa tendência tenha o potencial de provocar uma onda protecionista mundial, com reflexos negativos para as exportações brasileiras, pode representar oportunidades. Não se deve esquecer os impactos negativos que TTIP e TPP teriam para as exportações brasileiras, em razão de o Brasil encontrar-se à margem de tais acordos. Caso o discurso eleitoral do vencedor das eleições norte-americanas seja colocado em prática e tais acordos se frustrem, deixará de haver impactos negativos para o comércio brasileiro. Além disso, com a saída do Reino Unido do bloco europeu, já se fala na conclusão de acordo comercial entre aquele país e o Brasil, além de menores entraves à conclusão das negociações entre Mercosul e União Europeia, que se arrastam há mais de quinze $\operatorname{anos}^{528}$.

No mesmo sentido, por força das dificuldades previstas no âmbito do TLCAN, a partir de declarações contrárias ao acordo por parte do Presidente eleito dos Estados Unidos da América, prevê-se uma maior aproximação e possibilidade de acordos entre Brasil e/ou Mercosul, México e Canadá (já estando em andamento, relativamente a este último, diálogo exploratório para celebrar acordo comercial com o Mercosul).

A conclusão da pequena relevância dos tratados de comércio brasileiros, mormente nos últimos anos, foi corroborada por recente estudo feito pelo Credit Suisse, que afirmou possuir o Brasil a economia mais dentre os países emergentes e a menor corrente comercial em um grupo de vinte e um emergentes. Tal se deve, além do número diminuto de acordos comerciais nos últimos anos, aos altos impostos e barreiras tarifárias. ${ }^{529}$

\footnotetext{
${ }^{528}$ Interessante observar que, durante a troca de concessões realizadas entre Mercosul e UE em maio de 2016, devido a pressões dos produtores de carne bovina do País de Gales, que faz parte do Reino Unido, Bruxelas retirou, da oferta europeia ao Mercosul, concessões referentes ao mencionado produto, prejudicando a obtenção de acordo. ${ }^{529}$ Disponível em: <http://www.valor.com.br//brasil/4831064/brasil-tem-economia-mais-fechada-entre-osemergentes> Acesso em: 12 janeiro 2017
} 


\section{REFERÊNCIAS}

ACCIOLY, H. et al. Manual de Direito Internacional Público. 20. ed. São Paulo: Editora Saraiva, 2009.

AMARAL JÚNIOR, A. et al. A OMC: desafios e perspectivas. São Paulo: Aduaneiras, 2014. . Direito do comércio internacional. São Paulo: Editora Juarez Oliveira, 2002.

AMARAL, Antonio Carlos Rodrigues do (Coord). Direito do Comércio Internacional. São Paulo. Aduaneiras. 2004. . et al. Direito do Comércio Internacional: Aspectos fundamentais. São Paulo:

Aduaneiras, 2006.

ARAÚJO, A. et al. Associação Latino-Americana de Integração (ALADI), in MERCADANTE, Araminta. et al. "Blocos Econômicos e Integração na América Latina, África e Ásia". Juruá, Curitiba, 2006.

ARAUJO, Nadia de; RODAS, João Grandino. Contratos internacionais: Autonomia da vontade, MERCOSUL e Convenções Internacionais. Rio de Janeiro: Renovar, 2009.

AUST, Anthony. Handbook of International Law. Cambridge, UK: Cambridge University Press, 2010.

2010, New York.

Modern Treaty Law and Practice. Cambridge, UK: Cambridge University Press,

BAHIA, Saulo José Casali. Tratados Internacionais no Direito Brasileiro. Rio de Janeiro: Forense, 2004.

BAPTISTA, Luiz Olavo. Contratos internacionais. São Paulo: Lex Magister, 2011.

BARRAL, Welber. O Brasil e a OMC. Curitiba: Juruá Editora, 2010.

BASSO, Maristela. Contratos Internacionais do Comércio: negociação, conclusão prática. Porto Alegre: Livro do Advogado, 2002.

BLACHER, Philippe. Droit des Relations Internationals. Paris: Litec, 2004.

BONOMI, Andréa. Globalização e Direito Internacional Privado in POSENATO, Naiara. Contratos Internacionais. Tendências e Perspectivas. Ijuí: Editora Unijuí, 2006.

CABRAL, Dilma. Erário Régio. Disponível em: <http://linux.an.gov.br/mapa/?p=3259>. Acesso em: 31 mai. 2016. 
CAPUCIO, Camilla. Comércio Internacional e Integração Regional: a OMC e o regionalismo. Belo Horizonte: Arraes Editores, 2012.

CARREAU; B. Juliard. Droit International Economique. 4. ed. Paris: L.G.D.J., 1998.

CASELLA, Paulo Borba. Tratados no Direito Internacional Brasileiro. Brasília: Consulex: revista jurídica, 2011.

DALLARI, Pedro Bohomoletz de Abreu. Constituição e Tratados Internacionais .São Paulo: Saraiva, 2003.

Segurança, comércio e relações bilaterais. São Paulo, 2007.

DELBEZ, Louis. Les Príncipes Généraux de Droit International Public, Paris: LGDJ, 1964.

FERNÁNDEZ, Luis; CALVO, Alfonso-Luis. Derecho Mercantil Internacional, Madri: Tecnos, 1995.

GARCIA JÚNIOR, Armando Alvares. Lei aplicável aos contratos internacionais. São Paulo: Aduaneiras, 2004.

HERDEGEN, Matthias. Derecho Econômico Internacional. 2. ed. Medellín: Konrad Adenauer Stiftung, 1998.

LAFER, Celso. A OMC e os Blocos Regionais, in LAFER, Celso. "Direito Internacional. Um percurso no Direito no século XXI”. 2. vol. São Paulo: Gen/Atlas.

Descaminhos do MERCOSUL: "A suspensão da participação do Paraguai e a incorporação da Venezuela. Uma avaliação crítica da posição brasileira". in LAFER, Celso. "Direito Internacional. Um percurso do Direito no século XXI". 2. vol. São Paulo: Gen/Atlas.

Sobre a UNCTAD, in LAFER, Celso, "Direito Internacional. Um percurso no Direito no século XXI". 2. vol. São Paulo: Gen/Atlas.

Reflexões sobre a inserção do Brasil no Sistema de Solução de Controvérsias da OMC. São Paulo: Editora Quartier Latin do Brasil, 2013.

LOUSSOUARN, Yvon; BREDIN, Jean-Denis. Droit du Commerce Internactional. Paris: Sirey, 1969.

MAGAlHÃES, José Carlos de. Fontes do Direito do Comércio Internacional: a lex mercatória. São Paulo: Aduaneiras. Lex, 2004.

MATTOS, Adherbal Meira. Direito das Organizações Internacionais e Direito de Integração. Rio de Janeiro: Renovar, 2008. 
MELLO, Celso D. de Albuquerque. Curso de Direito Internacional Público. 13. ed. Rio de Janeiro: Renovar, 2001.

MENEZES, Wagner. Mercado Comum do Sul (MERCOSUL), in MERCANTE, Araminta. et al. "Blocos Econômicos e Integração na América Latina, África e Ásia”. Juruá, Curitiba, 2006.

MINISTÉRIO DA JUSTIÇA E CIDADANIA - GOVERNO FEDERAL. História. Disponível em: <http://www.justica.gov.br/Acesso/institucional/historia>. Acesso em: 25 mai. 2016.

O’CONNELL, Danil Patrick. International Law. Londres: Stevens and Sons, 1970.

POLETTI, Ronaldo. Ministério da Justiça. Atribuições e Organização. Disponível em: <http://www.revistajustitia.com.br/revistas/4ay0cx.pdf>. Acesso em: 19 jun. 2016.

PORTAL BRASIL: Ministério da Fazenda. Disponível em: <http://www.brasil.gov.br/economia-e-emprego/2009/11/ministerio-da-fazenda>. Acesso em: 30 mai. 2016.

REUTER, Paul. Introduction au Droit des Traités, 3. ed. Paris: PUF, 1995.

REZEK, José Francisco. Direito dos Tratados. Rio de Janeiro: Forense, 1984.

ROCHA, Leandro. Associação Latino-Americana de Integração (ALADI), in MERCADANTE, Araminta. et al. "Blocos Econômicos e Integração na América Latina, África e Ásia”. Juruá, Curitiba, 2006.

RODAS, João Grandino. Tratados Internacionais. São Paulo: Editora Revista dos Tribunais, 1991.

. Alguns Problemas de Direito dos Tratados: relacionados com direito constitucional a luz da convenção de Viena. São Paulo: [s.n.], 1973.

SANDERS, Pieter. The Work of UNCITRAL on Arbitration and Conciliation. The Hague: Kluwer Law International, 2004, New York.

SILVA, Karine de Souza. Organizações Internacionais de Integração Regional: União Européia, MERCOSUL e UNASUL. Florianópolis: FUNJAB: UFSC, 2013.

SILVA, Roberto Luiz. Direito Internacional Público. Belo Horizonte: Del Rey, 2002.

SOARES, Guido Fernando da Silva. O Direito Supranacional nas Comunidades Europeias e na América Latina: o Caso da ALALC/ALADI e o Mercado Comum-Brasil Argentina, in Revista dos Tribunais, 668. vol. São Paulo: junho de 1991.

Curso de Direito Internacional Público. São Paulo: Editora Atlas, 2002.

STRENGER, Irineu. Contratos internacionais do comércio. São Paulo: LTr, 2003. 
TRINDADE, Antônio Augusto Cançado. Direito das Organizações Internacionais. Belo Horizonte: Del Rey, 2003.

VALLEJO, Manuel Díez de Velasco. Las organizaciones internacionales. Madrid: Tecnos, 2008.

VASCONCELOS, Raphael Carvalho de. Direito Internacional entre Unidade e Fragmentação: MERCOSUL e o Multilateralismo. São Paulo: Dissertação de mestrado, Faculdade de Direito da USP, 2010.

\section{TRATADOS INTERNACIONAIS}

\section{ACORDOS BILATERAIS}

ACCORDO COMERCIAL PROVISÓRIO ENTRE O BRASIL E A LITHUANIA.1937. Sistema Consular Integrado. Atos Internacionais, Ministério das Relações Exteriores. Disponível em: <http://dai-mre.serpro.gov.br/atos-internacionais/bilaterais/1937/b_10>. Acesso em: 28 jun.2016.

ACCORDO COMERCIAL PROVISORIO ENTRE OS ESTADOS UNIDOS DO BRASIL E O REINO DOS PAISES BAIXOS. 1937. Sistema Consular Integrado. Atos Internacionais, Ministério das Relações Exteriores. Disponível em: <http://dai-mre.serpro.gov.br/atosinternacionais/bilaterais/1937/b_3>. Acesso em: 28 jun.2016.

ACCORDO COMMERCIAL PROVISORIO ENTRE O BRASIL E A HESPANHA. 1936. Sistema Consular Integrado. Atos Internacionais, Ministério das Relações Exteriores. Disponível em: <http://dai-mre.serpro.gov.br/atos-internacionais/bilaterais/1936/b_33>. Acesso em: 28 jun.2016.

ACCORDO FINANCEIRO E COMMERCIAL ENTRE O BRASIL E A FRANÇA EFEECTUADO POR TROCA DE NOTAS NO RIO DE JANEIRO, A 11 DE MAIO DE 1934. 1934. Sistema Consular Integrado. Atos Internacionais, Ministério das Relações Exteriores. Disponível em: <http://dai-mre.serpro.gov.br/atos-internacionais/bilaterais/1934/b_2>. Acesso em: 18 jun.2016.

ACORDO A LONGO PRAZO ENTRE A JUNTA DELIBERATIVA DO DEPARTAMENTO DE TRIGO DA SUPERINTENDÊNCIA NACIONAL DO ABASTECIMENTO RIO DE JANEIRO, BRASIL E "THE CANADIAN WHEAT BOARD" WINNIPEG, CANADÁ. Brasília, 1975. Sistema Consular Integrado. Atos Internacionais, Ministério das Relações Exteriores. Disponível em: <http://dai-mre.serpro.gov.br/atosinternacionais/bilaterais/1975/b_89>. Acesso em: 15 jul.2016.

ACORDO ADICIONAIS SOBRE FACILIDADES PARA INSTALAÇÃO EM TERRITÓRIO BRASILEIRO DE ENTREPOSTOS DE DEPÓSITO FRANCO. La Paz, 1958. 
Sistema Consular Integrado. Atos Internacionais, Ministério das Relações Exteriores. Disponível em: <http://dai-mre.serpro.gov.br/atos-internacionais/bilaterais/1958/b_35>. Acesso em: 10 jul.2016.

ACORDO AMPLIANDO A LISTA DE CONCESSÕES NO ÂMBITO DO PROTOCOLO DE EXPANSÃO COMERCIAL DE 12 DE JUNHO DE 1975. 1978. Sistema Consular Integrado. Atos Internacionais, Ministério das Relações Exteriores. Disponível em: <http://daimre.serpro.gov.br/atos-internacionais/bilaterais/1978/b_35>. Acesso em: 17 jul.2016.

ACORDO BRASIL - ESTADOS UNIDOS DA AMÉRICA. 1951. Sistema Consular Integrado. Atos Internacionais, Ministério das Relações Exteriores. Disponível em: <http://daimre.serpro.gov.br/atos-internacionais/bilaterais/1951/b_33>. Acesso em: 02 jul.2016.

ACORDO COMERCIA BRASIL-CHINA. Pequim, 1978. Sistema Consular Integrado. Atos Internacionais, Ministério das Relações Exteriores. Disponível em: <http://daimre.serpro.gov.br/atos-internacionais/bilaterais/1978/b_1>. Acesso em: 15 jul.2016.

ACORDO COMERCIAL BRASIL - COLÔMBIA.1932. Sistema Consular Integrado. Atos Internacionais, Ministério das Relações Exteriores. Disponível em: <http://daimre.serpro.gov.br/atos-internacionais/bilaterais/1932/b_16>. Acesso em: 18 jun.2016.

ACORDO COMERCIAL BRASIL - IUGOSLÁVIA. 1952. Sistema Consular Integrado. Atos Internacionais, Ministério das Relações Exteriores. Disponível em: <http://daimre.serpro.gov.br/atos-internacionais/bilaterais/1952/b_19>. Acesso em: 02 jul.2016.

ACORDO COMERCIAL BRASIL - REINO UNIDO. 1936. Sistema Consular Integrado. Atos Internacionais, Ministério das Relações Exteriores. Disponível em: <http://daimre.serpro.gov.br/atos-internacionais/bilaterais/1936/b_28>. Acesso em: 22 jun.2016.

ACORDO COMERCIAL BRASIL-SUÉCIA. 1931. Sistema Consular Integrado. Atos Internacionais, Ministério das Relações Exteriores. Disponível em: <http://daimre.serpro.gov.br/atos-internacionais/bilaterais/1931/b_7>. Acesso em: 15 jun.2016.

ACORDO COMERCIAL ENTRE A REPÚBLICA FEDERATIVA DO BRASIL E A COMUNIDADE ECONÔMICA EUROPEIA. Bruxelas, 1973. Sistema Consular Integrado. Atos Internacionais, Ministério das Relações Exteriores. Disponível em: <http://daimre.serpro.gov.br/atos-internacionais/bilaterais/1973/b_77>. Acesso em: 15 jul.2016.

ACORDO COMERCIAL ENTRE A REPÚBLICA FEDERATIVA DO BRASIL E A REPÚBLICA DA COSTA DO MARFIM. Abidjan, 1972. Sistema Consular Integrado. Atos Internacionais, Ministério das Relações Exteriores. Disponível em: <http://daimre.serpro.gov.br/atos-internacionais/bilaterais/1972/b_92>. Acesso em: 15 jul.2016.

ACORDO COMERCIAL ENTRE A REPÚBLICA FEDERATIVA DO BRASIL E A REPÚBLICA DA LIBÉRIA. Brasília, 1973. Sistema Consular Integrado. Atos Internacionais, Ministério das Relações Exteriores. Disponível em: <http://dai-mre.serpro.gov.br/atosinternacionais/bilaterais/1977/b_79>. Acesso em: 15 jul.2016. 
ACORDO COMERCIAL ENTRE BRASIL E ARGENTINA. 1954. Sistema Consular Integrado. Atos Internacionais, Ministério das Relações Exteriores. Disponível em: <http://daimre.serpro.gov.br/atos-internacionais/bilaterais/1954/b_17>. Acesso em: 02 jul.2016.

ACORDO COMERCIAL ENTRE BRASIL E DINAMARCA. Rio de Janeiro, 1931. Sistema Consular Integrado. Atos Internacionais, Ministério das Relações Exteriores. Disponível em: <http://dai-mre.serpro.gov.br/atos-internacionais/bilaterais/1931/b_15>. Acesso em: 15 jun.2016.

ACORDO COMERCIAL ENTRE BRASIL E FINLÂNDIA. 1953. Sistema Consular Integrado. Atos Internacionais, Ministério das Relações Exteriores. Disponível em: <http://daimre.serpro.gov.br/atos-internacionais/bilaterais/1953/b_15>. Acesso em: 02 jul.2016.

ACORDO COMERCIAL ENTRE BRASIL E IUGOSLÁVIA. 1950. Sistema Consular Integrado. Atos Internacionais, Ministério das Relações Exteriores. Disponível em: <http://daimre.serpro.gov.br/atos-internacionais/bilaterais/1950/b_2>. Acesso em: 28 jun.2016.

ACORDO COMERCIAL ENTRE BRASIL E LETÔNIA. 1932. Sistema Consular Integrado. Atos Internacionais, Ministério das Relações Exteriores. Disponível em: <http://daimre.serpro.gov.br/atos-internacionais/bilaterais/1932/b_17>. Acesso em: 18 jun.2016.

ACORDO COMERCIAL ENTRE BRASIL E NORUEGA. 1931. Sistema Consular Integrado. Atos Internacionais, Ministério das Relações Exteriores. Disponível em: <http://daimre.serpro.gov.br/atos-internacionais/bilaterais/1931/b_20>. Acesso em: 15 jun.2016.

ACORDO COMERCIAL ENTRE BRASIL E O BRASIL E O ESTADO LIVRE DA IRLANDA. 1931. Sistema Consular Integrado. Atos Internacionais, Ministério das Relações Exteriores. Disponível em: <http://dai-mre.serpro.gov.br/atosinternacionais/bilaterais/1931/b_6>. Acesso em: 15 jun.2016.

ACORDO COMERCIAL ENTRE BRASIL E POLÔNIA. Rio de Janeiro, 1932. Sistema Consular Integrado. Atos Internacionais, Ministério das Relações Exteriores. Disponível em: <http://dai-mre.serpro.gov.br/atos-internacionais/bilaterais/1932/b_6>. Acesso em: 15 jun.2016.

ACORDO COMERCIAL ENTRE BRASIL E RUMÂNIA.1936. Sistema Consular Integrado. Atos Internacionais, Ministério das Relações Exteriores. Disponível em: <http://daimre.serpro.gov.br/atos-internacionais/bilaterais/1931/b_18>. Acesso em: 15 jun.2016.

ACORDO COMERCIAL ENTRE BRASIL E SUÍÇA. 1931. Sistema Consular Integrado. Atos Internacionais, Ministério das Relações Exteriores. Disponível em: <http://daimre.serpro.gov.br/atos-internacionais/bilaterais/1931/b_9>. Acesso em: 15 jun.2016.

ACORDO COMERCIAL ENTRE O BRASIL E A HUNGRIA. Rio de Janeiro, 1931. Sistema Consular Integrado. Atos Internacionais, Ministério das Relações Exteriores. Disponível em: $<$ http://dai-mre.serpro.gov.br/atos-internacionais/bilaterais/1931/b_19>. Acesso em: 15 jun.2016. 
ACORDO COMERCIAL ENTRE O BRASIL E A ÍNDIA. 1932. Sistema Consular Integrado. Atos Internacionais, Ministério das Relações Exteriores. Disponível em: <http://daimre.serpro.gov.br/atos-internacionais/bilaterais/1932/b_13>. Acesso em: 18 jun.2016.

ACÔRDO COMERCIAL ENTRE O BRASIL E A IUGOSLÁVIA CONCLUÍDO EM BELGRADO, POR TROCA DE NOTAS, DATADAS DE 16 DE MAIO DE 1932. Belgrado, 1932. Sistema Consular Integrado. Atos Internacionais, Ministério das Relações Exteriores. Disponível em: <http://dai-mre.serpro.gov.br/atos-internacionais/bilaterais/1932/b_11>. Acesso em: 18 jun.2016.

ACÔRDO COMERCIAL ENTRE O BRASIL E A UNIÃO SUL AFRICANA. 1939. Sistema Consular Integrado. Atos Internacionais, Ministério das Relações Exteriores. Disponível em: $<$ http://dai-mre.serpro.gov.br/atos-internacionais/bilaterais/1939/b_6>. Acesso em: 28 jun.2016.

ACÔRDO COMERCIAL ENTRE O BRASIL E O IRAQUE, CONCLUÍDO EM BEIRUTE, POR TROCA DE NOTAS, DATADAS DE 5 DE JULHO DE 1939. Beirute, 1939. Sistema Consular Integrado. Atos Internacionais, Ministério das Relações Exteriores. Disponível em: $<$ http://dai-mre.serpro.gov.br/atos-internacionais/bilaterais/1939/b_12>. Acesso em: 28 jun.2016.

ACORDO COMERCIAL ENTRE O GOVERNO DA REPUBLICA FEDERATIVA DO BRASIL E O GOVERNO DA REPUBLICA POPULAR DO CONGO. Brasília, 1982. Sistema Consular Integrado. Atos Internacionais, Ministério das Relações Exteriores. Disponível em: <http://dai-mre.serpro.gov.br/atos-internacionais/bilaterais/1982/b_67>. Acesso em: 17 jul.2016.

ACORDO COMERCIAL ENTRE O GOVERNO DA REPÚBLICA FEDERATIVA DO BRASIL E O GOVERNO DA REPÚBLICA DE GANA. Acra, 1972. Sistema Consular Integrado. Atos Internacionais, Ministério das Relações Exteriores. Disponível em: <http://daimre.serpro.gov.br/atos-internacionais/bilaterais/1972/b_98>. Acesso em: 15 jul.2016.

ACORDO COMERCIAL ENTRE O GOVERNO DA REPÚBLICA FEDERATIVA DO BRASIL E O GOVERNO MILITAR FEDERAL DA REPÚBLICA FEDERAL DA NIGÉRIA. Lagos, 1972. Sistema Consular Integrado. Atos Internacionais, Ministério das Relações Exteriores. Disponível em: <http://dai-mre.serpro.gov.br/atosinternacionais/bilaterais/1972/b_113>. Acesso em: 15 jul.2016.

ACORDO COMERCIAL ENTRE O GOVERNO DA REPÚBLICA FEDERATIVA DO BRASIL E O GOVERNO DA REPÚBLICA ÁRABE DO EGITO. Cairo, 1973. Sistema Consular Integrado. Atos Internacionais, Ministério das Relações Exteriores. Disponível em: $<$ http://dai-mre.serpro.gov.br/atos-internacionais/bilaterais/1973/b_4>. Acesso em: 15 jul.2016.

ACORDO COMERCIAL ENTRE O GOVERNO DA REPÚBLICA FEDERATIVA DO BRASIL E O CONSELHO EXECUTIVO NACIONAL DA REPUBLICA DO ZAIRE. Brasília, 1973. Sistema Consular Integrado. Atos Internacionais, Ministério das Relações Exteriores. Disponível em: <http://dai-mre.serpro.gov.br/atosinternacionais/bilaterais/1973/b_24>. Acesso em: 15 jul.2016. 
ACORDO COMERCIAL ENTRE O GOVERNO DA REPÚBLICA FEDERATIVA DO BRASIL E O GOVERNO DO IMPÉRIO DO IRÃ. Brasília, 1977. Sistema Consular Integrado. Atos Internacionais, Ministério das Relações Exteriores. Disponível em: < http://daimre.serpro.gov.br/atos-internacionais/bilaterais/1977/b_46>. Acesso em: 15 jul.2016.

ACORDO COMERCIAL ENTRE O GOVERNO DA REPÚBLICA FEDERATIVA DO BRASIL E O GOVERNO DA AUSTRÁLIA. Camberra, 1978. Sistema Consular Integrado. Atos Internacionais, Ministério das Relações Exteriores. Disponível em: <http://daimre.serpro.gov.br/atos-internacionais/bilaterais/1978/b_21>. Acesso em: 15 jul.2016.

ACORDO COMERCIAL ENTRE O GOVERNO DA REPÚBLICA FEDERATIVA DO BRASIL E O GOVERNO DA REPÚBLICA ARGELINA DEMOCRÁTICA E POPULAR. Brasília, 1981. Sistema Consular Integrado. Atos Internacionais, Ministério das Relações Exteriores. Disponível em: <http://dai-mre.serpro.gov.br/atosinternacionais/bilaterais/1981/b_70>. Acesso em: 17 jul.2016.

ACORDO COMERCIAL ENTRE O GOVERNO DA REPÚBLICA FEDERATIVA DO BRASIL E O GOVERNO DA REPÚBLICA ISLÂMICA DO PAQUISTÃO. Brasília, 1982. Sistema Consular Integrado. Atos Internacionais, Ministério das Relações Exteriores. Disponível em: <http://dai-mre.serpro.gov.br/atos-internacionais/bilaterais/1982/b_103>. Acesso em: 17 jul.2016.

ACORDO COMERCIAL ENTRE O GOVERNO DA REPÚBLICA FEDERATIVA DO BRASIL E O GOVERNO DO REINO DO MARROCOS. Brasília, 1983. Sistema Consular Integrado. Atos Internacionais, Ministério das Relações Exteriores. Disponível em: <http://daimre.serpro.gov.br/atos-internacionais/bilaterais/1983/b_7>. Acesso em: 17 jul.2016.

ACORDO COMERCIAL ENTRE O GOVERNO DA REPÚBLICA FEDERATIVA DO BRASIL E O GOVERNO DA REPÚBLICA GABONESA. Brasília, 1984. Sistema Consular Integrado. Atos Internacionais, Ministério das Relações Exteriores. Disponível em: <http://daimre.serpro.gov.br/atos-internacionais/bilaterais/1984/b_75>. Acesso em: 17 jul.2016.

ACORDO COMERCIAL ENTRE O GOVERNO DA REPÚBLICA FEDERATIVA DO BRASIL E O GOVERNO DA REPÚBLICA DE CABO VERDE. Cidade da Praia, 1985. Sistema Consular Integrado. Atos Internacionais, Ministério das Relações Exteriores. Disponível em: <http://dai-mre.serpro.gov.br/atos-internacionais/bilaterais/1986/b_10>. Acesso em: 17 jul.2016.

ACORDO COMERCIAL ENTRE O GOVERNO DA REPÚBLICA FEDERATIVA DO BRASIL E O GOVERNO DA REPÚBLICA DE ZIMBÁBUE. Harare, 1988. Sistema Consular Integrado. Atos Internacionais, Ministério das Relações Exteriores. Disponível em: <http://daimre.serpro.gov.br/atos-internacionais/bilaterais/1988/b_38>. Acesso em: 17 jul.2016.

ACORDO COMERCIAL ENTRE O GOVERNO DA REPÚBLICA FEDERATIVA DO BRASIL E O GOVERNO DO REINO HASHEMITA DA JORDÂNIA. Amã, 1989. Sistema Consular Integrado. Atos Internacionais, Ministério das Relações Exteriores. Disponível em: <http://dai-mre.serpro.gov.br/atos-internacionais/bilaterais/1989/b_34>. Acesso em: 17 jul.2016. 
ACORDO COMERCIAL ENTRE O GOVERNO DA REPÚBLICA FEDERATIVA DO BRASIL E O GOVERNO DA REPÚBLICA DA TUNÍSIA. Brasília, 1990. Sistema Consular Integrado. Atos Internacionais, Ministério das Relações Exteriores. Disponível em: <http://daimre.serpro.gov.br/atos-internacionais/bilaterais/1990/b_66_2011-10-17-15-48-52>. Acesso em: 25 jul.2016.

ACORDO COMERCIAL ENTRE O GOVERNO DA REPÚBLICA FEDERATIVA DO BRASIL E O GOVERNO DA REPÚBLICA DA POLÔNIA. Brasília, 1993. Sistema Consular Integrado. Atos Internacionais, Ministério das Relações Exteriores. Disponível em: <http://daimre.serpro.gov.br/atos-internacionais/bilaterais/1993/b_32_2011-10-04-15-03-08>. Acesso em: 25 jul.2016.

ACORDO COMERCIAL ENTRE O GOVERNO DA REPÚBLICA FEDERATIVA DO BRASIL E O GOVERNO DA MALÁSIA. Kuala Lumpur, 1996. Sistema Consular Integrado. Atos Internacionais, Ministério das Relações Exteriores. Disponível em: <http://daimre.serpro.gov.br/atos-internacionais/bilaterais/1996/b_51>. Acesso em: 28 jul.2016.

ACORDO COMERCIAL ENTRE O GOVERNO DA REPÚBLICA FEDERATIVA DO BRASIL E O GOVERNO DA REPÚBLICA DA INDONÉSIA. Brasília, 1996. Sistema Consular Integrado. Atos Internacionais, Ministério das Relações Exteriores. Disponível em: <http://dai-mre.serpro.gov.br/atos-internacionais/bilaterais/1996/b_92>. Acesso em: 28 jul.2016.

ACORDO COMERCIAL ENTRE O GOVERNO DA REPÚBLICA FEDERATIVA DO BRASIL E O GOVERNO DA REPÚBLICA ARGELINA DEMOCRÁTICA E POPULAR. Argel, 2006. Sistema Consular Integrado. Atos Internacionais, Ministério das Relações Exteriores. Disponível em: <http://dai-mre.serpro.gov.br/atosinternacionais/bilaterais/2006/b_22>. Acesso em: 28 jul.2016.

ACORDO COMERCIAL ENTRE O GOVERNO DA REPÚBLICA FEDERATIVA DO BRASIL E O GOVERNO DA REPÚBLICA POPULAR DEMOCRÁTICA DA CORÉIA. Pyongyang, 2006. Sistema Consular Integrado. Atos Internacionais, Ministério das Relações Exteriores. Disponível em: <http://dai-mre.serpro.gov.br/atosinternacionais/bilaterais/2006/b_87>. Acesso em: 28 jul.2016.

ACORDO COMERCIAL ENTRE O GOVERNO DOS ESTADOS UNIDOS DO BRASIL E GOVERNO DA REPUBLICA FEDERAL DOS CAMARÕES. Iaundê, 1965. Sistema Consular Integrado. Atos Internacionais, Ministério das Relações Exteriores. Disponível em: <http://dai-mre.serpro.gov.br/atos-internacionais/bilaterais/1965/b_22>. Acesso em: 15 jul.2016.

ACORDO COMERCIAL ENTRE O GOVERNO DOS ESTADOS UNIDOS DO BRASIL E O GOVERNO DA REPUBLICA DO SENEGAL. Brasília, 1964. Sistema Consular Integrado. Atos Internacionais, Ministério das Relações Exteriores. Disponível em: <http://daimre.serpro.gov.br/atos-internacionais/bilaterais/1964/b_19>. Acesso em: 15 jul.2016.

ACORDO COMERCIAL ENTRE OS ESTADOS UNIDOS DO BRASIL E A REPÚBLICA DA LIBÉRIA. Monróvia, 1965. Sistema Consular Integrado. Atos Internacionais, Ministério das Relações Exteriores. Disponível em: <http://dai-mre.serpro.gov.br/atosinternacionais/bilaterais/1965/b_16>. Acesso em: 15 jul.2016. 
ACORDO COMERCIAL ISRAEL - BRASIL. 1956. Sistema Consular Integrado. Atos Internacionais, Ministério das Relações Exteriores. Disponível em: <http://daimre.serpro.gov.br/atos-internacionais/bilaterais/1955/b_28>. Acesso em: 09 jul.2016.

ACORDO COMERCIAL PROVISÓRIO ENTRE BRASIL E DINAMARCA. México D.F, 1936. Sistema Consular Integrado. Atos Internacionais, Ministério das Relações Exteriores. Disponível em: <http://dai-mre.serpro.gov.br/atos-internacionais/bilaterais/1936/b_16>. Acesso em: 22 jun.2016.

ACORDO COMERCIAL PROVISÓRIO ENTRE BRASIL E FINLÂNDIA. 1936. Sistema Consular Integrado. Atos Internacionais, Ministério das Relações Exteriores. Disponível em: $<$ http://dai-mre.serpro.gov.br/atos-internacionais/bilaterais/1936/b_7>. Acesso em: 22 jun.2016.

ACORDO COMERCIAL PROVISÓRIO ENTRE BRASIL E HUNGRIA. 1936. Sistema Consular Integrado. Atos Internacionais, Ministério das Relações Exteriores. Disponível em: <http://dai-mre.serpro.gov.br/atos-internacionais/bilaterais/1936/b_17>. Acesso em: 22 jun.2016.

ACORDO COMERCIAL PROVISÓRIO ENTRE BRASIL E ISLANDIA. 1936. Sistema Consular Integrado. Atos Internacionais, Ministério das Relações Exteriores. Disponível em: <http://dai-mre.serpro.gov.br/atos-internacionais/bilaterais/1936/b_18>. Acesso em: 22 jun.2016.

ACORDO COMERCIAL PROVISÓRIO ENTRE BRASIL E ITÁLIA.1936. Sistema Consular Integrado. Atos Internacionais, Ministério das Relações Exteriores. Disponível em: $<$ http://dai-mre.serpro.gov.br/atos-internacionais/bilaterais/1936/b_30>. Acesso em: 28 jun.2016.

ACORDO COMERCIAL PROVISÓRIO ENTRE BRASIL E MÉXICO. México D.F, 1936. Sistema Consular Integrado. Atos Internacionais, Ministério das Relações Exteriores. Disponível em: <http://dai-mre.serpro.gov.br/atos-internacionais/bilaterais/1936/b_20>. Acesso em: 22 jun.2016.

ACORDO COMERCIAL PROVISÓRIO ENTRE BRASIL E MÉXICO. Rio de Janeiro, 1931. Sistema Consular Integrado. Atos Internacionais, Ministério das Relações Exteriores. Disponível em: <http://dai-mre.serpro.gov.br/atos-internacionais/bilaterais/1931/b_17>. Acesso em: 15 jun.2016.

ACORDO COMERCIAL PROVISÓRIO ENTRE BRASIL E PERU. Rio de Janeiro, 1936. Sistema Consular Integrado. Atos Internacionais, Ministério das Relações Exteriores. Disponível em: <http://dai-mre.serpro.gov.br/atos-internacionais/bilaterais/1936/b_13>. Acesso em: 22 jun.2016.

ACORDO COMERCIAL PROVISÓRIO ENTRE BRASIL E POLÔNIA. 1936. Sistema Consular Integrado. Atos Internacionais, Ministério das Relações Exteriores. Disponível em: <http://dai-mre.serpro.gov.br/atos-internacionais/bilaterais/1936/b_23>. Acesso em: 22 jun.2016. 
ACORDO COMERCIAL PROVISÓRIO ENTRE BRASIL E SUÍÇA. 1936. Sistema Consular Integrado. Atos Internacionais, Ministério das Relações Exteriores. Disponível em: <http://daimre.serpro.gov.br/atos-internacionais/bilaterais/1936/b_10>. Acesso em: 22 jun.2016.

ACORDO COMERCIAL PROVISÓRIO ENTRE O BRASIL E A FRANÇA. Petrópolis, 1900. Sistema Consular Integrado. Atos Internacionais, Ministério das Relações Exteriores. Disponível em: <http://dai-mre.serpro.gov.br/atos-internacionais/bilaterais/1900/b_64>. Acesso em: 15 jun.2016.

ACORDO COMERCIAL PROVISÓRIO RELATIVO À TERRA NOVA. Londres, 1936. Sistema Consular Integrado. Atos Internacionais, Ministério das Relações Exteriores. Disponível em: <http://dai-mre.serpro.gov.br/atos-internacionais/bilaterais/1936/b_29>. Acesso em: 28 jun.2016.

ACORDO COMERCIAL. 1955. Sistema Consular Integrado. Atos Internacionais, Ministério das Relações Exteriores. Disponível em: <http://dai-mre.serpro.gov.br/atosinternacionais/bilaterais/1950/b_6>. Acesso em: 28 jun.2016.

ACORDO COMERCIAL. 1956. Sistema Consular Integrado. Atos Internacionais, Ministério das Relações Exteriores. Disponível em: <http://dai-mre.serpro.gov.br/atosinternacionais/bilaterais/1956/b_21>. Acesso em: 09 jul.2016.

ACORDO COMERCIAL.1928. Sistema Consular Integrado. Atos Internacionais, Ministério das Relações Exteriores. Disponível em: <http://dai-mre.serpro.gov.br/atosinternacionais/bilaterais/1938/b_15>. Acesso em: 28 jun.2016.

ACORDO COMPLEMENTAR AO ACORDO DE COMÉRCIO ENTRE BRASIL E PORTUGAL. 1954. Sistema Consular Integrado. Atos Internacionais, Ministério das Relações Exteriores. Disponível em: http://dai-mre.serpro.gov.br/atosinternacionais/bilaterais/1954/b_30>. Acesso em: 08 jul.2016.

ACORDO COMPLEMENTAR AO TRATADO DE COMÉRCIO E NAVEGAÇÃO FLUVIAL DE 12 DE MAIO DE 1910. 1938. Sistema Consular Integrado. Atos Internacionais, Ministério das Relações Exteriores. Disponível em: <http://dai-mre.serpro.gov.br/atosinternacionais/bilaterais/1938/b_9>. Acesso em: 28 jun.2016.

ACORDO DE COMÉRCIO - ACORDO PARA APLICAÇÃO AO "LAND BERLIN" DAS DISPOSIÇÕES DO PROTOCOLO DE BONN, DE 17 DE AGOSTO DE 1950. 1956. Sistema Consular Integrado. Atos Internacionais, Ministério das Relações Exteriores. Disponível em: <http://dai-mre.serpro.gov.br/atos-internacionais/bilaterais/1956/b_9>. Acesso em: 09 jul.2016.

ACORDO DE COMÉRCIO BRASIL - CHINA. Rio de Janeiro, 1964. Sistema Consular Integrado. Atos Internacionais, Ministério das Relações Exteriores. Disponível em: <http://daimre.serpro.gov.br/atos-internacionais/bilaterais/1962/b_34>. Acesso em: 15 jul.2016.

ACORDO DE COMÉRCIO DE PRODUTOS AGRÍCOLAS ENTRE GOVERNO DOS ESTADOS UNIDOS DA AMÉRICA E O GOVERNO DOS ESTADOS UNIDOS DO BRASIL. 1962. Sistema Consular Integrado. Atos Internacionais, Ministério das Relações 
Exteriores. Disponível em: <http://dai-mre.serpro.gov.br/atosinternacionais/bilaterais/1962/b_14>. Acesso em: 01 jul. 2016.

ACORDO DE COMÉRCIO E COOPERAÇÃO ECONÔMICA ENTRE O GOVERNO DA REPÚBLICA FEDERATIVA DO BRASIL E O GOVERNO DA ROMÊNIA. Brasília, 1994. Sistema Consular Integrado. Atos Internacionais, Ministério das Relações Exteriores. Disponível em: <http://dai-mre.serpro.gov.br/atos-internacionais/bilaterais/1994/b_11>. Acesso em: 25 jul.2016.

ACORDO DE COMÉRCIO E COOPERAÇÃO ECONÔMICA ENTRE O GOVERNO DA REPÚBLICA FEDERATIVA DO BRASIL E O GOVERNO DA REPÚBLICA DA ESLOVÊNIA. Liubliana, 1997. Sistema Consular Integrado. Atos Internacionais, Ministério das Relações Exteriores. Disponível em: <http://dai-mre.serpro.gov.br/atosinternacionais/bilaterais/1997/b_49_2011-09-01-14-09-59>. Acesso em: 28 jul.2016.

ACORDO DE COMÉRCIO E COOPERAÇÃO ECONÔMICA ENTRE O GOVERNO DA REPÚBLICA FEDERATIVA DO BRASIL E O GOVERNO DA REPÚBLICA ESLOVACA. Brasília, 2001. Sistema Consular Integrado. Atos Internacionais, Ministério das Relações Exteriores. Disponível em: <http://dai-mre.serpro.gov.br/atosinternacionais/bilaterais/2001/b_39>. Acesso em: 28 jul.2016.

ACORDO DE COMÉRCIO E COOPERAÇÃO ECONÔMICA ENTRE O GOVERNO DA REPÚBLICA FEDERATIVA DO BRASIL E O GOVERNO DOS ESTADOS UNIDOS DA AMÉRICA. Brasília, 2011. Sistema Consular Integrado. Atos Internacionais, Ministério das Relações Exteriores. Disponível em: <http://dai-mre.serpro.gov.br/atosinternacionais/bilaterais/2011/acordo-de-comercio-e-cooperacao-economica-entre-o-governoda-republica-federativa-do-brasil-e-o-governo-dos-estados-unidos-daamerica/at_download/arquivo >. Acesso em: 02 ago.2016.

ACORDO DE COMERCIO E PAGAMENTOS ENTRE O GOVERNO DA REPÚBLICA FEDERATIVA DO BRASIL E O GOVERNO DA REPÚBLICA SOCIALISTA DA ROMÊNIA. Brasília, 1975. Sistema Consular Integrado. Atos Internacionais, Ministério das Relações Exteriores. Disponível em: <http://dai-mre.serpro.gov.br/atosinternacionais/bilaterais/1975/b_44>. Acesso em: 15 jul.2016.

ACORDO DE COMÉRCIO E PAGAMENTOS ENTRE O GOVERNO DA REPÚBLICA FEDERATIVA DO BRASIL E O GOVERNO DA REPÚBLICA DEMOCRÁTICA ALEMÃ. Brasília, 1975. Sistema Consular Integrado. Atos Internacionais, Ministério das Relações Exteriores. Disponível em: <http://dai-mre.serpro.gov.br/atosinternacionais/bilaterais/1975/b_95>. Acesso em: 15 jul.2016.

ACORDO DE COMÉRCIO E PAGAMENTOS ENTRE O GOVERNO DA REPÚBLICA FEDERATIVA DO BRASIL E O GOVERNO DA REPÚBLICA SOCIALISTA FEDERATIVA DA IUGOSLÁVIA. Brasília, 1977. Sistema Consular Integrado. Atos Internacionais, Ministério das Relações Exteriores. Disponível em: <http://daimre.serpro.gov.br/atos-internacionais/bilaterais/1977/b_52>. Acesso em: 15 jul.2016. 
ACORDO DE COMÉRCIO E PAGAMENTOS ENTRE O GOVERNO DA REPÚBLICA FEDERATIVA DO BRASIL E O GOVERNO DA REPÚBLICA POPULAR DA HUNGRIA. Brasília, 1979. Sistema Consular Integrado. Atos Internacionais, Ministério das Relações Exteriores. Disponível em: <http://dai-mre.serpro.gov.br/atosinternacionais/bilaterais/1979/b_35>. Acesso em: 17 jul.2016.

ACORDO DE COMÉRCIO E PAGAMENTOS ENTRE OS ESTADOS UNIDOS DO BRASIL E A UNIÃO DAS REPÚBLICAS SOCIALISTAS SOVIÉTICAS. Rio de Janeiro, 1963. Sistema Consular Integrado. Atos Internacionais, Ministério das Relações Exteriores. Disponível em: <http://dai-mre.serpro.gov.br/atos-internacionais/bilaterais/1963/b_9>. Acesso em: 15 jul.2016.

ACORDO DE COMÉRCIO E PAGAMENTOS. Paris, 1961. Sistema Consular Integrado. Atos Internacionais, Ministério das Relações Exteriores. Disponível em: <http://daimre.serpro.gov.br/atos-internacionais/bilaterais/1961/b_39>. Acesso em: 11 jul.2016.

ACORDO DE COMÉRCIO E PAGAMENTOS. Rio de Janeiro, 1960. Sistema Consular Integrado. Atos Internacionais, Ministério das Relações Exteriores. Disponível em: <http://daimre.serpro.gov.br/atos-internacionais/bilaterais/1960/b_12>

ACORDO DE COMÉRCIO E PAGAMENTOS. Rio de Janeiro, 1960. Sistema Consular Integrado. Atos Internacionais, Ministério das Relações Exteriores. Disponível em: <http://daimre.serpro.gov.br/atos-internacionais/bilaterais/1960/b_20>. Acesso em: 11 jul.2016.

ACORDO DE COMÉRCIO ENTRE BRASIL E IUGOSLÁVIA. Rio de Janeiro, 1954. Sistema Consular Integrado. Atos Internacionais, Ministério das Relações Exteriores. Disponível em: <http://dai-mre.serpro.gov.br/atos-internacionais/bilaterais/1954/b_15>. Acesso em: 02 jul.2016.

ACORDO DE COMÉRCIO ENTRE O BRASIL E A GRÉCIA. Brasília, 1975. Sistema Consular Integrado. Atos Internacionais, Ministério das Relações Exteriores. Disponível em: <http://dai-mre.serpro.gov.br/atos-internacionais/bilaterais/1975/b_46>. Acesso em: 15 jul.2016.

ACORDO DE COMÉRCIO ENTRE O BRASIL E A INDIA. Nova Délhi, 1968. Sistema Consular Integrado. Atos Internacionais, Ministério das Relações Exteriores. Disponível em: <http://dai-mre.serpro.gov.br/atos-internacionais/bilaterais/1968/b_7>. Acesso em: 15 jul.2016.

ACORDO DE COMÉRCIO ENTRE O GOVERNO DA REPÚBLICA FEDERATIVA DO BRASIL E O GOVERNO DA REPÚBLICA SOCIALISTA DA TCHECOSLOVÁQUIA. Brasília, 1977. Sistema Consular Integrado. Atos Internacionais, Ministério das Relações Exteriores. Disponível em: <http://dai-mre.serpro.gov.br/atosinternacionais/bilaterais/1977/b_56>. Acesso em: 15 jul.2016.

ACORDO DE COMÉRCIO ENTRE O GOVERNO DA REPÚBLICA FEDERATIVA DO BRASIL E O GOVERNO DA REPÚBLICA DA GUINÉ-BISSAU. Brasília, 1978. Sistema Consular Integrado. Atos Internacionais, Ministério das Relações Exteriores. Disponível em: <http://dai-mre.serpro.gov.br/atos-internacionais/bilaterais/1978/b_36>. Acesso em: 17 jul.2016. 
ACORDO DE COMÉRCIO ENTRE O GOVERNO DA REPÚBLICA FEDERATIVA DO BRASIL E O GOVERNO DO REINO DA TAILÂNDIA. Brasília, 1984. Sistema Consular Integrado. Atos Internacionais, Ministério das Relações Exteriores. Disponível em: <http://daimre.serpro.gov.br/atos-internacionais/bilaterais/1984/b_82>. Acesso em: 17 jul.2016.

ACORDO DE COMÉRCIO ENTRE OS ESTADOS UNIDOS DO BRASIL E PORTUGAL. Lisboa, 1966. Sistema Consular Integrado. Atos Internacionais, Ministério das Relações Exteriores. Disponível em: <http://dai-mre.serpro.gov.br/atosinternacionais/bilaterais/1966/b_26>. Acesso em: 15 jul.2016.

ACORDO DE COMÉRCIO, PAGAMENTOS E COOPERAÇÃO ECONÔMICA. Budapeste, 1961. Sistema Consular Integrado. Atos Internacionais, Ministério das Relações Exteriores. Disponível em: <http://dai-mre.serpro.gov.br/atos-internacionais/bilaterais/1961/b_21>. Acesso em: 11 jul.2016.

ACORDO DE COMÉRCIO, PAGAMENTOS E COOPERAÇÃO ECONÔMICA. Sofia, 1961. Sistema Consular Integrado. Atos Internacionais, Ministério das Relações Exteriores. Disponível em: <http://dai-mre.serpro.gov.br/atos-internacionais/bilaterais/1961/b_9>. Acesso em: 14 ago. 2016.

ACORDO DE COMÉRCIO. 1960. Sistema Consular Integrado. Atos Internacionais, Ministério das Relações Exteriores. Disponível em: <http://dai-mre.serpro.gov.br/atosinternacionais/bilaterais/1954/b_27>. Acesso em: 08 jul.2016.

ACORDO DE COOPERAÇÃO E FACILITAÇÃO DE INVESTIMENTOS ENTRE A REPÚBLICA FEDERATIVA DO BRASIL E OS ESTADOS UNIDOS MEXICANOS. 1930. Sistema Consular Integrado. Atos Internacionais, Ministério das Relações Exteriores. Disponível em: <http://dai-mre.serpro.gov.br/atos-internacionais/bilaterais/2015/acordo-decooperacao-e-facilitacao-de-investimentos-entre-a-republica-federativa-do-brasil-e-osestados-unidos-mexicanos/at_download/arquivo >. Acesso em: 03 set. 2016.

ACORDO DE COOPERAÇÃO E FACILITAÇÃO DE INVESTIMENTOS ENTRE A REPÚBLICA FEDERATIVA DO BRASIL E O GOVERNO DA REPÚBLICA DE MOÇAMBIQUE. Maputo, 2015. Sistema Consular Integrado. Atos Internacionais, Ministério das Relações Exteriores. Disponível em: <http://dai-mre.serpro.gov.br/atosinternacionais/bilaterais/2015/acordo-de-cooperacao-e-facilitacao-de-investimentos-entre-ogoverno-da-republica-federativa-do-brasil-e-o-governo-da-republica-de-mocambique >. Acesso em: 09 mai. 2016.

ACORDO DE COOPERAÇÃO E FACILITAÇÃO DE INVESTIMENTOS ENTRE A REPÚBLICA FEDERATIVA DO BRASIL E O GOVERNO DA REPÚBLICA DE ANGOLA. Luanda, 2015. Sistema Consular Integrado. Atos Internacionais, Ministério das Relações Exteriores. Disponível em: <http://dai-mre.serpro.gov.br/atosinternacionais/bilaterais/2015/acordo-de-cooperacao-e-facilitacao-de-investimentos-entre-ogoverno-da-republica-federativa-do-brasil-e-o-governo-da-republica-deangola/at_download/arquivo >. Acesso em: 03 jul. 2016. 
ACORDO DE COOPERAÇÃO E FACILITAÇÃO DE INVESTIMENTOS ENTRE A REPÚBLICA FEDERATIVA DO BRASIL E A REPÚBLICA DO MALAUÍ. Brasília, 2015. Sistema Consular Integrado. Atos Internacionais, Ministério das Relações Exteriores. Disponível em: <http://dai-mre.serpro.gov.br/atos-internacionais/bilaterais/2015/acordo-decooperacao-e-facilitacao-de-investimentos-entre-a-republica-federativa-do-brasil-e-arepublica-do-malaui >. Acesso em: 05 mai. 2016.

ACORDO DE COOPERAÇÃO E FACILITAÇÃO DE INVESTIMENTOS ENTRE A REPÚBLICA FEDERATIVA DO BRASIL E A REPÚBLICA DA COLÔMBIA. Bogotá, 2015. Sistema Consular Integrado. Atos Internacionais, Ministério das Relações Exteriores. Disponível em: <http://dai-mre.serpro.gov.br/atos-internacionais/bilaterais/2015/acordo-decooperacao-e-facilitacao-de-investimentos-entre-a-republica-da-colombia-e-a-republicafederativa-do-brasil >. Acesso em: 05 mai. 2016.

ACORDO DE COOPERAÇÃO E FACILITAÇÃO DE INVESTIMENTOS ENTRE A REPÚBLICA FEDERATIVA DO BRASIL E A REPÚBLICA DO CHILE. Santiago, 2015. Sistema Consular Integrado. Atos Internacionais, Ministério das Relações Exteriores. Disponível em: <http://dai-mre.serpro.gov.br/atos-internacionais/bilaterais/2015/acordo-decooperacao-e-facilitacao-de-investimentos-entre-a-republica-federativa-do-brasil-e-arepublica-do-chile >. Acesso em: 03 mai. 2016.

ACORDO DE FORNECIMENTO RECÍPROCO A LONGO PRAZO. Brasília, 1982. Sistema Consular Integrado. Atos Internacionais, Ministério das Relações Exteriores. Disponível em: <http://dai-mre.serpro.gov.br/atos-internacionais/bilaterais/1982/b_29>. Acesso em: 17 jul.2016.

ACORDO DE INTERCÂMBIO COMERCIAL. 1985. Sistema Consular Integrado. Atos Internacionais, Ministério das Relações Exteriores. Disponível em: <http://daimre.serpro.gov.br/atos-internacionais/bilaterais/1984/b_82>. Acesso em: 17 jul.2016.

ACORDO DE VISTOS ENTRE O GOVERNO DO BRASIL E O GOVERNO DOS ESTADOS UNIDOS DA AMÉRICA RELATIVO A TÊXTEIS E ARTIGOS TÊXTEIS. Washington D.C. 1988. Sistema Consular Integrado. Atos Internacionais, Ministério das Relações Exteriores. Disponível em: <http://dai-mre.serpro.gov.br/atosinternacionais/bilaterais/1988/b_80>. Acesso em: 17 jul.2016.

ACORDO EMENDANDO E PRORROGANDO O ACORDO SOBRE COMÉRCIO DE TEXTEIS DE FIBRAS ARTIFICIAIS, COM SEUS ANEXOS E EMENDAS, DE 22 DE AGOSTO DE 1976, E PRORROGANDO O ACORDO SOBRE O COMÉRCIO DE TÊXTEIS DE FIBRAS ARTIFICIAIS, COM SEUS ANEXOS E EMENDAS. Washington D.C. 1979. Sistema Consular Integrado. Atos Internacionais, Ministério das Relações Exteriores. Disponível em: <http://dai-mre.serpro.gov.br/atos-internacionais/bilaterais/1979/b_23>. Acesso em: 17 jul.2016. 
ACORDO EMENDANDO E PRORROGANDO O ACORDO SOBRE COMÉRCIO DE TÊXTEIS DE ALGODÃO. Moscou, 1979. Sistema Consular Integrado. Atos Internacionais, Ministério das Relações Exteriores. Disponível em: <http://dai-mre.serpro.gov.br/atosinternacionais/bilaterais/1979/b_22>. Acesso em: 17 jul.2016.

ACORDO ENTRE A REPÚBLICA FEDERATIVA DO BRASIL E A COMUNIDADE ECONÔMICA EUROPÉIA SOBRE O COMÉRCIO DE PRODUTOS TÊXTEIS. Bruxelas, 1977. Sistema Consular Integrado. Atos Internacionais, Ministério das Relações Exteriores. Disponível em: <http://dai-mre.serpro.gov.br/atos-internacionais/bilaterais/1977/b_7>. Acesso em: 15 jul.2016.

ACORDO ENTRE A REPÚBLICA FEDERATIVA DO BRASIL E A COMUNIDADE ECONÔMICA EUROPÉIA SOBRE O COMÉRCIO DE PRODUTOS TÊXTEIS. Bruxelas, 1985. Sistema Consular Integrado. Atos Internacionais, Ministério das Relações Exteriores. Disponível em: <http://dai-mre.serpro.gov.br/atos-internacionais/bilaterais/1980/b_8>. Acesso em: 17 jul.2016.

ACORDO ENTRE A REPÚBLICA FEDERATIVA DO BRASIL E O REINO DA NORUEGA SOBRE COMÉRCIO E COOPERAÇÃO ECONÔMICA, INDUSTRIAL E TÉCNICA. Brasília, 1978. Sistema Consular Integrado. Atos Internacionais, Ministério das Relações Exteriores. Disponível em: <http://dai-mre.serpro.gov.br/atosinternacionais/bilaterais/1978/b_31>. Acesso em: 17 jul.2016.

ACORDO ENTRE O BANCO DO BRASIL E A SHELL INTERNACIONAL.1969. Sistema Consular Integrado. Atos Internacionais, Ministério das Relações Exteriores. Disponível em: $<$ http://dai-mre.serpro.gov.br/atos-internacionais/bilaterais/1961/b_52>. Acesso em: 15 jul.2016.

ACORDO ENTRE O GOVERNO DA REPÚBLICA FEDERATIVA DO BRASIL E A SECRETARIA-GERAL DA ORGANIZAÇÃO DOS ESTADOS AMERICANOS PARA INSTITUIÇÃO, NO NÍVEL REGIONAL, DOS CONHECIMENTOS SOBRE COMERCIALIZAÇÃO INTERNACIONAL, MEDIANTE O FORTALECIMENTO DO CENTRO INTERAMERICANO DE COMERCIALIZAÇÃO. Washington D.C. 1980. Sistema Consular Integrado. Atos Internacionais, Ministério das Relações Exteriores. Disponível em: <http://dai-mre.serpro.gov.br/atos-internacionais/bilaterais/1980/b_13>. Acesso em: 17 jul.2016.

ACORDO ENTRE O GOVERNO DA REPÚBLICA FEDERATIVA DO BRASIL E A SECRETARIA-GERAL DA ORGANIZAÇÃO DOS ESTADOS AMERICANOS PARA A MANUTENÇÃO DO CENTRO INTERAMERICANO DE COMERCIALIZAÇÃO. Rio de Janeiro, 1987. Sistema Consular Integrado. Atos Internacionais, Ministério das Relações Exteriores. Disponível em: <http://dai-mre.serpro.gov.br/atosinternacionais/bilaterais/1987/b_10>. Acesso em: 17 jul.2016.

ACORDO ENTRE O GOVERNO DA REPUBLICA FEDERATIVA DO BRASIL E O GOVERNO DO CANADÁ RELATIVO AOS TERMOS DE FINANCIAMENTO PARA A VENDA DE TRIGO PELO CANADÁ. Brasília, 1972. Sistema Consular Integrado. Atos Internacionais, Ministério das Relações Exteriores. Disponível em: <http://daimre.serpro.gov.br/atos-internacionais/bilaterais/1972/b_122>. Acesso em: 15 jul.2016. 
ACORDO ENTRE O GOVERNO DA REPÚBLICA FEDERATIVA DO BRASIL E O GOVERNO DO CANADÁ RELATIVO AOS TERMOS DE FINANCIAMENTO PARA A VENDA DE TRIGO PELO CANADÁ. Brasília, 1970. Sistema Consular Integrado. Atos Internacionais, Ministério das Relações Exteriores. Disponível em: <http://daimre.serpro.gov.br/atos-internacionais/bilaterais/1970/b_21>. Acesso em: 15 jul.2016.

ACORDO ENTRE O GOVERNO DA REPÚBLICA FEDERATIVA DO BRASIL E O GOVERNO DA REPÚBLICA DO PERU SOBRE A INSTALAÇÃO E FUNCIONAMENTO NA CIDADE DE SÃO PAULO DE UM ESCRITÓRIO DA MINERO PERU COMERCIAL Acordo sobre a Instalação e Funcionamento na Cidade de São Paulo de um Escritório da Minero Peru Comercial. Ucayali, 1976. Sistema Consular Integrado. Atos Internacionais, Ministério das Relações Exteriores. Disponível em: <http://dai-mre.serpro.gov.br/atosinternacionais/bilaterais/1976/b_77>. Acesso em: 15 jul.2016.

ACORDO ENTRE O GOVERNO DA REPÚBLICA FEDERATIVA DO BRASIL E O GOVERNO DA REPÚBLICA DA ÁUSTRIA, REFERENTE AO RECONHECIMENTO DOS CERTIFICADOS DE ORIGEM E DE BENS DE PRODUÇÃO ARTESANAL. Viena,1993. Sistema Consular Integrado. Atos Internacionais, Ministério das Relações Exteriores. Disponível em: <http://dai-mre.serpro.gov.br/atosinternacionais/bilaterais/1993/b_14_2011-10-04-15-03-02>. Acesso em: 25 jul.2016.

ACORDO ENTRE OS ESTADOS UNIDOS DO BRASIL E A REPUBLICA FEDERAL DA ALEMANHA PARA A CONSOLIDAÇÃO DE COMPROMISSOS COMERCIAIS DO BRASIL. Rio de Janeiro, 1964. Sistema Consular Integrado. Atos Internacionais, Ministério das Relações Exteriores. Disponível em: <http://dai-mre.serpro.gov.br/atosinternacionais/bilaterais/1964/b_24>. Acesso em: 15 jul.2016.

ACORDO MODIFICANDO AS DISPOSIÇÕES DO ACORDO DE 04 DE JULHO DE 1956. Rio de Janeiro, 1958. Sistema Consular Integrado. Atos Internacionais, Ministério das Relações Exteriores. Disponível em: <http://dai-mre.serpro.gov.br/atosinternacionais/bilaterais/1958/b_4>. Acesso em: 09 jul.2016.

ACORDO PARA A COMPRA DE LOCOMOTIVAS BRASIL - ESPANHA.1969. Sistema Consular Integrado. Atos Internacionais, Ministério das Relações Exteriores. Disponível em: <http://dai-mre.serpro.gov.br/atos-internacionais/bilaterais/1969/b_46>. Acesso em: 15 jul.2016.

ACORDO PARA A CONSECUÇÃO DOS COMPROMISSOS AO ABRIGO DO EXPIRADO ACORDO DE COMÉRCIO E PAGAMENTO COM A REPÚBLICA DEMOCRÁTICA DA ALEMANHA. 1992. Sistema Consular Integrado. Atos Internacionais, Ministério das Relações Exteriores. Disponível em: <http://dai-mre.serpro.gov.br/atosinternacionais/bilaterais/1992/b_44_2011-10-14-15-30-20>. Acesso em: 25 jul.2016.

ACORDO PARA A CONSOLIDAÇÃO DOS COMPROMISSOS COMERCIAIS DO BRASIL. Rio de Janeiro, 1961. Sistema Consular Integrado. Atos Internacionais, Ministério das Relações Exteriores. Disponível em: <http://dai-mre.serpro.gov.br/atosinternacionais/bilaterais/1961/b_64>. Acesso em: 20 mai.2016. 
ACORDO PARA A CRIAÇÃO DE UM GRUPO MISTO DE TRABALHO SOBRE FORNECIMENTO DE GÁS NATURAL. 1980. Sistema Consular Integrado. Atos Internacionais, Ministério das Relações Exteriores. Disponível em: $<$ http://daimre.serpro.gov.br/atos-internacionais/bilaterais/1980/b_81>. Acesso em: 17 jul.2016.

ACORDO PARA A MANUTENÇÃO DAS FACILIDADES DE INTERCÂMBIO ENTRE OS DOIS PAÍSES. 1961. Sistema Consular Integrado. Atos Internacionais, Ministério das Relações Exteriores. Disponível em: <http://dai-mre.serpro.gov.br/atosinternacionais/bilaterais/1961/b_42>. Acesso em: 15 Jul.2016.

ACORDO PARA A PRORROGAÇÃO DAS DISPOSIÇÕES DO TRATADO DE COMÉRCIO E NAVEGAÇÃO DE JANEIRO DE 1940 E DO AJUSTE DE COMÉRCIO DE 23 DE MARÇO DE 1953. Buenos Aires, 1959. Sistema Consular Integrado. Atos Internacionais, Ministério das Relações Exteriores. Disponível em: <http://daimre.serpro.gov.br/atos-internacionais/bilaterais/1959/b_19>. Acesso em: 11 jul.2016.

ACORDO PARA A PRORROGAÇÃO DAS DISPOSIÇÕES DO TRATADO DE COMÉRCIO E NAVEGAÇÃO. 1959. Sistema Consular Integrado. Atos Internacionais, Ministério das Relações Exteriores. Disponível em: <http://dai-mre.serpro.gov.br/atosinternacionais/bilaterais/1959/b_20>. Acesso em: 11 jul.2016.

ACORDO PARA A PRORROGAÇÃO DAS DISPOSIÇÕES DO TRATADO DE COMÉRCIO E NAVEGAÇÃO DE 1943, DO PROTOCOLO ADICIONAL E DAS RESPECTIVAS NOTAS ANEXAS. 1960. Sistema Consular Integrado. Atos Internacionais, Ministério das Relações Exteriores. Disponível em: <http://dai-mre.serpro.gov.br/atosinternacionais/bilaterais/1960/b_50>. Acesso em: 12 jul. 2016.

ACORDO PARA A PRORROGAÇÃO DAS DISPOSIÇÕES DO TRATADO DE COMÉRCIO E NAVEGAÇÃO DE 23 DE JANEIRO DE 1940. Buenos Aires, 1960. Sistema Consular Integrado. Atos Internacionais, Ministério das Relações Exteriores. Disponível em: <http://dai-mre.serpro.gov.br/atos-internacionais/bilaterais/1960/b_58>. Acesso em: 11 Jul.2016.

ACORDO PARA O ESTABELECIMENTO DE COMITÊ DE COOPERAÇÃO INTERGOVERNAMENTAL ENTRE O GOVERNO DA REPÚBLICA FEDERATIVA DO BRASIL E O GOVERNO DO ESTADO DO CATAR. Brasília, 2010. Sistema Consular Integrado. Atos Internacionais, Ministério das Relações Exteriores. Disponível em: <http://daimre.serpro.gov.br/atos-internacionais/bilaterais/2010/acordo-para-o-estabelecimento-decomite-de-cooperacao-intergovernamental-entre-o-governo-da-republica-federativa-do-brasile-o-governo-do-estado-do-catar >. Acesso em: 02 ago.2016.

ACORDO PARA O ESTABELECIMENTO DE UM MECANISMO DE COOPERAÇÃO COMERCIAL ENTRE A REPÚBLICA ARGENTINA E A REPÚBLICA FEDERATIVA DO BRASIL. Puerto Iguazu, 2005. Sistema Consular Integrado. Atos Internacionais, Ministério das Relações Exteriores. Disponível em: <http://dai-mre.serpro.gov.br/atosinternacionais/bilaterais/2005/b_207>. Acesso em: 28 jul.2016. 
ACORDO PARA O INÍCIO DAS NEGOCIAÇÕES SOBRE O ESTABELECIMENTO DE UM DEPÓSITO PARA O PERU EM TERRITÓRIO BRASILEIRO. Ucayali, 1976. Sistema Consular Integrado. Atos Internacionais, Ministério das Relações Exteriores. Disponível em: $<$ http://dai-mre.serpro.gov.br/atos-internacionais/bilaterais/1976/b_84>. Acesso em: 15 jul.2016.

ACORDO PARA PRORROGAÇÃO DO AJUSTE COMERCIAL DE 24 DE JULHO DE 1952. 1960. Sistema Consular Integrado. Atos Internacionais, Ministério das Relações Exteriores. Disponível em: <http://dai-mre.serpro.gov.br/atosinternacionais/bilaterais/1960/b_13>. Acesso em: 4 ago. 2016.

ACORDO PARA PRORROGAÇÃO DO TRATADO DE COMÉRCIO E NAVEGAÇÃO DE 1940 E DO AJUSTE E DO AJUSTE DE COMÉRCIO DE 1953. Buenos Aires, 1959. Sistema Consular Integrado. Atos Internacionais, Ministério das Relações Exteriores. Disponível em: $<$ http://dai-mre.serpro.gov.br/atos-internacionais/bilaterais/1959/b_5>. Acesso em: 11 jul.2016.

ACORDO PELO QUAL SE MANTÉM EM VIGOR AS CONCESSÕES OUTORGADAS PELO PROTOCOLO DE EXPANSÃO COMERCIAL, DE 12 DE JUNHO DE 1975, ATÉ A ENTRADA EM VIGOR DOS INSTRUMENTOS JURÍDICOS QUE CONSUBSTANCIEM OS RESULTADOS DAS RENEGOCIAÇÕES ENTRE OS DOIS PAÍSES. Montevidéu, 1980. Sistema Consular Integrado. Atos Internacionais, Ministério das Relações Exteriores. Disponível em: <http://dai-mre.serpro.gov.br/atos-internacionais/bilaterais/1980/b_136>. Acesso em: 17 jul.2016.

ACORDO POR TROCA DE NOTAS DE 26 DE JANEIRO DE 1967 INTRODUZINDO MODIFICAÇÕES NO ACORDO DE COMÉRCIO E PAGAMENTOS DE 24 DE JUNHO DE 1960. Praga, 1967. Sistema Consular Integrado. Atos Internacionais, Ministério das Relações Exteriores. Disponível em: <http://dai-mre.serpro.gov.br/atosinternacionais/bilaterais/1967/b_7>. Acesso em: 15 jul.2016.

ACORDO POR TROCA DE NOTAS REFERENTE A DENÚNCIA DO ACORDO DE 15.12.1937. 1973. Sistema Consular Integrado. Atos Internacionais, Ministério das Relações Exteriores. Disponível em: http://dai-mre.serpro.gov.br/atosinternacionais/bilaterais/1937/b_13>. Acesso em: 28 jun.2016.

ACORDO PRORROGANDO O ACORDO SOBRE O FORNECIMENTO DE MAQUINARIA E EQUIPAMENTOS DA URSS AO BRASIL E SOBRE FORNECIMENTO DE MERCADORIAS BRASILEIRAS À URSS. Moscou, 1979. Sistema Consular Integrado. Atos Internacionais, Ministério das Relações Exteriores. Disponível em: <http://daimre.serpro.gov.br/atos-internacionais/bilaterais/1979/b_21>. Acesso em: 17 jul.2016.

ACORDO PRORROGANDO O AJUSTE DE COMÉRCIO DE 17 DE MAIO DE 1950, ATÉ A ENTRADA EM VIGOR DO ACORDO DE COMÉRCIO E PAGAMENTOS DE 24 DE JUNHO DE 1960. 1960. Sistema Consular Integrado. Atos Internacionais, Ministério das Relações Exteriores. Disponível em: <http://dai-mre.serpro.gov.br/atosinternacionais/bilaterais/1960/b_21>. Acesso em: 11 jul.2016. 
ACORDO PROVISÓRIO DE COMÉRCIO E PAGAMENTOS. Atenas, 1960. Sistema Consular Integrado. Atos Internacionais, Ministério das Relações Exteriores. Disponível em: <http://dai-mre.serpro.gov.br/atos-internacionais/bilaterais/1960/b_26>. Acesso em: 11 jul.2016.

ACORDO PROVISORIO ENTRE BRASIL E LITUANIA. Rio de Janeiro, 1932. Sistema Consular Integrado. Atos Internacionais, Ministério das Relações Exteriores. Disponível em: $<$ http://dai-mre.serpro.gov.br/atos-internacionais/bilaterais/1932/b_21>. Acesso em: 18 jun.2016.

ACORDO PROVISÓRIO ENTRE O BRASIL E A GRÉCIA.1933. Sistema Consular Integrado. Atos Internacionais, Ministério das Relações Exteriores. Disponível em: <http://daimre.serpro.gov.br/atos-internacionais/bilaterais/1933/b_5>. Acesso em: 18 jun.2016.

ACORDO PROVISÓRIO SOBRE COUROS E PELES BOVINOS SALGADOS E PRODUTOS MANUFATURADOS DE COURO E OUTROS ASSUNTOS COMERCIAIS. Brasília, 1980. Sistema Consular Integrado. Atos Internacionais, Ministério das Relações Exteriores. Disponível em: <http://dai-mre.serpro.gov.br/atosinternacionais/bilaterais/1980/b_22>. Acesso em: 17 jul.2016.

ACORDO QUE MODIFICA E PRORROGA O ACORDO SOBRE FORNECIMENTO DE MÁQUINAS E EQUIPAMENTOS DA URSS AO BRASIL E FORNECIMENTO DE PRODUTOS BRASILEIROS À URSS. 1982. Sistema Consular Integrado. Atos Internacionais, Ministério das Relações Exteriores. Disponível em: <http://daimre.serpro.gov.br/atos-internacionais/bilaterais/1982/b_74>. Acesso em: 17 jul.2016.

ACORDO QUE MODIFICA E PRORROGA O ACORDO SOBRE FORNECIMENTO DE MÁQUINAS DA URSS AO BRASIL E FORNECIMENTO DE MERCADORIAS BRASILEIRAS À URSS. Moscou, 1975. Sistema Consular Integrado. Atos Internacionais, Ministério das Relações Exteriores. Disponível em: <http://dai-mre.serpro.gov.br/atosinternacionais/bilaterais/1985/b_76>. Acesso em: 17 jul.2016.

ACORDO REGULANDO AS RELAÇÕES COMERCIAIS. Bruxelas, 1864. Sistema Consular Integrado. Atos Internacionais, Ministério das Relações Exteriores. Disponível em: $<$ http://dai-mre.serpro.gov.br/atos-internacionais/bilaterais/1864/b_84>. Acesso em: 15 jun.2016.

ACORDO RELATIVO À COMPRA DE TRIGO. 1975. Sistema Consular Integrado. Atos Internacionais, Ministério das Relações Exteriores. Disponível em: <http://daimre.serpro.gov.br/atos-internacionais/bilaterais/1975/b_15>. Acesso em: 15 jul.2016.

ACORDO RELATIVO À DENUNCIA DO CONVÊNIO DE INTERCÂMBIO BRASILEIRO-BOLIVIANO DE GADO, DE 10 DE OUTUBRO DE 1953. 1958. Sistema Consular Integrado. Atos Internacionais, Ministério das Relações Exteriores. Disponível em: $<$ http://dai-mre.serpro.gov.br/atos-internacionais/bilaterais/1958/b_33>. Acesso em: 12 ago. 2016.

ACORDO RELATIVO AO ESTABELECIMENTO DE UM ENTREPOSTO DE DEPÓSITO FRANCO DE MERCADORIAS EXPORTADAS OU IMPORTADAS PELO BRASIL. Georgetown, 1971. Sistema Consular Integrado. Atos Internacionais, Ministério das Relações 
Exteriores. Disponível em: <http://dai-mre.serpro.gov.br/atosinternacionais/bilaterais/1971/b_98>. Acesso em: 15 jul.2016.

ACORDO RELATIVO ÀS EXPORTAÇÕES DE TÊXTEIS DE ALGODÃO DO BRASIL PARA OS EUA. 1978. Sistema Consular Integrado. Atos Internacionais, Ministério das Relações Exteriores. Disponível em: <http://dai-mre.serpro.gov.br/atosinternacionais/bilaterais/1978/b_41>. Acesso em: 17 jul.2016.

ACORDO RELATIVO ÀS EXPORTAÇÕES DE TÊXTEIS DE FIBRAS ARTIFICIAIS DO BRASIL PARA OS EUA. 1978. Sistema Consular Integrado. Atos Internacionais, Ministério das Relações Exteriores. Disponível em: <http://dai-mre.serpro.gov.br/atosinternacionais/bilaterais/1978/b_41>. Acesso em: 17 jul.2016.

ACORDO SANITÁRIO SOBRE CARNES E DERIVADOS DE CARNE BOVINA BRASIL - BÉLGICA. Bruxelas, 1965. Sistema Consular Integrado. Atos Internacionais, Ministério das Relações Exteriores. Disponível em: <http://dai-mre.serpro.gov.br/atosinternacionais/bilaterais/1965/b_36>. Acesso em: 15 jul.2016.

ACORDO SOBRE A AQUISIÇÃO DE TRIGO PELO BRASIL NA HUNGRIA. Rio de Janeiro, 1967. Sistema Consular Integrado. Atos Internacionais, Ministério das Relações Exteriores. Disponível em <http://dai-mre.serpro.gov.br/atosinternacionais/bilaterais/1967/b_15>. Acesso em: 15 jul.2016.

ACORDO SOBRE A EXPORTAÇÃO DE TÊXTEIS DE ALGODÃO. Washington D.C, 1970. Sistema Consular Integrado. Atos Internacionais, Ministério das Relações Exteriores. Disponível em: <http://dai-mre.serpro.gov.br/atos-internacionais/bilaterais/1970/b_43>. Acesso em: 15 jul.2016.

ACORDO SOBRE A VENDA DE CAFÉ VERDE ÀS INDÚSTRIAS NORTEAMERICANAS. Brasília, 1971. Sistema Consular Integrado. Atos Internacionais, Ministério das Relações Exteriores. Disponível em: <http://dai-mre.serpro.gov.br/atosinternacionais/bilaterais/1971/b_17>. Acesso em: 15 jul.2016.

ACORDO SOBRE A VENDA DE TRIGO AO BRASIL. 1971. Sistema Consular Integrado. Atos Internacionais, Ministério das Relações Exteriores. Disponível em: <http://daimre.serpro.gov.br/atos-internacionais/bilaterais/1971/b_58>. Acesso em: 15 jul.2016.

ACORDO SOBRE A VENDA DE TRIGO AO BRASIL.1971. Sistema Consular Integrado. Atos Internacionais, Ministério das Relações Exteriores. Disponível em: <http://daimre.serpro.gov.br/atos-internacionais/bilaterais/1971/b_77>. Acesso em: 15 jul.2016.

ACORDO SOBRE AS EXPORTAÇÕES DE CERTOS PRODUTOS TÊXTEIS DO BRASIL PARA A SUÉCIA. 1980. Sistema Consular Integrado. Atos Internacionais, Ministério das Relações Exteriores. Disponível em: <http://dai-mre.serpro.gov.br/atosinternacionais/bilaterais/1980/b_87>. Acesso em: 17 jul.2016.

ACORDO SOBRE AS POSSIBILIDADES DE UMA AÇÃO CONJUNTA DE UMA EMPRESA MINEIRA ESPECIAL, DESTINADA A REALIZAR ATIVIDADES NO SETOR DE COBRE. Ucayali, 1976. Sistema Consular Integrado. Atos Internacionais, Ministério das 
Relações Exteriores. Disponível em: <http://dai-mre.serpro.gov.br/atosinternacionais/bilaterais/1976/b_88>. Acesso em: 15 jul.2016.

ACORDO SOBRE ATRASADOS COMERCIAIS ENTRE BRASIL E REINO UNIDO. 1953. Sistema Consular Integrado. Atos Internacionais, Ministério das Relações Exteriores. Disponível em: <http://dai-mre.serpro.gov.br/atos-internacionais/bilaterais/1953/b_48>. Acesso em: 02 jul.2016.

ACORDO SOBRE ATRASADOS COMERCIAIS MODIFICANDO O ACORDO DE 1953. 1955. Sistema Consular Integrado. Atos Internacionais, Ministério das Relações Exteriores. Disponível em: <http://dai-mre.serpro.gov.br/atos-internacionais/bilaterais/1955/b_21>. Acesso em: 08 jul.2016.

ACORDO SOBRE COMÉRCIO DE PRODUTOS TÊXTEIS. Bruxelas, 1985. Sistema Consular Integrado. Atos Internacionais, Ministério das Relações Exteriores. Disponível em: <http://dai-mre.serpro.gov.br/atos-internacionais/bilaterais/1985/b_52>. Acesso em: 17 jul.2016.

ACORDO SOBRE COMÉRCIO DE TÊXTEIS DE ALGODÃO, LÃ E FIBRAS SINTÉTICAS. Brasília, 1985. Sistema Consular Integrado. Atos Internacionais, Ministério das Relações Exteriores. Disponível em: <http://dai-mre.serpro.gov.br/atosinternacionais/bilaterais/1985/b_48>. Acesso em: 17 jul.2016.

ACORDO SOBRE COMÉRCIO E COOPERAÇÃO ECONÔMICA ENTRE O GOVERNO DA REPÚBLICA FEDERATIVA DO BRASIL E O GOVERNO DA REPÚBLICA DA BULGÁRIA. Brasília, 1993. Sistema Consular Integrado. Atos Internacionais, Ministério das Relações Exteriores. Disponível em: <http://dai-mre.serpro.gov.br/atosinternacionais/bilaterais/1993/b_62_2011-10-04-15-03-17 >. Acesso em: 25 jul.2016.

ACORDO SOBRE COMÉRCIO E COOPERAÇÃO ECONÔMICA ENTRE O GOVERNO DA REPÚBLICA FEDERATIVA DO BRASIL E O GOVERNO DA REPÚBLICA TCHECA. Brasília, 1994. Sistema Consular Integrado. Atos Internacionais, Ministério das Relações Exteriores. Disponível em: <http://dai-mre.serpro.gov.br/atosinternacionais/bilaterais/1994/b_29>. Acesso em: 28 jul.2016.

ACORDO SOBRE COMÉRCIO E PAGAMENTOS ENTRE BRASIL E ALEMANHA. Rio de Janeiro, 1955. Sistema Consular Integrado. Atos Internacionais, Ministério das Relações Exteriores. Disponível em: <http://dai-mre.serpro.gov.br/atosinternacionais/bilaterais/1955/b_15>. Acesso em: 08 jul.2016.

ACORDO SOBRE COMPRA DE TRIGO ENTRE BRASIL E IUGOSLÁVIA. Rio de Janeiro, 1969. Sistema Consular Integrado. Atos Internacionais, Ministério das Relações Exteriores. Disponível em: <http://dai-mre.serpro.gov.br/atos-internacionais/bilaterais/1969/b_31>. Acesso em: 15 jul.2016. 
ACORDO SOBRE COMPRA E VENDA DE TRIGO. 1969. Sistema Consular Integrado. Atos Internacionais, Ministério das Relações Exteriores. Disponível em: <http://daimre.serpro.gov.br/atos-internacionais/bilaterais/1969/b_1>. Acesso em: 15 jul.2016.

ACORDO SOBRE COOPERAÇÃO COMERCIAL ENTRE O GOVERNO DA REPÚBLICA FEDERATIVA DO BRASIL E O GOVERNO DA REPÚBLICA DO IRAQUE. Bagdá, 1971. Sistema Consular Integrado. Atos Internacionais, Ministério das Relações Exteriores. Disponível em: <http://dai-mre.serpro.gov.br/atos-internacionais/bilaterais/1971/b_34>. Acesso em: 15 jul.2016.

ACORDO SOBRE COOPERAÇÃO NO CAMPO SIDERÚRGICO. Sofia, 1973. Sistema Consular Integrado. Atos Internacionais, Ministério das Relações Exteriores. Disponível em: <http://dai-mre.serpro.gov.br/atos-internacionais/bilaterais/1973/b_35>. Acesso em: 15 jul.2016.

ACORDO SOBRE INTERCÂMBIO DE MÁQUINAS, EQUIPAMENTOS E OUTRAS MERCADORIAS ENTRE A REPÚBLICA FEDERATIVA DO BRASIL E A UNIÃO DAS REPÚBLICAS SOCIALISTAS SOVIÉTICAS. Moscou, 1988. Sistema Consular Integrado. Atos Internacionais, Ministério das Relações Exteriores. Disponível em: <http://daimre.serpro.gov.br/atos-internacionais/bilaterais/1988/b_88>. Acesso em: 17 jul.2016.

ACORDO SOBRE O FORNECIMENTO DE MAQUINARIA E EQUIPAMENTOS DA URSS AO BRASIL E SOBRE FORNECIMENTO DE MERCADORIAS BRASILEIRAS À URSS. Moscou, 1979. Sistema Consular Integrado. Atos Internacionais, Ministério das Relações Exteriores. Disponível em: <http://dai-mre.serpro.gov.br/atosinternacionais/bilaterais/1975/b_19>. Acesso em: 15 jul.2016.

ACORDO SOBRE O INTERCÂMBIO COMERCIAL. Madrid, 1962. Sistema Consular Integrado. Atos Internacionais, Ministério das Relações Exteriores. Disponível em: <http://daimre.serpro.gov.br/atos-internacionais/bilaterais/1962/b_20>. Acesso em: 15 jul.2016.

ACORDO SOBRE O INTERCÂMBIO DE FRUTAS FRESCAS ENTRE BRASIL E URUGUAI. Rio de Janeiro, 1954. Sistema Consular Integrado. Atos Internacionais, Ministério das Relações Exteriores. Disponível em: <http://dai-mre.serpro.gov.br/atosinternacionais/bilaterais/1954/b_19>

ACORDO SOBRE VENDA DE CELULOSE (NOTA BRASILEIRA). 1969. Sistema Consular Integrado. Atos Internacionais, Ministério das Relações Exteriores. Disponível em: <http://dai-mre.serpro.gov.br/atos-internacionais/bilaterais/1969/b_15>. Acesso em: 15 jul.2016.

ACORDO SOBRE VENDA DE TRIGO AO BRASIL. 1972. Sistema Consular Integrado. Atos Internacionais, Ministério das Relações Exteriores. Disponível em: <http://daimre.serpro.gov.br/atos-internacionais/bilaterais/1972/b_64>. Acesso em: 15 jul.2016.

ACORDO, POR TROCA DE NOTAS ENTRE O GOVERNO BRASILEIRO E A UNIÃO SOVIÉTICA CONCLUÍDO EM 31 DE DEZEMBRO DE 1962, RELATIVO À PRORROGAÇÃO DOS “TERMOS DE ENTENDIMENTO" E SEUS PROTOCOLOS ADICIONAIS. 1962. Sistema Consular Integrado. Atos Internacionais, Ministério das Relações Exteriores. Disponível em: <http://dai-mre.serpro.gov.br/atosinternacionais/bilaterais/1962/b_35>. Acesso em: 15 jul.2016. 
ACORDO, POR TROCA DE NOTAS, PARA A ISENÇÃO DA TAXA DE MELHORAMENTO DE PORTOS (TMP) PARA MERCADORIAS DESTINADAS À BOLÍVIA, OU PROCEDENTES DESSE PAÍS, EM TRÂNSITO PELO TERRITÓRIO BRASILEIRO. 1985. Sistema Consular Integrado. Atos Internacionais, Ministério das Relações Exteriores. Disponível em: <http://dai-mre.serpro.gov.br/atosinternacionais/bilaterais/1985/b_47>. Acesso em: 17 jul.2016.

ACORDO, POR TROCA DE NOTAS, PARA FORTALECER AS RELAÇÕES COMERCIAIS. Brasília, 2004. Sistema Consular Integrado. Atos Internacionais, Ministério das Relações Exteriores. Disponível em: <http://dai-mre.serpro.gov.br/atosinternacionais/bilaterais/2004/b_119>. Acesso em: 28 jul.2016.

ACORDO, RELATIVO AO COMÉRCIO DE TÊXTEIS DE ALGODÃO, DE LÃ E FIBRAS QUÍMICAS E DE PRODUTOS TÊXTEIS, POR TROCA DE NOTAS. Brasília, 1985. Sistema Consular Integrado. Atos Internacionais, Ministério das Relações Exteriores. Disponível em: $<$ http://dai-mre.serpro.gov.br/atos-internacionais/bilaterais/1988/b_79>. Acesso em: 17 jul.2016.

ACTA APROVADA ENTRE A REPUBLICA FEDERATIVA DO BRASIL E A COMUNIDADE EUROPEIA. Bruxelas, 2007. Sistema Consular Integrado. Atos Internacionais, Ministério das Relações Exteriores. Disponível em: <http://daimre.serpro.gov.br/atos-internacionais/bilaterais/2007/b_105>. Acesso em: 28 jul.2016.

AJUSTE ADICIONAL SOBRE CRIAÇÃO DE COMISSÕES MISTAS PERMANENTES, PREVISTA PELO CONVENIO COMERCIAL. La Paz, 1958. Sistema Consular Integrado. Atos Internacionais, Ministério das Relações Exteriores. Disponível em: <http://daimre.serpro.gov.br/atos-internacionais/bilaterais/1958/b_29>. Acesso em: 10 jul.2016.

AJUSTE ADICIONAL SOBRE OPERAÇÕES EM CRUZEIROS E PESOS BOLIVIANOS. La Paz, 1958. Sistema Consular Integrado. Atos Internacionais, Ministério das Relações Exteriores. Disponível em: <http://dai-mre.serpro.gov.br/atosinternacionais/bilaterais/1958/b_30>. Acesso em: 10 jul.2016.

AJUSTE ADMINISTRATIVO DE COMÉRCIO BRASIL - TCHECOSLOVÁQUIA. 1953. Sistema Consular Integrado. Atos Internacionais, Ministério das Relações Exteriores. Disponível em: <http://dai-mre.serpro.gov.br/atos-internacionais/bilaterais/1953/b_52>. Acesso em: 02 jul.2016.

AJUSTE ADMINISTRATIVO DE COMÉRCIO ENTRE O GOVERNO DA REPÚBLICA DOS ESTADOS UNIDOS DO BRASIL E O GOVERNO DO JAPÃO. Rio de Janeiro, 1952. Sistema Consular Integrado. Atos Internacionais, Ministério das Relações Exteriores. Disponível em: <http://dai-mre.serpro.gov.br/atos-internacionais/bilaterais/1952/b_37>. Acesso em: 02 jul.2016.

AJUSTE AO ACORDO DE COMÉRCIO BRASIL - PORTUGAL, DE 9 DE SETEMBRO DE 1949. 1954. Sistema Consular Integrado. Atos Internacionais, Ministério das Relações 
Exteriores. Disponível em: <http://dai-mre.serpro.gov.br/atosinternacionais/bilaterais/1949/b_12>. Acesso em: 28 jun.2016.

AJUSTE COMERCIAL BRASIL - ESPANHA. Rio de Janeiro, 1952. Sistema Consular Integrado. Atos Internacionais, Ministério das Relações Exteriores. Disponível em: <http://daimre.serpro.gov.br/atos-internacionais/bilaterais/1952/b_22>. Acesso em: 02 jul.2016.

AJUSTE COMERCIAL BRASIL - GRÉCIA. 1952. Sistema Consular Integrado. Atos Internacionais, Ministério das Relações Exteriores. Disponível em: <http://daimre.serpro.gov.br/atos-internacionais/bilaterais/1952/b_17>. Acesso em: 02 jul.2016.

AJUSTE COMERCIAL BRASIL - ISLÂNDIA. 1952. Sistema Consular Integrado. Atos Internacionais, Ministério das Relações Exteriores. Disponível em: <http://daimre.serpro.gov.br/atos-internacionais/bilaterais/1952/b_11>. Acesso em: 02 jul.2016.

AJUSTE COMERCIAL BRASIL - TCHECOSLOVÁQUIA. 1952. Sistema Consular Integrado. Atos Internacionais, Ministério das Relações Exteriores. Disponível em: <http://daimre.serpro.gov.br/atos-internacionais/bilaterais/1952/b_32>. Acesso em: 02 jul.2016.

AJUSTE COMERCIAL E DO CONVÊNIO DE PAGAMENTOS DE 1950 PRORROGAÇÃO DO PRAZO DE DENÚNCIA. Bonn, 1955. Sistema Consular Integrado. Atos Internacionais, Ministério das Relações Exteriores. Disponível em: <http://daimre.serpro.gov.br/atos-internacionais/bilaterais/1955/b_4>. Acesso em: 08 jul.2016.

AJUSTE COMERCIAL ENTRE BRASIL E FRANÇA. 1953. Sistema Consular Integrado. Atos Internacionais, Ministério das Relações Exteriores. Disponível em: <http://daimre.serpro.gov.br/atos-internacionais/bilaterais/1953/b_30>. Acesso em: 02 jul.2016.

AJUSTE COMERCIAL ENTRE BRASIL E REINO UNIDO. Londres, 1936. Sistema Consular Integrado. Atos Internacionais, Ministério das Relações Exteriores. Disponível em: <http://dai-mre.serpro.gov.br/atos-internacionais/bilaterais/1932/b_4>. Acesso em: 15 jun.2016.

AJUSTE COMERCIAL ENTRE OS GOVERNOS DOS ESTADOS UNIDOS DO BRASIL E A RAPÚBLICA FEDERAL DA ALEMANHA. Bonn, 1950. Sistema Consular Integrado. Atos Internacionais, Ministério das Relações Exteriores. Disponível em: <http://daimre.serpro.gov.br/atos-internacionais/bilaterais/1950/b_21>. Acesso em: 02 jul.2016.

AJUSTE COMERCIAL. 1955. Sistema Consular Integrado. Atos Internacionais, Ministério das Relações Exteriores. Disponível em: <http://dai-mre.serpro.gov.br/atosinternacionais/bilaterais/1955/b_14>. Acesso em: 08 jul.2016.

AJUSTE COMPLEMENTAR AO ACORDO BÁSICO DE COOPERAÇÃO CIENTÍFICA E TÉCNICA ENTRE O GOVERNO DA REPÚBLICA FEDERATIVA DO BRASIL E O GOVERNO DA REPÚBLICA DO PERU NA ÁREA DE PROMOÇÃO COMERCIAL. Lima, 1999. Sistema Consular Integrado. Atos Internacionais, Ministério das Relações Exteriores. Disponível em: <http://dai-mre.serpro.gov.br/atos-internacionais/bilaterais/1999/b_34>. Acesso em: 28 jul.2016. 
AJUSTE COMPLEMENTAR AO ACORDO BÁSICO DE COOPERAÇÃO TÉCNICA E CIENTÍFICA ENTRE A REPÚBLICA FEDERATIVA DO BRASIL E A REPÚBLICA DA BOLÍVIA NO CAMPO DA PRODUÇÃO, PROCESSAMENTO E COMERCIALIZAÇÃO DA BORRACHA. Cruz de la Sierra, 1984. Disponível em: <http://dai-mre.serpro.gov.br/atosinternacionais/bilaterais/1984/b_11>. Acesso em: 17 jul.2016.

AJUSTE COMPLEMENTAR AO ACORDO COMERCIAL ENTRE O GOVERNO DA REPÚBLICA FEDERATIVA DO BRASIL E O GOVERNO DA REPÚBLICA DO PERU. Brasília, 1986. Sistema Consular Integrado. Atos Internacionais, Ministério das Relações Exteriores. Disponível em: <http://dai-mre.serpro.gov.br/atosinternacionais/bilaterais/1986/b_54>. Acesso em: 17 jul.2016.

AJUSTE COMPLEMENTAR AO ACORDO DE COMÉRCIO E PAGAMENTOS BRASIL - POLÔNIA, DE 19 DE MARÇO DE 1960. 1969. Sistema Consular Integrado. Atos Internacionais, Ministério das Relações Exteriores. Disponível em: <http://daimre.serpro.gov.br/atos-internacionais/bilaterais/1969/b_46>. Acesso em: 15 jul.2016.

AJUSTE COMPLEMENTAR AO ACORDO DE COMÉRCIO E PAGAMENTOS DE 20 DE ABRIL DE 1963 (NOTA BRASILEIRA). 1969. Sistema Consular Integrado. Atos Internacionais, Ministério das Relações Exteriores. Disponível em: <http://daimre.serpro.gov.br/atos-internacionais/bilaterais/1969/b_24>. Acesso em: 15 jul.2016.

AJUSTE COMPLEMENTAR AO ACORDO DE COMÉRCIO E PAGAMENTOS, DE 20 DE ABRIL DE 1963, SOBRE EXPORTAÇÃO E IMPORTAÇÃO DE MERCADORIAS. 1981. Sistema Consular Integrado. Atos Internacionais, Ministério das Relações Exteriores. Disponível em: <http://dai-mre.serpro.gov.br/atos-internacionais/bilaterais/1981/b_94>. Acesso em: 17 jul.2016.

AJUSTE COMPLEMENTAR AO ACORDO DE COOPERAÇÃO ECONÔMICA, CIENTÍFICA E TÉCNICA ENTRE O GOVERNO DA REPÚBLICA FEDERATIVA DO BRASIL E O GOVERNO DA REPÚBLICA POPULAR DE ANGOLA. Brasília, 1983. Sistema Consular Integrado. Atos Internacionais, Ministério das Relações Exteriores. Disponível em: <http://dai-mre.serpro.gov.br/atos-internacionais/bilaterais/1983/b_17>. Acesso em: 17 jul.2016.

AJUSTE COMPLEMENTAR AO ACORDO DE COOPERAÇÃO TÉCNICA ENTRE O GOVERNO DA REPÚBLICA FEDERATIVA DO BRASIL E O GOVERNO DA REPÚBLICA DA COSTA RICA NA ÁREA DE COMÉRCIO EXTERIOR. Costa Rica, 2000. Sistema Consular Integrado. Atos Internacionais, Ministério das Relações Exteriores. Disponível em: <http://dai-mre.serpro.gov.br/atos-internacionais/bilaterais/2000/b_18>. Acesso em: 28 jul.2016.

AJUSTE COMPLEMENTAR AO ACORDO SOBRE O FORNECIMENTO DE MAQUINARIA E EQUIPAMENTOS DA URSS AO BRASIL E SOBRE FORNECIMENTO DE MERCADORIAS BRASILEIRAS À URSS. Brasília, 1978. Sistema Consular Integrado. Atos Internacionais, Ministério das Relações Exteriores. Disponível em: <http://daimre.serpro.gov.br/atos-internacionais/bilaterais/1978/b_47>. Acesso em: 17 jul.2016. 
AJUSTE COMPLEMENTAR AO ACORDO SOBRE O FORNECIMENTO DE MAQUINARIA E EQUIPAMENTOS DA UNIÃO SOVIÉTICA AO BRASIL E SOBRE FORNECIMENTO DE MERCADORIAS BRASILEIRAS À UNIÃO SOVIÉTICA, DE 24 DE MARÇO DE 1975. Brasília, 1979. Sistema Consular Integrado. Atos Internacionais, Ministério das Relações Exteriores. Disponível em: <http://dai-mre.serpro.gov.br/atosinternacionais/bilaterais/1979/b_62>. Acesso em: 17 jul.2016.

II

AJUSTE COMPLEMENTAR AO CONVÊNIO COMERCIAL ENTRE O GOVERNO DA REPUBLICA FEDERATIVA DO BRASIL E O GOVERNO DA REPÚBLICA DO PERU. Lima, 1981. Sistema Consular Integrado. Atos Internacionais, Ministério das Relações Exteriores. Disponível em: <http://dai-mre.serpro.gov.br/atosinternacionais/bilaterais/1981/b_83>. Acesso em: 17 jul.2016.

II

AJUSTE COMPLEMENTAR AO CONVÊNIO COMERCIAL ENTRE O GOVERNO DA REPÚBLICA FEDERATIVA DO BRASIL E O GOVERNO DA REPÚBLICA DO PERU. Lima, 1981. Sistema Consular Integrado. Atos Internacionais, Ministério das Relações Exteriores. Disponível em: <http://dai-mre.serpro.gov.br/atosinternacionais/bilaterais/1981/b_82>. Acesso em: 17 jul.2016.

AJUSTE COMPLEMENTAR AO CONVÊNIO COMERCIAL ENTRE O GOVERNO DA REPÚBLICA FEDERATIVA DO BRASIL E O GOVERNO DA REPÚBLICA DO PERU. Lima,1981. Sistema Consular Integrado. Atos Internacionais, Ministério das Relações Exteriores. Disponível em: <http://dai-mre.serpro.gov.br/atosinternacionais/bilaterais/1981/b_84>. Acesso em: 17 jul.2016.

AJUSTE COMPLEMENTAR AO CONVÊNIO COMERCIAL ENTRE O GOVERNO DA REPÚBLICA FEDERATIVA DO BRASIL E O GOVERNO DA REPÚBLICA DO PERU. Lima, 1981. Sistema Consular Integrado. Atos Internacionais, Ministério das Relações Exteriores. Disponível em: <http://dai-mre.serpro.gov.br/atosinternacionais/bilaterais/1981/b_116>. Acesso em: 17 jul.2016.

AJUSTE DE COMÉRCIO E DE PAGAMENTOS ENTRE O GOVERNO DOS ESTADOS UNIDOS DO BRASIL E O GOVERNO DO JAPÃO. 1958. Sistema Consular Integrado. Atos Internacionais, Ministério das Relações Exteriores. Disponível em: <http://daimre.serpro.gov.br/atos-internacionais/bilaterais/1958/b_72>. Acesso em: 11 jul.2016.

AJUSTE DE COMÉRCIO E PAGAMENTOS. 1958. Sistema Consular Integrado. Atos Internacionais, Ministério das Relações Exteriores. Disponível em: <http://daimre.serpro.gov.br/atos-internacionais/bilaterais/1958/b_41>. Acesso em: 10 jul.2016.

AJUSTE DE COMÉRCIO ENTRE BRASIL E ISLÂNDIA. 1953. Sistema Consular Integrado. Atos Internacionais, Ministério das Relações Exteriores. Disponível em: <http://daimre.serpro.gov.br/atos-internacionais/bilaterais/1953/b_19>. Acesso em: 02 Jul.2016.

AJUSTE DE PAGAMENTOS E COMÉRCIO. Rio de Janeiro, 1955. Sistema Consular Integrado. Atos Internacionais, Ministério das Relações Exteriores. Disponível em: <http://daimre.serpro.gov.br/atos-internacionais/bilaterais/1955/b_23>. Acesso em: 08 jul.2016. 
AJUSTE DE PAGAMENTOS E COMÉRCIO. Rio de Janeiro, 1955. Sistema Consular Integrado. Atos Internacionais, Ministério das Relações Exteriores. Disponível em: <http://daimre.serpro.gov.br/atos-internacionais/bilaterais/1955/b_40>. Acesso em: 09 jul.2016.

AJUSTE MODIFICATIVO DO ACORDO DE COMÉRCIO E PAGAMENTOS DE 1948. 1955. Sistema Consular Integrado. Atos Internacionais, Ministério das Relações Exteriores. Disponível em: <http://dai-mre.serpro.gov.br/atos-internacionais/bilaterais/1955/b_22>. Acesso em: 08 jul.2016.

Ajuste Modificativo do Acordo sobre Venda de Celulose. 1971. Sistema Consular Integrado. Atos Internacionais, Ministério das Relações Exteriores. Disponível em: <http://daimre.serpro.gov.br/atos-internacionais/bilaterais/1971/b_106>. Acesso em: 15 jul.2016.

AJUSTE PARA A INTERPRETAÇÃO DO ARTIGO $1^{\circ}$ DO TRATADO DE COMÉRCIO E NAVEGAÇÃO, FIRMADO EM 27 DE MAIO DE 1949. Montevidéu, 1956. Sistema Consular Integrado. Atos Internacionais, Ministério das Relações Exteriores. Disponível em: <http://daimre.serpro.gov.br/atos-internacionais/bilaterais/1956/b_48>. Acesso em: 09 jul.2016.

AJUSTE PARA PRORROGAÇÃO DE ACORDOS ENTRE BRASIL E ARGENTINA.1957. Sistema Consular Integrado. Atos Internacionais, Ministério das Relações Exteriores. Disponível em: <http://dai-mre.serpro.gov.br/atos-internacionais/bilaterais/1957/b_15>. Acesso em: 09 jul.2016.

AJUSTE QUE ALTERA O ACORDO PARA CONSOLIDAÇÃO DOS COMPROMISSOS COMERCIAIS BRASILEIROS DE 1961.1964. Sistema Consular Integrado. Atos Internacionais, Ministério das Relações Exteriores. Disponível em: <http://daimre.serpro.gov.br/atos-internacionais/bilaterais/1964/b_17>. Acesso em: 15 jul.2016.

AJUSTE SOBRE A UTILIZAÇÃO DE ZONA FRANCA EM MANAUS. La Paz, 1958. Sistema Consular Integrado. Atos Internacionais, Ministério das Relações Exteriores. Disponível em: <http://dai-mre.serpro.gov.br/atos-internacionais/bilaterais/1958/b_36>. Acesso em: 10 jul.2016.

AJUSTE SOBRE LISTAS DE MERCADORIAS. 1963. Sistema Consular Integrado. Atos Internacionais, Ministério das Relações Exteriores. Disponível em: <http://daimre.serpro.gov.br/atos-internacionais/bilaterais/1963/b_10>. Acesso em: 15 jul.2016.

AJUSTE SOBRE LISTAS DE MERCADORIAS. Praga, 1964. Sistema Consular Integrado. Atos Internacionais, Ministério das Relações Exteriores. Disponível em: <http://daimre.serpro.gov.br/atos-internacionais/bilaterais/1964/b_5>. Acesso em: 15 jul.2016.

AJUSTE SOBRE PROMOÇÃO DE VENDAS E VIAGENS DE NATUREZA COMERCIAL. 1963. Sistema Consular Integrado. Atos Internacionais, Ministério das Relações Exteriores. Disponível em: <http://dai-mre.serpro.gov.br/atos-internacionais/bilaterais/1963/b_11>. Acesso em: 15 jul.2016.

ARTIGO ADDICIONAL AO TRATADO DE COMMERCIO E NAVEGAÇÃO DE 19 DE MAIO DE 1836, ENTRE O SENHOR D. PEDRO II IMPERADOR DO BRASIL, E A SENHORA D. MARIA II RAINHA DE PORTUGAL, ASSIGNADO NO RIO DE JANEIRO 
A 6 DE JULHO DE 1836. Rio de Janeiro, 1836. Sistema Consular Integrado. Atos Internacionais, Ministério das Relações Exteriores. Disponível em: <http://daimre.serpro.gov.br/atos-internacionais/bilaterais/1836/artigo-adicional-ao-tratado-decomercio-e-navegacao-de-19-de-maio-de-1836>. Acesso em: 15 jul.2016.

ATA SOBRE A VENDA DE GÁS ARGENTINO AO BRASIL. Uruguaiana, 1989. Sistema Consular Integrado. Atos Internacionais, Ministério das Relações Exteriores. Disponível em: <http://dai-mre.serpro.gov.br/atos-internacionais/bilaterais/1989/b_43>. Acesso em: 25 jul.2016.

CONVENÇÃO DE COMÉRCIO E NAVEGAÇÃO N.1. Capital Federal, 1897. Sistema Consular Integrado. Atos Internacionais, Ministério das Relações Exteriores. Disponível em:<http://dai-mre.serpro.gov.br/atos-internacionais/bilaterais/1897/b_76>. Acesso em: 15 jun.2016.

CONVENCAO ENTRE O GOVERNO DA REPUBLICA PORTUGUESA E O GOVERNO DA UNIÃO DA ÁFRICA DO SUL. Pretória, 1827. Sistema Consular Integrado. Atos Internacionais, Ministério das Relações Exteriores. Disponível :<http://daimre.serpro.gov.br/atos-internacionais/bilaterais/1928/b_5>. Acesso em: 15 jun.2016.

CONVENÇÃO ESPECIAL DE COMÉRCIO, NAVEGAÇÃO FLUVIAL E LIMITES. Lima, 1881. Sistema Consular Integrado. Atos Internacionais, Ministério das Relações Exteriores. Disponível em: <http://dai-mre.serpro.gov.br/atos-internacionais/bilaterais/1851/b_31>. Acesso em: 15 jun.2016.

CONVÊNIO COMERCIAL ENTRE O GOVERNO DA REPÚBLICA FEDERATIVA DO BRASIL E O GOVERNO DA REPÚBLICA DO PERU. 1976. Sistema Consular Integrado. Atos Internacionais, Ministério das Relações Exteriores. Disponível em: <http://daimre.serpro.gov.br/atos-internacionais/bilaterais/1976/b_76>. Acesso em: 15 jul.2016.

CONVÊNIO COMERCIAL ENTRE O GOVERNO DA REPÚBLICA FEDERATIVA DO BRASIL E O GOVERNO DA REPÚBLICA DE CUBA. Brasília, 1989. Sistema Consular Integrado. Atos Internacionais, Ministério das Relações Exteriores. Disponível em: <http://daimre.serpro.gov.br/atos-internacionais/bilaterais/1989/b_61>. Acesso em: 25 jul.2016.

CONVÊNIO COMERCIAL. La Paz, 1958. Sistema Consular Integrado. Atos Internacionais, Ministério das Relações Exteriores. Disponível em: <http://dai-mre.serpro.gov.br/atosinternacionais/bilaterais/1958/b_10>. Acesso em: 10 jul.2016.

CONVÊNIO DE COMÉRCIO FRONTEIRIÇO ENTRE BRASIL E PARAGUAI. Assunção, 1956. Sistema Consular Integrado. Atos Internacionais, Ministério das Relações Exteriores. Disponível em: <http://dai-mre.serpro.gov.br/atos-internacionais/bilaterais/1956/b_37>. Acesso em: 09 jul.2016.

CONVÊNIO DE COMÉRCIO INTER-REGIONAL. La Paz, 1958. Sistema Consular Integrado. Atos Internacionais, Ministério das Relações Exteriores. Disponível em: <http://daimre.serpro.gov.br/atos-internacionais/bilaterais/1958/b_11>. Acesso em: 10 jul.2016. 
Integrado. Atos Internacionais, Ministério das Relações Exteriores. Disponível em: <http://daimre.serpro.gov.br/atos-internacionais/bilaterais/1958/b_12>. Acesso em: 10 jul.2016.

CONVÊNIO DE TRÂNSITO LIVRE ENTRE A REPÚBLICA DOS ESTADOS UNIDOS DO BRASIL E A REPUBLICA DA BOLÍVIA. La Paz, 1958. Sistema Consular Integrado. Atos Internacionais, Ministério das Relações Exteriores. Disponível em: <http://daimre.serpro.gov.br/atos-internacionais/bilaterais/1958/b_14>. Acesso em: 10 jul.2016.

CONVÊNIO ENTRE O COMITÊ EMPRESARIAL PERMANENTE DO MINISTÉRIO DAS RELAÇÕES EXTERIORES DA REPÚBLICA FEDERATIVA DO BRASIL E A CONFEDERAÇÃO DA PRODUÇÃO DO COMÉRCIO DA REPÚBLICA DO CHILE. Santiago, 1993. Sistema Consular Integrado. Atos Internacionais, Ministério das Relações Exteriores. Disponível em: <http://dai-mre.serpro.gov.br/atosinternacionais/bilaterais/1993/b_17_2011-10-04-15-03-03>. Acesso em: 25 jul.2016.

CONVÊNIO ENTRE O GOVERNO DA REPÚBLICA FEDERATIVA DO BRASIL E O GOVERNO DA REPÚBLICA DO PARAGUAI SOBRE COOPERAÇÃO EM MATÉRIA DE REGISTRO DE COMÉRCIO. Assunção, 1982. Sistema Consular Integrado. Atos Internacionais, Ministério das Relações Exteriores. Disponível em: <http://daimre.serpro.gov.br/atos-internacionais/bilaterais/1982/b_62>. Acesso em: 17 jul.2016.

CONVÊNIO ENTRE O GOVERNO DA REPÚBLICA FEDERATIVA DO BRASIL E O GOVERNO DA REPÚBLICA DA BOLÍVIA PARA O ESTABELECIMENTO DE UM DEPÓSITO FRANCO NO PORTO DE PARANAGUÁ. Brasília, 1990. Sistema Consular Integrado. Atos Internacionais, Ministério das Relações Exteriores. Disponível em: <http://daimre.serpro.gov.br/atos-internacionais/bilaterais/1990/b_39_2011-10-17-15-48-42>. Acesso em: 25 jul.2016.

CONVÊNIO PARA O ESTABELECIMENTO, NA CIDADE DE PORTO VELHO, DE UM ENTREPOSTO DE DEPÓSITO FRANCO PARA MERCADORIAS IMPORTADAS E EXPORTADAS PELA BOLÍVIA. 1958. Sistema Consular Integrado. Atos Internacionais, Ministério das Relações Exteriores. Disponível em: <http://dai-mre.serpro.gov.br/atosinternacionais/bilaterais/1958/b_16>. Acesso em: 10 jul.2016.

CONVÊNIO PARA O ESTABELECIMENTO, NO PORTO DE BELÉM, DE UM ENTREPOSTO DE DEPÓSITO FRANCO PARA MERCADORIAS IMPORTADAS E EXPORTADAS PELA BOLÍVIA. La Paz, 1958. Sistema Consular Integrado. Atos Internacionais, Ministério das Relações Exteriores. Disponível em: <http://daimre.serpro.gov.br/atos-internacionais/bilaterais/1958/b_15>. Acesso em: 10 jul.2016.

CONVÊNIO PARA O ESTABELECIMENTO, NO PORTO DE CORUMBÁ, DE UM ENTREPOSTO DE DEPÓSITO FRANCO PARA MERCADORIAS IMPORTADAS E EXPORTADAS PELA BOLÍVIA. La Paz, 1958. Sistema Consular Integrado. Atos Internacionais, Ministério das Relações Exteriores. Disponível em: <http://daimre.serpro.gov.br/atos-internacionais/bilaterais/1958/b_17>. Acesso em: 10 jul.2016.

CONVÊNIO PARA O ESTABELECIMENTO, NO PORTO DE SANTOS, DE UM ENTREPOSTO DE DEPÓSITO FRANCO PARA MERCADORIAS IMPORTADAS E EXPORTADAS PELA BOLÍVIA. La Paz, 1958. Sistema Consular Integrado. Atos Internacionais, Ministério das Relações Exteriores. Disponível em: <http://daimre.serpro.gov.br/atos-internacionais/bilaterais/1958/b_18>. Acesso em: 10 jul.2016. 
CONVÊNIO SOBRE ABASTECIMENTO DE TRIGO ENTRE O GOVERNO DA REPÚBLICA FEDERATIVA DO BRASIL E O GOVERNO DA REPÚBLICA ORIENTAL DO URUGUAI. Brasília, 1991. Sistema Consular Integrado. Atos Internacionais, Ministério das Relações Exteriores. Disponível em: <http://dai-mre.serpro.gov.br/atosinternacionais/bilaterais/1991/b_1_2011-10-17-10-44-47>. Acesso em: 25 jul.2016.

CONVÊNIO SOBRE LEGALIZAÇÃO DE MANIFESTOS ENTRE A REPÚBLICA DOS ESTADOS UNIDOS DO BRASIL E A REPÚBLICA ORIENTAL DO URUGUAI. Montevidéu, 1942. Sistema Consular Integrado. Atos Internacionais, Ministério das Relações Exteriores. Disponível em: <http://dai-mre.serpro.gov.br/atosinternacionais/bilaterais/1942/b_1>. Acesso em: 28 jun.2016.

DECLARAÇÃO DE QUITO. 1958 .Sistema Consular Integrado. Atos Internacionais, Ministério das Relações Exteriores. Disponível em: <http://dai-mre.serpro.gov.br/atosinternacionais/bilaterais/1907/b_52>. Acesso em: 15 jun.2016.

EMENDA E PRORROGAÇÃO DO ACORDO SOBRE TEXTEIS DE ALGODÃO DE 23 DE OUTUBRO DE 1970. Washington D.C, 1972. Sistema Consular Integrado. Atos Internacionais, Ministério das Relações Exteriores. Disponível em: <http://daimre.serpro.gov.br/atos-internacionais/bilaterais/1972/b_49>. Acesso em: 15 jul.2016.

ENTENDIMENTO COM URUGUAI (ACORDO) PARA O INTERCÂMBIO DE FRUTAS 1935. Sistema Consular Integrado. Atos Internacionais, Ministério das Relações Exteriores. Disponível em: <http://dai-mre.serpro.gov.br/atos-internacionais/bilaterais/1935/b_19>. Acesso em: 18 jun.2016.

ENTENDIMENTO COMERCIAL BRASIL - AUSTRÁLIA. 1954. Sistema Consular Integrado. Atos Internacionais, Ministério das Relações Exteriores. Disponível em: <http://daimre.serpro.gov.br/atos-internacionais/bilaterais/1950/b_34>. Acesso em: 02 jul.2016.

ENTENDIMENTO COMERCIAL BRASIL - REINO UNIDO. 1950. Sistema Consular Integrado. Atos Internacionais, Ministério das Relações Exteriores. Disponível em: <http://daimre.serpro.gov.br/atos-internacionais/bilaterais/1950/b_28>. Acesso em: 02 jul.2016.

ENTENDIMENTO COMERCIAL ENTRE BRASIL E ITÁLIA. 1950. Sistema Consular Integrado. Atos Internacionais, Ministério das Relações Exteriores. Disponível em: <http://daimre.serpro.gov.br/atos-internacionais/bilaterais/1950/b_20>. Acesso em: 02 jul.2016.

ENTENDIMENTO COMERCIAL ENTRE BRASIL E ITÁLIA. 1950. Sistema Consular Integrado. Atos Internacionais, Ministério das Relações Exteriores. Disponível em: <http://daimre.serpro.gov.br/atos-internacionais/bilaterais/1950/b_21>. Acesso em: 12 jun.2016.

ENTENDIMENTO COMPLEMENTAR AO ACORDO PARA A CONSOLIDAÇÃO DOS COMPROMISSOS COMERCIAIS. Rio de Janeiro, 1961. Sistema Consular Integrado. Atos Internacionais, Ministério das Relações Exteriores. Disponível em: <http://daimre.serpro.gov.br/atos-internacionais/bilaterais/1961/b_51>. Acesso em: 15 jul.2016.

ENTENDIMENTOS SOBRE O INTERCÂMBIO COMERCIAL BRASIL - ARGENTINA CONCLUÍDOS EM BUENOS AIRES A 23 DE JUNHO DE 1950. Buenos Aires, 1950. Sistema Consular Integrado. Atos Internacionais, Ministério das Relações Exteriores. 
Disponível em: <http://dai-mre.serpro.gov.br/atos-internacionais/bilaterais/1950/b_12>. Acesso em: 28 jun.2016.

MEMORANDO DE ENTENDIMENTO ENTRE O BRASIL E A LÍBIA PARA A PROMOÇÃO DO COMÉRCIO, DO INVESTIMENTO E DA INFRAESTRUTURA. Brasília, 2009. Sistema Consular Integrado. Atos Internacionais, Ministério das Relações Exteriores. Disponível em: <http://dai-mre.serpro.gov.br/atos-internacionais/bilaterais/2009/b_6287>. Acesso em: 02 ago.2016.

MEMORANDO DE ENTENDIMENTO ENTRE O GOVERNO DA REPUBLICA FEDERATIVA DO BRASIL E O GOVERNO DO CANADA PARA A REALIZAÇÃO DE UMA PESQUISA DE MERCADO PARA PRODUTOS BRASILEIROS NO CANADÁ.1970. Sistema Consular Integrado. Atos Internacionais, Ministério das Relações Exteriores. Disponível em: <http://dai-mre.serpro.gov.br/atos-internacionais/bilaterais/1970/b_54>. Acesso em: 15 jul.2016.

MEMORANDO DE ENTENDIMENTO ENTRE O GOVERNO DA REPÚBLICA FEDERATIVA DO BRASIL E O GOVERNO DA NOVA ZELÂNDIA SOBRE INTERCÂMBIO COMERCIAL E COOPERAÇÃO CIENTÍFICO-TECNOLÓGICA, INDUSTRIAL E ECONÔMICA. Brasília, 1986. Sistema Consular Integrado. Atos Internacionais, Ministério das Relações Exteriores. Disponível em: <http://daimre.serpro.gov.br/atos-internacionais/bilaterais/1986/b_51>. Acesso em: 17 jul.2016.

MEMORANDO DE ENTENDIMENTO ENTRE O GOVERNO DA REPÚBLICA FEDERATIVA DO BRASIL E O GOVERNO DA REPÚBLICA DO SURINAME SOBRE COOPERAÇÃO NA ÁREA DE PROMOÇÃO COMERCIAL. Paramaribo, 1992. Sistema Consular Integrado. Atos Internacionais, Ministério das Relações Exteriores. Disponível em: <http://dai-mre.serpro.gov.br/atos-internacionais/bilaterais/1992/b_2_2011-10-14-15-30-07>. Acesso em: 25 jul.2016.

MEMORANDO DE ENTENDIMENTO ENTRE O GOVERNO DA REPÚBLICA FEDERATIVA DO BRASIL E O GOVERNO DA REPÚBLICA DO CHILE PARA O ESTABELECIMENTO DA COMISSÃO BILATERAL BRASIL-CHILE. São Paulo, 2009. Sistema Consular Integrado. Atos Internacionais, Ministério das Relações Exteriores. Disponível em: <http://dai-mre.serpro.gov.br/atos-internacionais/bilaterais/2009/b_6401 >. Acesso em: 02 ago.2016.

MEMORANDO DE ENTENDIMENTO ENTRE O GOVERNO DA REPÚBLICA FEDERATIVA DO BRASIL E O GOVERNO DA REPÚBLICA DA GUIANA PARA A PROMOÇÃO DO COMÉRCIO E DO INVESTIMENTO. Bonfim, 2009. Sistema Consular Integrado. Atos Internacionais, Ministério das Relações Exteriores. Disponível em: <http://daimre.serpro.gov.br/atos-internacionais/bilaterais/2009/b_6467 >. Acesso em: 02 Ago.2016.

MEMORANDO DE ENTENDIMENTO ENTRE O GOVERNO DA REPÚBLICA FEDERATIVA DO BRASIL E O GOVERNO DA REPÚBLICA BOLIVARIANA DA VENEZUELA PARA A COOPERAÇÃO NO SETOR ALIMENTAR E NOS SETORES DE INVESTIMENTO E COMERCIALIZAÇÃO DE ALIMENTOS. Cidade del Tigre, 2009. Sistema Consular Integrado. Atos Internacionais, Ministério das Relações Exteriores. 
Disponível em: <http://dai-mre.serpro.gov.br/atos-internacionais/bilaterais/2009/memorandode-entendimento-entre-o-governo-da-republica-federativa-do-brasil-e-o-governo-darepublica-bolivariana-da-venezuela-para-a-cooperacao-no-setor-alimentar-e-nos-setores-deinvestimento-e-comercializacao-de-alimentos>. Acesso em: 02 ago.2016.

MEMORANDO DE ENTENDIMENTO ENTRE O GOVERNO DA REPÚBLICA FEDERATIVA DO BRASIL E O GOVERNO DA REPÚBLICA DO QUÊNIA SOBRE PROMOÇÃO DE COMÉRCIO E DE INVESTIMENTOS. Nairóbi, 2010. Sistema Consular Integrado. Atos Internacionais, Ministério das Relações Exteriores. Disponível em: <http://daimre.serpro.gov.br/atos-internacionais/bilaterais/2010/memorando-de-entendimento-entre-ogoverno-da-republica-federativa-do-brasil-e-o-governo-da-republica-do-quenia-sobrepromocao-de-comercio-e-de-investimentos >. Acesso em: 02 ago.2016.

MEMORANDO DE ENTENDIMENTO ENTRE O GOVERNO DA REPÚBLICA FEDERATIVA DO BRASIL E O GOVERNO DA REPÚBLICA ARGENTINA PARA A PROMOÇÃO COMERCIAL CONJUNTA. Buenos Aires, 2011. Sistema Consular Integrado. Atos Internacionais, Ministério das Relações Exteriores. Disponível em: <http://daimre.serpro.gov.br/atos-internacionais/bilaterais/2011/memorando-de-entendimento-entre-ogoverno-da-republica-federativa-do-brasil-e-o-governo-da-republica-argentina-para-apromocao-comercial-conjunta >. Acesso em: 02 ago.2016.

MEMORANDO DE ENTENDIMENTO ENTRE O MDIC E O MINISTÉRIO DE FOMENTO, INDÚSTRIA E COMÉRCIO DA NICARÁGUA NA ÁREA DE COOPERAÇÃO TECNOLÓGICA EMPRESARIAL, COMÉRCIO E INVESTIMENTOS. Manágua, 2007. Sistema Consular Integrado. Atos Internacionais, Ministério das Relações Exteriores. Disponível em: <http://dai-mre.serpro.gov.br/atos-internacionais/bilaterais/2007/b_152>. Acesso em: 28 jul.2016.

MEMORANDO DE ENTENDIMENTO ENTRE O MINISTÉRIO DO DESENVOLVIMENTO, INDÚSTRIA E COMÉRCIO EXTERIOR DA REPÚBLICA FEDERATIVA DO BRASIL E O DEPARTAMENTO DE COMÉRCIO E INDÚSTRIA DA REPÚBLICA DA ÁFRICA DO SUL PARA PROMOÇÃO DO COMÉRCIO E INVESTIMENTO. Brasília, 2009. Sistema Consular Integrado. Atos Internacionais, Ministério das Relações Exteriores. Disponível em: <http://dai-mre.serpro.gov.br/atosinternacionais/bilaterais/2009/memorando-de-entendimento-entre-o-ministerio-dodesenvolvimento-industria-e-comercio-exterior-da-republica-federativa-do-brasil-e-odepartamento-de-comercio-e-industria-da-republica-da-africa-do-sul-para-promocao-docomercio-e-investimento >. Acesso em: 02 ago.2016.

MEMORANDO DE ENTENDIMENTO ENTRE O MINISTÉRIO DO DESENVOLVIMENTO, INDÚSTRIA E COMÉRCIO EXTERIOR DA REPÚBLICA FEDERATIVA DO BRASIL E O MINISTÉRIO DO COMÉRCIO EXTERNO E DO INVESTIMENTO ESTRANGEIRO DA REPÚBLICA DE CUBA. Havana, 2012. Sistema Consular Integrado. Atos Internacionais, Ministério das Relações Exteriores. Disponível em: $<$ http://dai-mre.serpro.gov.br/atos-internacionais/bilaterais/2012/momorando-deentendimento-entre-o-ministerio-do-desenvolvimento-industria-e-comercio-exterior-da- 
republica-federativa-do-brasil-e-o-ministerio-do-comercio-externo-e-do-investimentoestrangeiro-da-republica-de-cuba >. Acesso em: 02 ago.2016.

MEMORANDO DE ENTENDIMENTO PARA A PROMOÇÃO DO COMÉRCIO E INVESTIMENTO ENTRE O GOVERNO DA REPÚBLICA FEDERATIVA DO BRASIL E O GOVERNO DA REPÚBLICA ORIENTAL DO URUGUAI. San Juan Anchorena, 2007. Sistema Consular Integrado. Atos Internacionais, Ministério das Relações Exteriores. Disponível em: <http://dai-mre.serpro.gov.br/atos-internacionais/bilaterais/2007/b_24>. Acesso em: 28 jul.2016.

MEMORANDO DE ENTENDIMENTO PARA A PROMOÇÃO DO COMÉRCIO E INVESTIMENTO ENTRE O GOVERNO DA REPÚBLICA FEDERATIVA DO BRASIL E O GOVERNO DA REPÚBLICA DO SURINAME. Paramaribo, 2007. Sistema Consular Integrado. Atos Internacionais, Ministério das Relações Exteriores. Disponível em: <http://daimre.serpro.gov.br/atos-internacionais/bilaterais/2007/b_135>. Acesso em: 28 jul.2016.

MEMORANDO DE ENTENDIMENTO PARA ESTABELECER AS BASES DO COMÉRCIO, ENTRE A REPÚBLICA FEDERATIVA DO BRASIL E A REPÚBLICA DEMOCRÁTICA ALEMÃ. Brasília, 1982. Sistema Consular Integrado. Atos Internacionais, Ministério das Relações Exteriores. Disponível em: <http://dai-mre.serpro.gov.br/atosinternacionais/bilaterais/1982/b_108>. Acesso em: 17 jul.2016.

MEMORANDO DE ENTENDIMENTO. Buenos Aires, 1984. Sistema Consular Integrado. Atos Internacionais, Ministério das Relações Exteriores. Disponível em: <http://daimre.serpro.gov.br/atos-internacionais/bilaterais/1984/b_40>. Acesso em: 17 jul.2016.

MEMORANDUM DE ENTENDIMENTO ENTRE O GOVERNO DA REPÚBLICA FEDERATIVA DO BRASIL E O GOVERNO DA REPÚBLICA DA COLÔMBIA, PARA A COOPERAÇÃO EM MATÉRIA DE PROMOÇÃO COMERCIAL. Bogotá, 1988. Sistema Consular Integrado. Atos Internacionais, Ministério das Relações Exteriores. Disponível em: <http://dai-mre.serpro.gov.br/atos-internacionais/bilaterais/1988/b_6>. Acesso em: 17 jul.2016.

MEMORANDUM DE ENTENDIMENTO PARA A PROMOÇÃO DO COMERCIO E DOS INVESTIMENTOS ENTRE O GOVERNO DA REPÚBLICA FEDERATIVA DO BRASIL E O GOVERNO DA REPÚBLICA DA COLÔMBIA. Bogotá, 2005. Sistema Consular Integrado. Atos Internacionais, Ministério das Relações Exteriores. Disponível em: <http://daimre.serpro.gov.br/atos-internacionais/bilaterais/2005/b_106>. Acesso em: 28 jul.2016.

MEMORANDUM DE ENTENDIMENTO PARA A PROMOÇÃO DO COMÉRCIO E DOS INVESTIMENTOS ENTRE O GOVERNO DA REPÚBLICA FEDERATIVA DO BRASIL E O GOVERNO DA REPÚBLICA DO CHILE. Santiago, 2004. Sistema Consular Integrado. Atos Internacionais, Ministério das Relações Exteriores. Disponível em: <http://daimre.serpro.gov.br/atos-internacionais/bilaterais/2004/b_76>. Acesso em: 28 jul.2016. 
MEMORANDUM DE ENTENDIMENTO PARA A PROMOÇÃO DO COMÉRCIO E INVESTIMENTO ENTRE O GOVERNO DA REPÚBLICA FEDERATIVA DO BRASIL E O GOVERNO DA REPÚBLICA DA BOLÍVIA. Brasília, 2003. Sistema Consular Integrado. Atos Internacionais, Ministério das Relações Exteriores. Disponível em< http://daimre.serpro.gov.br/atos-internacionais/bilaterais/2003/b_162>. Acesso em: 28 jul.2016.

MEMORANDUM DE ENTENDIMENTO PARA A PROMOÇÃO DO COMÉRCIO E INVESTIMENTO ENTRE O GOVERNO DA REPÚBLICA FEDERATIVA DO BRASIL E O GOVERNO DA REPÚBLICA DO PERU. Lima, 2006. Sistema Consular Integrado. Atos Internacionais, Ministério das Relações Exteriores. Disponível em: <http://daimre.serpro.gov.br/atos-internacionais/bilaterais/2006/b_33>. Acesso em: 28 jul.2016.

MEMORANDUM DE ENTENDIMENTO PARA A PROMOÇÃO DO COMÉRCIO E INVESTIMENTO ENTRE O GOVERNO DA REPÚBLICA FEDERATIVA DO BRASIL E O GOVERNO DA REPÚBLICA DO EQUADOR. Rio de Janeiro, 2006. Sistema Consular Integrado. Atos Internacionais, Ministério das Relações Exteriores. Disponível em: <http://daimre.serpro.gov.br/atos-internacionais/bilaterais/2006/b_134>. Acesso em: 28 jul.2016.

MEMORANDUM DE ENTENDIMENTO. Brasília, 1980. Sistema Consular Integrado. Atos Internacionais, Ministério das Relações Exteriores. Disponível em: <http://daimre.serpro.gov.br/atos-internacionais/bilaterais/1980/b_88>. Acesso em: 17 jul.2016.

MEMORANDUM ENTRE O GOVERNO DA REPÚBLICA FEDERATIVA DO BRASIL E O GOVERNO DA REPÚBLICA ARGENTINA PARA A CRIAÇÃO DA COMISSÃO DE MONITORAMENTO DO COMÉRCIO ENTRE BRASIL E ARGENTINA. Buenos Aires, 2003. Sistema Consular Integrado. Atos Internacionais, Ministério das Relações Exteriores. Disponível em: <http://dai-mre.serpro.gov.br/atos-internacionais/bilaterais/2003/b_89>. Acesso em: 28 jul.2016.

Ministério das Relações Exteriores ACORDO COMERCIAL PROVISÓRIO E ALEMANHA. 1936. Sistema Consular Integrado. Atos Internacionais, Ministério das Relações Exteriores. Disponível em: <http://dai-mre.serpro.gov.br/atos-internacionais/bilaterais/1936/b_5>. Acesso em: 22 jun.2016.

MODIFICAÇÃO AO ACORDO DE COMÉRCIO E PAGAMENTOS DE 1960. Praga, 1962. Sistema Consular Integrado. Atos Internacionais, Ministério das Relações Exteriores. Disponível em: <http://dai-mre.serpro.gov.br/atos-internacionais/bilaterais/1963/b_1>. Acesso em: 15 jul.2016.

MODUS-VIVENDI COMERCIAL. 1950. 1950. Sistema Consular Integrado. Atos Internacionais, Ministério das Relações Exteriores. Disponível em: <http://daimre.serpro.gov.br/atos-internacionais/bilaterais/1950/b_5>. Acesso em: 22 jul. 2016.

NOTA BRASILEIRA ACORDO RELATIVO ÀS EXPORTAÇÕES BRASILEIRAS DE FIOS DE ALGODÃO. Ottawa, 1971. Sistema Consular Integrado. Atos Internacionais, Ministério das Relações Exteriores. Disponível em: <http://dai-mre.serpro.gov.br/atosinternacionais/bilaterais/1971/b_78>. Acesso em: 15 jul.2016. 
NOTA BRASILEIRA. Lisboa, 1966. Sistema Consular Integrado. Atos Internacionais, Ministério das Relações Exteriores. Disponível em: <http://dai-mre.serpro.gov.br/atosinternacionais/bilaterais/1966/b_30>. Acesso em: 15 jul.2016.

NOTA COMERCIAL ENTRE BRASIL E PORTUGAL. 1952. Sistema Consular Integrado. Atos Internacionais, Ministério das Relações Exteriores. Disponível em: <http://daimre.serpro.gov.br/atos-internacionais/bilaterais/1952/b_13>. Acesso em: 02 jul.2016.

NOTA COMERCIAL. Buenos Aires, 1953. Sistema Consular Integrado. Atos Internacionais, Ministério das Relações Exteriores. Disponível em: <http://dai-mre.serpro.gov.br/atosinternacionais/bilaterais/1953/b_9>. Acesso em: 02 jul.2016.

NOTA DA EMBAIXADA DOS ESTADOS UNIDOS DA AMÉRICA AO GOVÊRNO BRASILEIRO. 1945. Sistema Consular Integrado. Atos Internacionais, Ministério das Relações Exteriores. Disponível em: http://dai-mre.serpro.gov.br/atosinternacionais/bilaterais/1945/b_7>. Acesso em: 28 jun.2016.

NOTA ENTRE BRASIL E ÁUSTRIA. 1952. Sistema Consular Integrado. Atos Internacionais, Ministério das Relações Exteriores. Disponível em: <http://daimre.serpro.gov.br/atos-internacionais/bilaterais/1952/b_40>. Acesso em: 02 jul.2016.

NOTAS REVERSAIS RELATIVAS À DENUNCIA DO ACORDO DE COMÉRCIO E DO AJUSTE DE PAGAMENTOS ENTRE O BANCO DO BRASIL E O BANCO CENTRAL DA BOLÍVIA, AMBOS DE 25 DE DEZEMBRO DE 1953. 1958. Sistema Consular Integrado. Atos Internacionais, Ministério das Relações Exteriores. Disponível em: <http://daimre.serpro.gov.br/atos-internacionais/bilaterais/1958/b_31>. Acesso em: 15 ago. 2016.

NOTAS REVERSAIS RELATIVAS À DENÚNCIA DO CONVÊNIO SOBRE O REGIME CAMBIAL PARA O COMÉRCIO FRONTEIRIÇO, DE 28 DE JUNHO DE 1943. 1958. Sistema Consular Integrado. Atos Internacionais, Ministério das Relações Exteriores. Disponível em: <http://dai-mre.serpro.gov.br/atos-internacionais/bilaterais/1958/b_3>. Acesso em: 02 dez. 2016.

NOTAS REVERSAIS TROCADAS ENTRE O GOVERNO DO BRASIL E O DE S. M. O REI DOS BELGAS, FIXANDO O PRAZO POR QUE DEVERÁ VIGORAR O TRATADO. Bruxelas, 1835. Sistema Consular Integrado. Atos Internacionais, Ministério das Relações Exteriores. Disponível em: <http://dai-mre.serpro.gov.br/atosinternacionais/bilaterais/1835/b_13>. Acesso em: 15 jun. 2016.

PRORROGAÇÃO DO AJUSTE ADMINISTRATIVO DE COMÉRCIO ENTRE BRASIL E JAPÃO. 1954. Sistema Consular Integrado. Atos Internacionais, Ministério das Relações Exteriores. Disponível em: <http://dai-mre.serpro.gov.br/atosinternacionais/bilaterais/1954/b_21>. Acesso em: 02 jul.2016.

PRORROGAÇÃO DO AJUSTE DE COMÉRCIO ENTRE O BRASIL E A ESPANHA. Rio de Janeiro, 1954. Sistema Consular Integrado. Atos Internacionais, Ministério das Relações Exteriores. Disponível em: <http://dai-mre.serpro.gov.br/atosinternacionais/bilaterais/1954/b_34>. Acesso em: 08 jul.2016. 
PRORROGAÇÃO DO PRAZO DE VALIDADE DAS LISTAS DE MERCADORIAS DO AJUSTE ADMINISTRATIVO DE COMÉRCIO DE 12 DE SETEMBRO DE 1952 ENTRE BRASIL E JAPÃO. Rio de Janeiro, 1955. Sistema Consular Integrado. Atos Internacionais, Ministério das Relações Exteriores. Disponível em: http://dai-mre.serpro.gov.br/atosinternacionais/bilaterais/1955/b_2>. Acesso em: 08 jul.2016.

PRORROGAÇÃO DO PRAZO DE VALIDADE DO ACORDO COMERCIAL DE 1953 ENTRE BRASIL E FRANÇA. Rio de Janeiro, 1954. Sistema Consular Integrado. Atos Internacionais, Ministério das Relações Exteriores. Disponível em: <http://daimre.serpro.gov.br/atos-internacionais/bilaterais/1954/b_35>. Acesso em: 08 jul.2016.

PRORROGAÇÃO DO PRAZO DE VALIDADE DO TRATADO DE COMÉRCIO E NAVEGAÇÃO DE 23 DE JANEIRO DE 1940. Buenos Aires, 1958. Sistema Consular Integrado. Atos Internacionais, Ministério das Relações Exteriores. Disponível em: <http://daimre.serpro.gov.br/atos-internacionais/bilaterais/1958/b_53>. Acesso em: 11 jul.2016.

PRORROGAÇÃO DO PRAZO DE VIGÊNCIA DO TRATADO DE COMÉRCIO E NAVEGAÇÃO ENTRE BRASIL E URUGUAI DE 25 DE AGOSTO DE 1933. Rio de Janeiro, 1954. Sistema Consular Integrado. Atos Internacionais, Ministério das Relações Exteriores. Disponível em: <http://dai-mre.serpro.gov.br/atos-internacionais/bilaterais/1954/b_24>. Acesso em: 08 jul.2016.

PROTOCOLO ADICIONAL AO ACORDO COMERCIAL ENTRE O GOVERNO DA REPÚBLICA FEDERATIVA DO BRASIL E O GOVERNO DA REPÚBLICA POPULAR DEMOCRÁTICA DA CORÉIA. Pyongyang, 2009. Sistema Consular Integrado. Atos Internacionais, Ministério das Relações Exteriores. Disponível em: <http://daimre.serpro.gov.br/atos-internacionais/bilaterais/2009/protocolo-adicional-ao-acordocomercial-entre-o-governo-da-republica-federativa-do-brasil-e-o-governo-da-republicapopular-democratica-da-coreia >. Acesso em: 02 ago.2016.

PROTOCOLO ADICIONAL AO ACORDO DE COMÉRCIO ENTRE O GOVERNO DA REPÚPLICA FEDERATIVA DO BRASIL E O GOVERNO DA REPÚBLICA ISLÂMICA DO PAQUISTÃO. Islamabad, 1984. Sistema Consular Integrado. Atos Internacionais, Ministério das Relações Exteriores. Disponível em: <http://dai-mre.serpro.gov.br/atosinternacionais/bilaterais/1984/b_24>. Acesso em: 17 jul.2016.

PROTOCOLO ADICIONAL AO ACORDO DE COMÉRCIO ENTRE O GOVERNO DA REPÚBLICA FEDERATIVA DO BRASIL E O GOVERNO DA REPÚBLICA POPULAR DA CHINA. Beijing, 1984. Sistema Consular Integrado. Atos Internacionais, Ministério das Relações Exteriores. Disponível em: <http://dai-mre.serpro.gov.br/atosinternacionais/bilaterais/1984/b_55>. Acesso em: 17 jul.2016.

PROTOCOLO ADICIONAL AO ACORDO DE COMÉRCIO, PAGAMENTOS E COOPERAÇÃO ECONÔMICA, ASSINADO ENTRE OS ESTADOS UNIDOS DO BRASIL E A REPÚBLICA POPULAR DA BULGARIA EM 21 DE ABRIL DE 1961.Rio de Janeiro, 1963. Sistema Consular Integrado. Atos Internacionais, Ministério das Relações Exteriores. Disponível em: <http://dai-mre.serpro.gov.br/atos-internacionais/bilaterais/1963/b_38>. Acesso em: 15 jul.2016. 
PROTOCOLO ADICIONAL AO ACORDO ENTRE A REPÚBLICA FEDERATIVA DO BRASIL E A COMUNIDADE ECONÔMICA EUROPÉIA RELATIVO AO COMÉRCIO DE PRODUTOS TÊXTEIS, DECORRENTE DA ADESÃO DA GRÉCIA ÀS COMUNIDADES EUROPÉIAS. Bruxelas, 1982. Sistema Consular Integrado. Atos Internacionais, Ministério das Relações Exteriores. Disponível em: <http://dai-mre.serpro.gov.br/atosinternacionais/bilaterais/1982/b_107>. Acesso em: 17 jul.2016.

PROTOCOLO ADICIONAL AO AJUSTE COMERCIAL 1950 ENTRE BRASIL E ALEMANHA. Bonn, 1953. Sistema Consular Integrado. Atos Internacionais, Ministério das Relações Exteriores. Disponível em: <http://dai-mre.serpro.gov.br/atosinternacionais/bilaterais/1953/b_21>. Acesso em: 02 jul.2016.

PROTOCOLO ADICIONAL AO PROTOCOLO REFERENTE À COOPERAÇÃO COMERCIAL E ECONÔMICA ENTRE A REPÚBLICA FEDERATIVA DO BRASIL, DE UMA PARTE, E A COMUNIDADE EUROPEIA DO CARVÃO E DO AÇO DE OUTRA PARTE, COMO CONSEQUÊNCIA DA ADESÃO DA REPÚBLICA HELÊNICA ÀS COMUNIDADES EUROPEIAS. Bruxelas, 1983. Sistema Consular Integrado. Atos Internacionais, Ministério das Relações Exteriores. Disponível em: <http://daimre.serpro.gov.br/atos-internacionais/bilaterais/1983/b_49>. Acesso em: 17 jul.2016.

PROTOCOLO ADICIONAL AO TRATADO DE AMIZADE, COOPERAÇÃO E COMÉRCIO ENTRE A REPÚBLICA FEDERATIVA DO BRASIL E A REPÚBLICA ORIENTAL DO URUGUAI SOBRE FACILITAÇÃO DE ATIVIDADES EMPRESARIAIS. Montevidéu, 1997. Sistema Consular Integrado. Atos Internacionais, Ministério das Relações Exteriores. Disponível em: <http://dai-mre.serpro.gov.br/atosinternacionais/bilaterais/1997/b_41_2011-09-01-14-09-55>. Acesso em: 28 jul.2016.

PROTOCOLO ADICIONAL AO TRATADO DE COMÉRCIO E NAVEGAÇÃO ENTRE O BRASIL E A REPÚBLICA ARGENTINA. Rio de Janeiro, 1933. Sistema Consular Integrado. Atos Internacionais, Ministério das Relações Exteriores. Disponível em: <http://daimre.serpro.gov.br/atos-internacionais/bilaterais/1933/b_19>. Acesso em: 18 jun.2016.

PROTOCOLO ADICIONAL N $\mathrm{N}^{\circ} 1$ AO ACORDO DE COOPERAÇÃO ENTRE O GOVERNO DA REPÚBLICA FEDERATIVA DO BRASIL E A UNIÃO POSTAL UNIVERSAL PARA FACILITAÇÃO DO COMÉRCIO ATRAVÉS DE REDES POSTAIS EM PAÍSES EM DESENVOLVIMENTO E EM PAÍSES MENOS AVANÇADOS. Suíça, 2013. Sistema Consular Integrado. Atos Internacionais, Ministério das Relações Exteriores. Disponível em: <http://dai-mre.serpro.gov.br/atos-internacionais/bilaterais/2013/protocoloadicional-no-1-ao-acordo-de-cooperacao-entre-o-governo-da-republica-federativa-do-brasil-ea-uniao-postal-universal-para-facilitacao-do-comercio-atraves-de-redes-postais-em-paisesem-desenvolvimento-e-em-paises-menos-avancados>. Acesso em: 07 ago.2016.

PROTOCOLO ADICIONAL $\mathrm{N}^{\circ} 2$ AO ACORDO DE COOPERAÇÃO ENTRE O GOVERNO DA REPÚBLICA FEDERATIVA DO BRASIL E A UNIÃO POSTAL UNIVERSAL PARA FACILITAÇÃO DO COMÉRCIO ATRAVÉS DE REDES POSTAIS EM PAÍSES EM DESENVOLVIMENTO E EM PAÍSES COM MENOR DESENVOLVIMENTO RELATIVO. Suíça, 2015. Sistema Consular Integrado. Atos Internacionais, Ministério das Relações Exteriores. Disponível em: <http://dai- 
mre.serpro.gov.br/atos-internacionais/bilaterais/2015/protocolo-adicional-no-2-ao-acordo-decooperacao-entre-o-governo-da-republica-federativa-do-brasil-e-a-uniao-postal-universalpara-facilitacao-do-comercio-atraves-de-redes-postais-em-paises-em-desenvolvimento-e-empaises-com-menor-desenvolvimento-relativo>. Acesso em: 07 ago.2016.

PROTOCOLO AO ACORDO DE COMÉRCIO E PAGAMENTOS ENTRE O GOVERNO DA REPÚBLICA FEDERATIVA DO BRASIL E O GOVERNO DA REPÚBLICA DEMOCRÁTICA ALEMÃ COM VISTAS AO DESENVOLVIMENTO DO INTERCÂMBIO COMERCIAL ENTRE OS DOIS PAÍSES NO PERÍODO DE JANEIRO DE 1987 A DEZEMBRO DE 1990. Brasília, 1986. Sistema Consular Integrado. Atos Internacionais, Ministério das Relações Exteriores. Disponível em: <http://dai-mre.serpro.gov.br/atosinternacionais/bilaterais/1987/b_10>. Acesso em: 17 jul.2016.

PROTOCOLO AOS "TERMOS DO ENTENDIMENTO ENTRE A MISSÃO COMERCIAL BRASILEIRA E A DELEGAÇÃO COMERCIAL SOVIÉTICA SOBRE PROBLEMAS DE COMÉRCIO E PAGAMENTOS" ASSINADOS EM MOSCOU, EM 9 DE DEZEMBRO DE 1959". Moscou, 1961. Sistema Consular Integrado. Atos Internacionais, Ministério das Relações Exteriores. Disponível em: <http://dai-mre.serpro.gov.br/atosinternacionais/bilaterais/1961/b_30>. Acesso em: 11 jul.2016.

PROTOCOLO CONCERNENTE À EMENDA AO ACORDO DE COMÉRCIO E PAGAMENTOS ENTRE O GOVERNO DA REPÚBLICA FEDERATIVA DO BRASIL E O GOVERNO DA REPÚBLICA SOCIALISTA DA ROMÊNIA, DE 5 DE JUNHO DE 1975. Brasília, 1983. Sistema Consular Integrado. Atos Internacionais, Ministério das Relações Exteriores. Disponível em: <http://dai-mre.serpro.gov.br/atosinternacionais/bilaterais/1984/b_11>. Acesso em: 17 jul.2016.

PROTOCOLO DA REUNIÃO PREPARATÓRIA DA X COMISSÃO INTERGOVERNAMENTAL BRASIL-URSS DE COOPERAÇÃO COMERCIAL, ECONÔMICA, CIENTÍFICA E TECNOLÓGICA. Brasília, 1984. Sistema Consular Integrado. Atos Internacionais, Ministério das Relações Exteriores. Disponível em: <http://daimre.serpro.gov.br/atos-internacionais/bilaterais/1981/b_55>. Acesso em: 17 jul.2016.

PROTOCOLO DAS CONFERÊNCIAS ENTRE O EMBAIXADOR BRASILEIRO JOÃO DANTAS E O MINISTRO ALEMÃO DOS NEGÓCIOS ESTRANGEIROS E INTERIORES DA REPÚBLICA DEMOCRÁTICA ALEMÃ. Berlim, 1961. Sistema Consular Integrado. Atos Internacionais, Ministério das Relações Exteriores. Disponível em: <http://daimre.serpro.gov.br/atos-internacionais/bilaterais/1961/b_32>. Acesso em: 11 jul.2016.

PROTOCOLO DE CÂMBIOS ENTRE OS GOVERNOS DOS ESTADOS UNIDOS DO BRASIL E DA REPÚBLICA ORIENTAL DO URUGUAI. Rio de Janeiro, 1939. Sistema Consular Integrado. Atos Internacionais, Ministério das Relações Exteriores. Disponível em: $<$ http://dai-mre.serpro.gov.br/atos-internacionais/bilaterais/1939/b_13>. Acesso em: 28 jun.2016.

PROTOCOLO DE CONVERSAÇÕES BRASIL - POLÔNIA. Varsóvia, 1967. Sistema Consular Integrado. Atos Internacionais, Ministério das Relações Exteriores. Disponível em: <http://dai-mre.serpro.gov.br/atos-internacionais/bilaterais/1967/b_5>. Acesso em: 15 jul.2016. 
PROTOCOLO DE ENTENDIMENTO - Protocolo de Entendimento entre o Brasil e a República Democrática Alemã. Brasília, 1980. Sistema Consular Integrado. Atos Internacionais, Ministério das Relações Exteriores. Disponível em: <http://daimre.serpro.gov.br/atos-internacionais/bilaterais/1980/b_123>. Acesso em: 17 jul.2016.

PROTOCOLO DE EXPANSÃO COMERCIAL BRASIL-URUGUAI. Riviera, 1975. Sistema Consular Integrado. Atos Internacionais, Ministério das Relações Exteriores. Disponível em: <http://dai-mre.serpro.gov.br/atos-internacionais/bilaterais/1975/b_49>. Acesso em: 15 jul.2016.

PROTOCOLO DE INTENÇÕES ENTRE O GOVERNO DA REPÚBLICA FEDERATIVA DO BRASIL E O GOVERNO DA REPÚBLICA POPULAR DA CHINA SOBRE O INCREMENTO DO COMERCIO BILATERAL DE MINÉRIO DE FERRO E A PROMOÇÃO DA EXPLORAÇÃO CONJUNTA DE RESERVAS DE MINÉRIO DE FERRO. Brasília, 1993. Sistema Consular Integrado. Atos Internacionais, Ministério das Relações Exteriores. Disponível em: <http://dai-mre.serpro.gov.br/atosinternacionais/bilaterais/1993/b_82_2011-10-04-15-03-24>. Acesso em: 25 jul.2016.

PROTOCOLO DE INTENÇÕES ENTRE O GOVERNO DA REPÚBLICA FEDERATIVA DO BRASIL E O GOVERNO DA REPÚBLICA DO CHILE PARA A CRIAÇÃO DE GRUPO DE TRABALHO DE COOPERAÇÃO EM MATÉRIA DE INTEGRAÇÃO PRODUTIVA. Brasília, 2010. Sistema Consular Integrado. Atos Internacionais, Ministério das Relações Exteriores. Disponível em: <http://dai-mre.serpro.gov.br/atosinternacionais/bilaterais/2010/protocolo-de-intencoes-entre-o-governo-da-republicafederativa-do-brasil-e-o-governo-da-republica-do-chile-para-a-criacao-de-grupo-de-trabalhode-cooperacao-em-materia-de-integracao-positiva >. Acesso em: 02 ago.2016.

PROTOCOLO DE INTENÇÕES SOBRE COOPERAÇÃO COMERCIAL ENTRE O GOVERNO DA REPÚBLICA FEDERATIVA DO BRASIL E O GOVERNO DA REPÚBLICA DO EQUADOR. Quito, 1989. Sistema Consular Integrado. Atos Internacionais, Ministério das Relações Exteriores. Disponível em: <http://dai-mre.serpro.gov.br/atosinternacionais/bilaterais/1989/b_70>. Acesso em: 25 jul.2016.

PROTOCOLO DE INTENÇÕES. Brasília, 1983. Sistema Consular Integrado. Atos Internacionais, Ministério das Relações Exteriores. Disponível em: <http://daimre.serpro.gov.br/atos-internacionais/bilaterais/1983/b_51>. Acesso em: 17 jul.2016.

PROTOCOLO DE INTENÇÕES. Praga, 1990. Sistema Consular Integrado. Atos Internacionais, Ministério das Relações Exteriores. Disponível em: <http://daimre.serpro.gov.br/atos-internacionais/bilaterais/1990/b_47_2011-10-17-15-48-44>. Acesso em: 25 jul.2016.

PROTOCOLO DE NEGOCIAÇÕES ECONÔMICAS ENTRE O BRASIL E A POLÔNIA. 1961. Sistema Consular Integrado. Atos Internacionais, Ministério das Relações Exteriores. 
Disponível em: <http://dai-mre.serpro.gov.br/atos-internacionais/bilaterais/1961/b_29>. Acesso em: 11 jul.2016.

PROTOCOLO ENTRE A REPÚBLICA FEDERATIVA DO BRASIL E A REPÚBLICA ARGENTINA SOBRE AVALIAÇÃO DA CONFORMIDADE. Buenos Aires, 1999. Sistema Consular Integrado. Atos Internacionais, Ministério das Relações Exteriores. Disponível em: $<$ http://dai-mre.serpro.gov.br/atos-internacionais/bilaterais/1999/b_71>. Acesso em: 28 jul.2016.

PROTOCOLO ENTRE O GOVERNO DA REPÚBLICA FEDERATIVA DO BRASIL E O GOVERNO DOS ESTADOS UNIDOS MEXICANOS EM MATÉRIA DE APOIO FINANCEIRO AO COMERCIO BILATERAL. Brasília, 1984. Sistema Consular Integrado. Atos Internacionais, Ministério das Relações Exteriores. Disponível em: <http://daimre.serpro.gov.br/atos-internacionais/bilaterais/1984/b_27>. Acesso em: 17 jul.2016.

PROTOCOLO ESTABELECENDO AS BASES PARA A NEGOCIAÇÃO DE UM TRATADO DE COMÉRCIO E NAVEGAÇÃO. Rio de Janeiro, 1896. Sistema Consular Integrado. Atos Internacionais, Ministério das Relações Exteriores. Disponível em: <http://daimre.serpro.gov.br/atos-internacionais/bilaterais/1896/b_81>. Acesso em: 15 jun.2016.

PROTOCOLO RELATIVO À COOPERAÇÃO COMERCIAL E ECONÔMICA ENTRE A REPÚBLICA FEDERATIVA DO BRASIL E A COMUNIDADE EUROPÉIA DO CARVÃO E DO AÇO. Bruxelas, 1980. Sistema Consular Integrado. Atos Internacionais, Ministério das Relações Exteriores. Disponível em: <http://dai-mre.serpro.gov.br/atosinternacionais/bilaterais/1980/b_101>. Acesso em: 17 jul.2016.

PROTOCOLO RELATIVO AO ESCRITÓRIO DE EXPANSÃO COMERCIAL DO BRASIL NA URSS E À REPRESENTAÇÃO COMERCIAL DA URSS NO BRASIL. Rio de Janeiro, 1963. Sistema Consular Integrado. Atos Internacionais, Ministério das Relações Exteriores. Disponível em: <http://dai-mre.serpro.gov.br/atos-internacionais/bilaterais/1963/b_12>. Acesso em: 15 jul.2016.

PROTOCOLO SOBRE FORNECIMENTO DE MAQUINARIA E EQUIPAMENTOS DA URSS AO BRASIL. Rio de Janeiro, 1969. Sistema Consular Integrado. Atos Internacionais, Ministério das Relações Exteriores. Disponível em: <http://dai-mre.serpro.gov.br/atosinternacionais/bilaterais/1969/b_69>. Acesso em: 15 jul.2016.

PROTOCOLO SOBRE INTERCÂMBIO COMERCIAL, EM 1962, ENTRE OS ESTADOS UNIDOS DO BRASIL E A UNIÃO DAS REPÚBLICAS SOCIALISTAS SOVIÉTICAS. Rio de Janeiro, 1962. Sistema Consular Integrado. Atos Internacionais, Ministério das Relações Exteriores. Disponível em: http://dai-mre.serpro.gov.br/atosinternacionais/bilaterais/1962/b_17>. Acesso em: 15 jul.2016.

PROTOCOLO SOBRE O ESTABELECIMENTO DE REPRESENTAÇÕES COMERCIAIS. Moscou, 1961. Sistema Consular Integrado. Atos Internacionais, Ministério das Relações Exteriores. Disponível em: <http://dai-mre.serpro.gov.br/atosinternacionais/bilaterais/1961/b_31>. Acesso em: 11 jul.2016. 
RELAÇÕES COMERCIAIS BRASIL - SUÉCIA. ACORDO TÊXTIL BILATERAL. TROCA DE NOTAS. Brasília, 1983. Sistema Consular Integrado. Atos Internacionais, Ministério das Relações Exteriores. Disponível em: <http://dai-mre.serpro.gov.br/atosinternacionais/bilaterais/1983/b_20>. Acesso em: 17 jul.2016.

SUSPENSÃO DO ACORDO COMERCIAL DE 02 DE FEVEREIRO DE 1935. 1948. Sistema Consular Integrado. Atos Internacionais, Ministério das Relações Exteriores. Disponível em: <http://dai-mre.serpro.gov.br/atos-internacionais/bilaterais/1948/b_8>. Acesso em: 28 jun.2016.

TERMOS DE REFERÊNCIA CONSELHO DE DESENVOLVIMENTO EMPRESARIAL BRASIL - ESTADOS UNIDOS. Brasília, 1995. Sistema Consular Integrado. Atos Internacionais, Ministério das Relações Exteriores. Disponível em: <http://daimre.serpro.gov.br/atos-internacionais/bilaterais/1995/b_18>. Acesso em: 28 jul.2016.

TRATADO DE AMIZADE, COMMERCIO E NAVEGAÇÃO ENTRE O IMPÉRIO DO BRASIL E A REPÚBLICA DE BOLIVIA. Rio de Janeiro, 1887. Sistema Consular Integrado. Atos Internacionais, Ministério das Relações Exteriores. Disponível em: < http://daimre.serpro.gov.br/atos-internacionais/bilaterais/1887/b_103>. Acesso em: 15 jun.2016.

TRATADO DE AMIZADE, COMMERCIO E NAVEGAÇÃO ENTRE O SR. D. PEDRO II IMPERADOR DO BRASIL E SUA MAGESTADE O IMPERADOR DOS OTTOMANOS; ASSIGNADO EM LONDRES EM 5 DE FEVEREIRO DE 1858, E RATIFICADO POR PARTE DO BRASIL EM 10 DE ABRIL DE 1858. Londres, 1858. Sistema Consular Integrado. Atos Internacionais, Ministério das Relações Exteriores. Disponível em: em:<http://dai-mre.serpro.gov.br/atos-internacionais/bilaterais/1858/b_63>. Acesso em: 15 jun.2016.

TRATADO DE AMIZADE, COOPERAÇÃO E COMÉRCIO ENTRE O GOVERNO DA REPÚBLICA FEDERATIVA DO BRASIL O GOVERNO DA REPÚBLICA DE ZÂMBIA. Lusaca, 1980. Sistema Consular Integrado. Atos Internacionais, Ministério das Relações Exteriores. Disponível em: <http://dai-mre.serpro.gov.br/atosinternacionais/bilaterais/1980/b_48>. Acesso em: 17 jul.2016.

TRATADO DE AMIZADE, DE COMÉRCIO E NAVEGAÇÃO ENTRE OS ESTADOS UNIDOS DO BRASIL E O LÍBANO. Rio de Janeiro, 1956. Sistema Consular Integrado. Atos Internacionais, Ministério das Relações Exteriores. Disponível em: <http://daimre.serpro.gov.br/atos-internacionais/bilaterais/1954/b_10>. Acesso em: 02 jul.2016.

TRATADO DE AMIZADE, DE COMMERCIO E DE NAVEGAÇÃO, FIRMADO EM PARIS A 5 DE NOVEMBRO DE 1895. Paris, 1895. Sistema Consular Integrado. Atos Internacionais, Ministério das Relações Exteriores. Disponível em: <http://daimre.serpro.gov.br/atos-internacionais/bilaterais/1895/b_89>. Acesso em: 15 jun.2016.

TRATADO DE COMÉRCIO E NAVEGAÇÃO ENTRE A REPÚBLICA DOS ESTADOS UNIDOS DO BRASIL E A REPUBLICA ARGENTINA. Buenos Aires, 1940. Sistema Consular Integrado. Atos Internacionais, Ministério das Relações Exteriores. Disponível em: <http://dai-mre.serpro.gov.br/atos-internacionais/bilaterais/1935/b_7>. Acesso em: 18 jun.2016. 
TRATADO DE COMÉRCIO E NAVEGAÇÃO ENTRE O BRASIL E A REPÚBLICA ARGENTINA. Rio de Janeiro, 1933. Sistema Consular Integrado. Atos Internacionais, Ministério das Relações Exteriores. Disponível em: <http://dai-mre.serpro.gov.br/atosinternacionais/bilaterais/1933/b_16>. Acesso em: 18 jun.2016.

TRATADO DE COMÉRCIO E NAVEGAÇÃO ENTRE O BRASIL E O URUGUAI. Rio de Janeiro, 1933. Sistema Consular Integrado. Atos Internacionais, Ministério das Relações Exteriores. Disponível em: <http://dai-mre.serpro.gov.br/atosinternacionais/bilaterais/1933/b_8>. Acesso em: 18 jun.2016.

TRATADO DE COMÉRCIO E NAVEGAÇÃO ENTRE OS ESTADOS UNIDOS DO BRASIL E A REPÚBLICA ORIENTAL DO URUGUAI. 1954. Sistema Consular Integrado. Atos Internacionais, Ministério das Relações Exteriores. Disponível em: <http://daimre.serpro.gov.br/atos-internacionais/bilaterais/1949/b_5>. Acesso em: 28 jun.2016.

TRATADO DE COMÉRCIO ENTRE O BRASIL E PORTUGAL. Rio de Janeiro, 1933. Sistema Consular Integrado. Atos Internacionais, Ministério das Relações Exteriores. Disponível em: <http://dai-mre.serpro.gov.br/atos-internacionais/bilaterais/1933/b_9>. Acesso em: 18 jun.2016.

TRATADO DE COMÉRCIO ENTRE OS ESTADOS UNIDOS DO BRASIL E OS ESTADOS UNIDOS DA AMÉRICA. Washington, 1935. Sistema Consular Integrado. Atos Internacionais, Ministério das Relações Exteriores. Disponível em: <http://daimre.serpro.gov.br/atos-internacionais/bilaterais/1935/b_4>. Acesso em: 18 jun.2016.

TRATADO DE COMMERCIO E NAVEGAÇÃO FLUVIAL ENTRE OS ESTADOS UNIDOS DO BRASIL E A BOLÍVIA. Rio de Janeiro, 1910. Sistema Consular Integrado. Atos Internacionais, Ministério das Relações Exteriores. Disponível em:<http://daimre.serpro.gov.br/atos-internacionais/bilaterais/1910/b_16>. Acesso em: 15 jun.2016.

TRATADO DE COMMERCIO, E NAVEGAÇÃO ENTRE O SENHOR D. PEDRO I, IMPERADOR DO BRASIL, E FRANCISCO I, IMPERADOR DA AUSTRIA, ASSIGNADO EM VIENNA EM 16 DE JUNHO DE 1827, E RATIFICADO POR PARTE DO BRASIL EM 29 DE NOVEMBRO DO DITO ANNO, E PELA DA AUSTRIA EM 28 DE FEVEREIRO DE 1828. Viena, 1827. Sistema Consular Integrado. Atos Internacionais, Ministério das Relações Exteriores. Disponível em: <http://dai-mre.serpro.gov.br/atosinternacionais/bilaterais/1927/b_14>. Acesso em: 15 jun.2016.

TRATADO DE COMMERCIO, E NAVEGAÇÃO ENTRE O SENHOR D. PEDRO I, IMPERADOR DO BRASIL, E FREDERICO VI, REI DE DINAMARCA, ASSIGNADO NO RIO DE RANEIRO EM 26 DE ABRIL DE 1828, E RATIFICADO POR PARTE DO BRASIL EM 26 DE OUTUBRO, E PELA DA DINAMARCA EM 23 DE JULHO DE 1828. Rio de Janeiro, 1828. Sistema Consular Integrado. Atos Internacionais, Ministério das Relações 
Exteriores. Disponível em: <http://dai-mre.serpro.gov.br/atosinternacionais/bilaterais/1828/b_6>. Acesso em: 15 jun.2016.

TRATADO DE COMMERCIO, E NAVEGAÇÃO ENTRE O SENHOR D. PEDRO II IMPERADOR DO BRASIL, REPRESENTADO PELA REGENCIA EM SEU AUGUSTO NOME, E SUA MAGESTADE O REI DOS BELGAS, ASSIGNADO NO RIO DE JANEIRO EM 22 DE SETEMBRO DE 1834, E RATIFICADO POR PARTE DO BRASIL EM 17 DE JUNHO DE 1835, E PELA DA BELGICA EM 27 DE SETEMBRO DO MESMO ANNO. Rio de Janeiro, 1834. Sistema Consular Integrado. Atos Internacionais, Ministério das Relações Exteriores. Disponível em: <http://dai-mre.serpro.gov.br/atosinternacionais/bilaterais/1834/tratado-de-comercio-e-navegacao>. Acesso em: 15 jun.2016.

TRATADO DE COMMERCIO, E NAVEGAÇÃO ENTRE O SENHOR D. PEDRO II IMPERADOR DO BRASIL, REPRESENTADO PELA REGENCIA ESTABELECIDA EM VIRTUDE DA CONSTITUIÇÃO DO IMPERIO, E SUA MAGESTADE O IMPERADOR DA AUSTRIA, ASSIGNADO NO RIO DE JANEIRO EM 27 DE JUNHO DE 1835 PELOS RESPECTIVOS PLENIPOTENCIARIOS. Rio de Janeiro, 1835. Sistema Consular Integrado. Atos Internacionais, Ministério das Relações Exteriores. Disponível em: <http://daimre.serpro.gov.br/atos-internacionais/bilaterais/1835/b_11>. Acesso em: 15 jun. 2016.

TRATADO DE COMMERCIO, E NAVEGAÇÃO ENTRE O SENHOR D. PEDRO II IMPERADOR DO BRASIL, REPRESENTADO PELO REGENTE EM SEU AUGUSTO NOME, E A SENHORA D. MARIA II RAINHA DE PORTUGAL, ASSIGNADO NO RIO DE JANEIRO, EM 19 DE MAIO DE 1836, PELOS RESPECTIVOS PLENIPOTENCIÁRIOS. Rio de Janeiro, 1836. Sistema Consular Integrado. Atos Internacionais, Ministério das Relações Exteriores. Disponível em: <http://dai-mre.serpro.gov.br/atosinternacionais/bilaterais/1836/tratado-de-comercio-e-navegacao>. Acesso em: 15 jun. 2016.

TRATADO GERAL DE COMÉRCIO E INVESTIMENTOS ENTRE A REPÚBLICA DOS ESTADOS UNIDOS DO BRASIL E A REPÚBLICA DO PARAGUAI. Assunção, 1956. Sistema Consular Integrado. Atos Internacionais, Ministério das Relações Exteriores. Disponível em: <http://dai-mre.serpro.gov.br/atos-internacionais/bilaterais/1956/b_36>. Acesso em: 09 jul.2016.

TRATADO PARA O ESTABELECIMENTO DE UM ESTATUTO DAS EMPRESAS BINACIONAIS BRASILEIRO - ARGENTINAS. Buenos Aires, 1990. Sistema Consular Integrado. Atos Internacionais, Ministério das Relações Exteriores. Disponível em: <http://daimre.serpro.gov.br/atos-internacionais/bilaterais/1990/b_26_2011-10-17-15-48-38>. Acesso em: 25 fev. 2016 .

TROCA DE NOTAS DANDO APLICAÇÃO AO PROTOCOLO DE EXPANSÃO COMERCIAL. 1976. Sistema Consular Integrado. Atos Internacionais, Ministério das 
Relações Exteriores. Disponível em: <http://dai-mre.serpro.gov.br/atosinternacionais/bilaterais/1976/b_57>. Acesso em: 15 jul.2016.

TROCA DE NOTAS ENTRE BRASIL E CHILE. 1955. Sistema Consular Integrado. Atos Internacionais, Ministério das Relações Exteriores. Disponível em: <http://daimre.serpro.gov.br/atos-internacionais/bilaterais/1955/b_26>. Acesso em: 08 jul.2016.

TROCA DE NOTAS ENTRE BRASIL E GRÃ-BRETANHA. 1955. Sistema Consular Integrado. Atos Internacionais, Ministério das Relações Exteriores. Disponível em: <http://daimre.serpro.gov.br/atos-internacionais/bilaterais/1955/b_28>. Acesso em: 08 jul.2016.

TROCA DE NOTAS RELATIVA À APLICAÇÃO DAS DISPOSIÇÕES, ATÉ 31 DE MAIO DE 1956, DOS AJUSTES DE COMÉRCIO E DE PAGAMENTOS. Rio de Janeiro, 1956. Sistema Consular Integrado. Atos Internacionais, Ministério das Relações Exteriores. Disponível em: <http://dai-mre.serpro.gov.br/atos-internacionais/bilaterais/1956/b_18>. Acesso em: 09 jul.2016.

TROCA DE NOTAS RELATIVA A OPERAÇÕES DE TRÂNSITO COM MERCADORIAS BRASILEIRAS. Rio de Janeiro, 1956. Sistema Consular Integrado. Atos Internacionais, Ministério das Relações Exteriores. Disponível em: <http://dai-mre.serpro.gov.br/atosinternacionais/bilaterais/1956/b_16>. Acesso em: 09 jul.2016.

TROCA DE NOTAS RELATIVA AO PERÍODO DE TRANSIÇÃO. Rio de Janeiro, 1956. Sistema Consular Integrado. Atos Internacionais, Ministério das Relações Exteriores. Disponível em: <http://dai-mre.serpro.gov.br/atos-internacionais/bilaterais/1956/b_17>. Acesso em: 09 jul.2016.

Troca de Notas sobre Tratamento de Produtos da Argélia Marrocos Francês e Tunísia. 1932. Sistema Consular Integrado. Atos Internacionais, Ministério das Relações Exteriores. Disponível em: <http://dai-mre.serpro.gov.br/atos-internacionais/bilaterais/1932/b_12 >. Acesso em: 18 jun.2016.

\section{OMC}

ACORDO QUE CRIA A ORGANIZAÇÃO MUNDIAL DO COMÉRCIO (OMC). Marraquexe, 1994. Organização Mundial do Comércio. Disponível em: <https://www.wto.org/English/docs_e/legal_e/04-wto.pdf>. Acesso em: 07 ago.2016.

ANEXO 1A - ACORDOS MULTILATERAIS SOBRE COMÉRCIO DE BENS - GATT (ACORDO GERAL SOBRE TARIFAS E COMERCIO 1994). Organização Mundial do Comércio. Disponível em: <https://www.wto.org/english/docs_e/legal_e/05-anx1a.pdf>. Acesso em: 07 abr.2016.

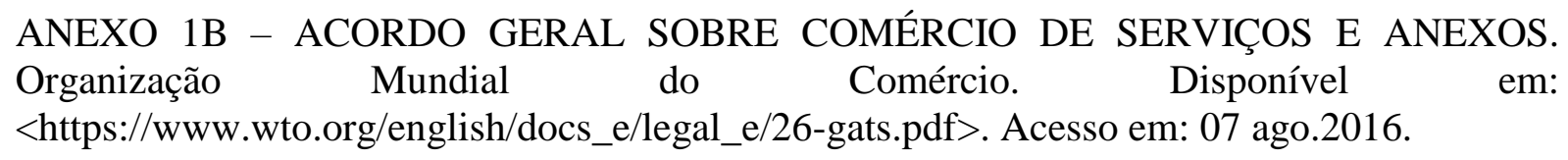


ANEXO 1C - ACORDO SOBRE ASPECTOS DOS DIREITOS DE PROPRIEDADE INTELECTUAL RELACIONADOS COM O COMÉRCIO. Organização Mundial do Comércio. Disponível em: <https://www.wto.org/english/docs_e/legal_e/27-trips.pdf>. Acesso em: 07 abr.2016.

ANEXO 2 - ENTENDIMENTO SOBRE REGRAS E PROCEDIMENTOS SOBRE SOLUÇÃO DE CONTROVÉRSIAS. Organização Mundial do Comércio. Disponível em: <https://www.wto.org/english/docs_e/legal_e/28-dsu.pdf>. Acesso em: 19 ago.2016.

ANEXO 3 - MECANISMO DE EXAME DE POLÍTICAS COMERCIAIS. Organização Mundial do Comércio. Disponível em: <https://www.wto.org/english/docs_e/legal_e/29tprm.pdf>. Acesso em: 17 ago.2016.

\section{ALADI}

ALADI/AAP.A14TM/12 de 18.04.1998 - ACORDO-QUADRO DE COMÉRCIO E INVESTIMENTO ENTRE O MERCOSUL E O MERCADO COMUM CENTROAMERICANO (MCCA). Chile, 1998. ALADI. Disponível em: <http://www.aladi.org/nsfaladi/textacdos.nsf/684d10f0073e490a032574e10069fdb7/f08b566f 1593c51e03256cd20053feec?OpenDocument>. Acesso em: 19 ago.2016.

ALADI/AAP.A14TM/6 de 26.06.1992 - ACORDO DE ALCANCE PARCIAL DE COOPERAÇÃO E INTERCÂMBIO DE BENS UTILIZADOS NA DEFESA E PROTEÇÃO DO MEIO AMBIENTE ENTRE O GOVERNO DA REPUBLICA ARGENTINA E O GOVERNO DA REPUBLICA FEDERATIVA DO BRASIL. Las Leñas, 1992. ALADI. Disponível em: <http://www.aladi.org/nsfaladi/textacdos.nsf/684d10f0073e490a032574e10069fdb7/a66a727 8e52a8d1d03256cd2004e936d?OpenDocument>. Acesso em: 19 ago.2016.

ALADI/AAP.A25TM/38 de 27.06.2001 - ACORDO DE ALCANCE PARCIAL DE COMPLEMENTAÇÃO ECONÔMICA N ${ }^{\circ}$ 38, SUBCRITO AO AMPARO DO ARTIGO 25 DO TRATADO DE MONTEVIDÉU 1980, ENTRE A REPÚBLICA FEDERATIVA DO BRASIL E A REPÚBLICA COOPERATIVISTA DA GUIANA. Brasília, 2001. ALADI. Disponível em: <http://www.aladi.org/nsfaladi/textacdos.nsf/3818b74a0bf856c4032574e1006b920f/d1769fc0 6bd781d503256b5f006070ee?OpenDocument>. Acesso em: 19 ago.2016.

ALADI/AAP.A25TM/41 de 21.04.2005 - ACORDO DE ALCANCE PARCIAL DE COMPLEMENTAÇÃO ECONÔMICA N ${ }^{\circ}$ 41, SUBSCRITO AO AMPARO DO ARTIGO 25 DO TRATADO DE MONTEVIDÉU 1980 ENTRE A REPÚBLICA FEDERATIVA DO BRASIL E A REPUBLICA DO SURINAME PARA A CONCESSÃO DE PREFERÊNCIAS TARIFÁRIAS PARA O COMÉRCIO DE ARROZ. Brasília, 2005. ALADI. Disponível em: 
<http://www.aladi.org/nsfaladi/textacdos.nsf/3818b74a0bf856c4032574e1006b920f/be29fabf a688a35003256ff900543387?OpenDocument >. Acesso em: 19 ago.2016.

\begin{abstract}
ALADI/AAP.AG/2 de 22.11.1991 - ACORDO DE ALCANCE PARCIAL PARA A LIBERAÇÃO E EXPANSÃO DO COMÉRCIO INTRA-REGIONAL DE SEMENTES. Montevidéu, 1991. ALADI. Disponível em: <http://www.aladi.org/nsfaladi/textacdos.nsf/9aa510590562d4aa032574e100681d18/89c24d5 3059e9701032571c7005e9260?OpenDocument>. Acesso em: 19 ago.2016.
\end{abstract}

ALADI/AAP.CE/14 de 20.12.1990 - ACORDO DE COMPLEMENTAÇÃO ECONÔMICA $\mathrm{N}^{\circ} \quad$ 14. Montevidéu, 1990. ALADI. Disponível em: <http://www.aladi.org/nsfaladi/textacdos.nsf/f7a2d493807d9e8c032574e100640526/e377080 d92b06968032578db0056359f?OpenDocument>. Acesso em: 11 ago.2016.

ALADI/AAP.CE/18 de 29.11.1991 - ACORDO DE COMPLEMENTAÇÃO ECONÔMICA $\mathrm{N}^{\circ}$ 18. Montevidéu, 1991. ALADI. Disponível em: <http://www.aladi.org/nsfaladi/textacdos.nsf/f7a2d493807d9e8c032574e100640526/652dbbc bd46beca803257743005af6fe?OpenDocument>. Acesso em: 11 ago.2016.

ALADI/AAP.CE/2 de 27.12.1982 - ADEQUAÇÃO DO PROTOCOLO DE EXPANSÃO COMERCIAL SUBSCRITO ENTRE O BRASIL E O URUGUAI AO MECANISMO DE ACORDOS DE ALCANCE PARCIAL PREVISTO PELO TRATADO DE MONTEVIDÉU 1980. Montevidéu, 1982. ALADI. Disponível em: <http://www.aladi.org/biblioteca/publicaciones/aladi/acuerdos/ace/pt/ace02/web/ACE_002_0 Acuerdo.pdf $>$. Acesso em: 07 ago.2016.

ALADI/AAP.CE/35 de 25.06.1996 - ACORDO DE COMPLEMENTAÇÃO ECONÔMICA $\mathrm{N}^{\circ} \quad 35$. Potrero de los Fues, 1996. ALADI. Disponível em:<http://www.aladi.org/nsfaladi/textacdos.nsf/4d2dc6693e37b12903256a720069462b/3e6c 420c8b9c471703256a81005a4288?OpenDocument>. Acesso em: 11 ago.2016.

ALADI/AAP.CE/36 de 17.12.1996 - ACORDO DE COMPLEMENTAÇÃO ECONÔMICA $\mathrm{N}^{\circ} 36$ CELEBRADO ENTRE OS ESTADOS-PARTE DO MERCOSUL E O GOVERNO DA REPÚBLICA DA BOLÍVIA. Fortaleza, 1996. ALADI. Disponível em: <http://www.aladi.org/biblioteca/publicaciones/aladi/acuerdos/ace/pt/ace36/web/ACE_036_A cordo_pt.pdf $>$. Acesso em: 11 ago.2016. 
ALADI/AAP.CE/53 de 03.07.2002 - ACORDO DE COMPLEMENTAÇÃO ECONÔMICA ENTRE A REPÚBLICA FEDERATIVA DO BRASIL E OS ESTADOS UNIDOS MEXICANOS. $\quad$ Brasília, 2002. ALADI. Disponível em: <http://www.aladi.org/nsfaladi/textacdos.nsf/f7a2d493807d9e8c032574e100640526/bdfac04b 86bc534103256c7d00589384?OpenDocument>. Acesso em: 11 ago.2016.

ALADI/AAP.CE/54 de 05.07.2002 - ACORDO DE COMPLEMENTAÇÃO ECONÔMICA $\mathrm{N}^{\circ} 54$ CELEBRADO ENTRE OS ESTADOS PARTE DO MERCOSUL E OS ESTADOS UNIDOS MEXICANOS. Buenos Aires, 2002. ALADI. Disponível em: <http://www.aladi.org/nsfaladi/textacdos.nsf/f7a2d493807d9e8c032574e100640526/b1fb2a6 ba0bcd95603256c3200596373?OpenDocument>. Acesso em: 11 ago.2016.

ALADI/AAP.CE/55 de 27.09.2002 - ACORDO DE COMPLEMENTAÇÃO ECONÔMICA $\mathrm{N}^{\circ} 55$ CELEBRADO ENTRE O MERCOSUL E OS ESTADOS UNIDOS MEXICANOS. Montevidéu, 2002. ALADI. Disponível em: <http://www.aladi.org/nsfaladi/textacdos.nsf/f7a2d493807d9e8c032574e100640526/8d9bfd8 c540ed0e8032578950047d2bf?OpenDocument>. Acesso em: 11 ago.2016.

ALADI/AAP.CE/58 de 30.11.2005 - ACORDO DE COMPLEMENTAÇÃO ECONÔMICA $\mathrm{N}^{\circ} 58$ ASSINADO ENTRE OS GOVERNOS DA REPÚBLICA ARGENTINA, DA REPÚBLICA FEDERATIVA DO BRASIL, DA REPÚBLICA DO PARAGUAI E DA REPÚBLICA ORIENTAL DO URUGUAI, ESTADOS PARTES DO MERCOSUL E O GOVERNO DA REPÚBLICA DO PERU. Montevidéu, 2005. ALADI. Disponível em: <http://www.aladi.org/nsfaladi/textacdos.nsf/4d2dc6693e37b12903256a720069462b/c872096 8fdbabb59032570c3005bead4?OpenDocument>. Acesso em: 15 ago.2016.

ALADI/AAP.CE/59 de 18.10.2004 - ACORDO DE COMPLEMENTAÇÃO ECONÔMICA ASSINADO ENTRE OS GOVERNOS DA REPÚBLICA DA ARGENTINA, DA REPÚBLICA FEDERATIVA DO BRASIL, DA REPÚBLICA DO PARAGUAI E DA REPÚBLICA ORIENTAL DO URUGUAI - ESTADOS PARTES DO MERCOSUL E OS GOVERNOS DA REPÚBLICA DA COLÔMBIA, DA REPÚBLICA DO EQUADOR E DA REPÚBLICA BOLIVARIANA DA VENEZUELA - PAÍSES MEMBROS DA COMUNIDADE ANDINA. Montevidéu, 2004. ALADI. Disponível em: <http://www.aladi.org/nsfaladi/textacdos.nsf/4d2dc6693e37b12903256a720069462b/e428fe4 f7644441303256f7100458504?OpenDocument>. Acesso em: 15 ago.2016.

ALADI/AAP.CE/62 de 21.07.06 - ACORDO DE COMPLEMENTAÇÃO ECONÔMICA CELEBRADO ENTRE O MERCOSUL E A REPÚBLICA DE CUBA. Córdoba, 2006. ALADI. Disponível em: <http://www.aladi.org/nsfaladi/textacdos.nsf/f7a2d493807d9e8c032574e100640526/4e948f3 4e509039503257ae10059b550?OpenDocument>. Acesso em: 15 ago.2016.

ALADI/AAP.CE/69 de 26.12.2012 - ACORDO DE ALCANCE PARCIAL DE COMPLEMENTAÇÃO ECONÔMICA N 69 ENTRE A REPÚBLICA FEDERATIVA DO BRASIL E A REPÚBLICA BOLIVARIANA DA VENEZUELA. Montevidéu, 2012. ALADI. 
Disponível

em: <http://www.aladi.org/biblioteca/publicaciones/aladi/acuerdos/ace/pt/ace69/ACE_069_pt.pdf $>$. Acesso em: 15 ago.2016.

ALADI/AAP.PC/19 de 09.12.2005 - ACORDO-QUADRO SOBRE COMPLEMENTAÇÃO ENERGÉTICA REGIONAL ENTRE OS ESTADOS PARTES DO MERCOSUL E ESTADOS ASSOCIADOS. Montevidéu, 2005. ALADI. Disponível em: <http://www.aladi.org/nsfaladi/textacdos.nsf/40b43aa8273eeafc032574e10069d74e/799f6432 8de300490325712c005f8dce?OpenDocument>. Acesso em: 15 ago.2016.

ALADI/AAP.PC/2 de 17.08.1992 - ACORDO DE ALCANCE PARCIAL SOBRE A PROMOÇÃO DE COMÉRCIO ENTRE O GOVERNO DA REPÚBLICA FEDERATIVA DO BRASIL E O GOVERNO DA REPÚBLICA DA BOLÍVIA (FORNECIMENTO DE GÁS NATURAL). Santa Cruz de la Sierra, 2002. ALADI. Disponível em:<http://www.aladi.org/nsfaladi/textacdos.nsf/40b43aa8273eeafc032574e10069d74e/36b1 6fa728a4319503256b76004d049e?OpenDocument>. Acesso em: 15 ago.2016.

ALADI/AAP.PC/5 de 18.05.1994 - ACORDO DE ALCANCE PARCIAL PARA A FACILITAÇÃO DO COMÉRCIO. CONCLUÍDO ENTRE A REPÚBLICA DA ARGENTINA, A REPÚBLICA FEDERATIVA DO BRASIL, A REPÚBLICA DO PARAGUAI E A REPÚBliCA ORIENTAL DO URUGUAI. Montevidéu, 1994. ALADI. Disponível em: <http://www.aladi.org/nsfaladi/textacdos.nsf/40b43aa8273eeafc032574e10069d74e/d4ffe4a5 04153f2783256b060065adbc?OpenDocument>. Acesso em: 15 ago.2016.

ALADI/AAP.PC/7 de 30.12.1994 - ACORDO DE ALCANCE PARCIAL PARA FACILITAÇÃO DE TRANSPORTE DE PRODUTOS PERIGOSOS. Montevidéu, 1994. ALADI. Disponível

em: <http://www.aladi.org/nsfaladi/textacdos.nsf/40b43aa8273eeafc032574e10069d74e/b57be81c 5345671a03256b76004d829d?OpenDocument>. Acesso em: 15 ago.2016.

ALADI/AAP.PC/8 de 30.12.1994 - ACORDO DE ALCANCE PARCIAL PARA A FACILITAÇÃO DO TRANSPORTE MULTIMODAL DE MERCADORIAS. Montevidéu, 1994. ALADI. Disponível em: <http://www.aladi.org/nsfaladi/textacdos.nsf/40b43aa8273eeafc032574e10069d74e/13434a7e 0c80f4e803256b76004feee3?OpenDocument>. Acesso em: 15 ago.2016.

ALADI/AR.AM/1 de 30.04.1983 - ACORDO REGIONAL DE ABERTURA DE MERCADOS EM FAVOR DA BOLIVIA. Montevidéu, 1983. ALADI. Disponível em: <http://www.aladi.org/nsfaladi/textacdos.nsf/f3ff77caf23b5bc3032574e1005a1ca9/0b3060a1 96e5da7d83256b3d0056ea51?OpenDocument>. Acesso em: 15 ago.2016.

ALADI/AR.AM/2 de 30.04.1983 - ACORDO REGIONAL DE ABERTURA DE MERCADOS EM FAVOR DO EQUADOR. Montevidéu, 1983. ALADI. Disponível em: 
<http://www.aladi.org/nsfaladi/textacdos.nsf/f3ff77caf23b5bc3032574e1005a1 ca9/38be7473 2bdf91f883256b4100451973?OpenDocument>. Acesso em: 19 ago.2016.

ALADI/AR.AM/3 de 30.04.1983 - ACORDO REGIONAL DE ABERTURA DE MERCADOS EM FAVOR DO PARAGUAI. Montevidéu, 1983. ALADI. Disponível em: <http://www.aladi.org/nsfaladi/textacdos.nsf/f3ff77caf23b5bc3032574e1005a1 ca9/51afeface4 a3745d83256b4100526d4b?OpenDocument>. Acesso em: 19 ago.2016.

ALADI/AR.CEYC/7 de 05.03.1997 - ACORDO REGIONAL DE COOPERAÇÃO E INTERCÂMBIO DE BENS NAS ÁREAS CULTURAL, EDUCACIONAL E CIENTÍFICA. Montevidéu, $1997 . \quad$ ALADI. Disponível em: <http://www.aladi.org/nsfaladi/textacdos.nsf/5d515cfbc869bc6d032574e100625e7b/04988a4 b96f3a1e7032579a0005534ea?OpenDocument>. Acesso em: 19 ago.2016.

\begin{abstract}
ALADI/AR.OTC/8 de 08.12.1997 - ACORDO-QUADRO PARA A PROMOÇÃO DO COMÉRCO MEDIANTE A SUPERAÇÃO DAS BARREIRAS TÉCNICAS AO COMÉRCIO. Montevidéu, 1997. ALADI. Disponível em: <http://www.aladi.org/nsfaladi/textacdos.nsf/837cad1e6912d3c0032574e100632662/aebda12 91322c74f03256ace005255af?OpenDocument>. Acesso em: 19 ago.2016.
\end{abstract}

ALADI/AR.PAR/4 de 27.04.1984 - ACORDO REGIONAL REFERENTE A PREFERÊNCIA TARIFÁRIA REGIONAL. Montevidéu, 1984. ALADI. Disponível em: <http://www.aladi.org/nsfaladi/textacdos.nsf/73acb8d4f4da4415032574e10060a6dd/2871512 cc5679d2883256b42005423d3?OpenDocument>. Acesso em: 19 ago.2016.

\title{
MERCOSUL
}

ACORDO DE COMÉRCIO PREFERENCIAL ENTRE O MERCOSUL E A REPÚBLICA DA INDIA. Nova Déli, 2005. Ministério das Relações Exteriores do Paraguai. Disponível em:

<http://www.mre.gov.py/tratados/public_web/DetallesTratado.aspx?id=ROno6rWOcDsMyq 7PZqpKTA\%3d\%3d\&em=lc4aLYHVB0dF+kNrtEvsmZ96BovjLlz0mcrZruYPcn8\%3d>.

Acesso em: 28 ago.2016.

ACORDO DE COMERCIO PREFERENCIAL ENTRE O MERCOSUL E A UNIÃO ADUANEIRA DA ÁFRICA AUSTRAL (SACU). Belo Horizonte, 2004. Ministério das Relações Exteriores do Paraguai. Disponível em: <http://www.mre.gov.py/tratados/public_web/DetallesTratado.aspx?id=pxb\%2fifcQ9Dq0Yr vIuZEE7w\%3d\%3d\&em=lc4aLYHVB0dF+kNrtEvsmZ96BovjLlz0mcrZruYPcn8\%3d>. Acesso em: 28 ago.2016. 
ACORDO PARA A FACILITAÇÃO DE ATIVIDADES EMPRESARIAIS NO MERCOSUL. Belo Horizonte, 2004. Ministério das Relações Exteriores do Paraguai. Disponível em: <http://www.mre.gov.py/tratados/public_web/DetallesTratado.aspx?id=Y++puUIb73gMjog Wml8z2w\%3d\%3d\&em=lc4aLYHVB0dF+kNrtEvsmZ96BovjLlz0mcrZruYPcn8\%3d>. Acesso em: 28 ago.2016.

ACORDO PREFERENCIAL DE COMÉRCIO ENTRE O MERCOSUL E A UNIÃO ADUANEIRA DA ÁFRICA DO SUL (SACU). Salvador, 2008. Ministério das Relações Exteriores do Paraguai. Disponível em: <http://www.mre.gov.py/tratados/public_web/DetallesTratado.aspx?id=yXaIpYvAwx02Ha ApPk1Qaw\%3d\%3d\&em=lc4aLYHVB0dF+kNrtEvsmZ96BovjLlz0mcrZruYPcn8\%3d>. Acesso em: 30 ago.2016.

ACORDO QUADRO ENTRE O MERCOSUL E A REPUBLICA ARABE DO EGITO. Porto Iguaçu, 2004. Ministério das Relações Exteriores do Paraguai. Disponível em: <http://www.mre.gov.py/tratados/public_web/DetallesTratado.aspx?id=u5nFKMTngr1YnF YWddHvQg\%3d\%3d\&em=lc4aLYHVB0dF+kNrtEvsmZ96BovjLlz0mcrZruYPcn8\%3d>. Acesso em: 28 ago.2016.

ACORDO QUADRO ENTRE O MERCOSUL E O REINO DE MARROCOS. Brasília, 2004. Ministério das Relações Exteriores do Paraguai. Disponível em: <http://www.mre.gov.py/tratados/public_web/DetallesTratado.aspx?id=nWJqzUXlmXXvz V77w2jW6w\%3d\%3d\&em=lc4aLYHVB0dF+kNrtEvsmZ96BovjLlz0mcrZruYPcn8\%3d>. Acesso em: 28 ago.2016.

ACORDO QUADRO PARA A ADESÃO DA REPUBLICA BOLIVARIANA DA VENEZUELA AO MERCOSUL. Montevidéu, 2005. Ministério das Relações Exteriores do Paraguai. Disponível em: <http://www.mre.gov.py/tratados/public_web/DetallesTratado.aspx?id=bB7KvmTfltlUB1L 6\%2fgCzow\%3d\%3d\&em=lc4aLYHVB0dF+kNrtEvsmZ96BovjLlz0mcrZruYPcn8\%3d>. Acesso em: 28 ago.2016.

ACORDO QUADRO PARA A CRIAÇÃO DE UMA AREA DE LIVRE COMERCIO ENTRE O MERCOSUL E A REPUBLICA DA AFRICA DO SUL. Florianópolis, 2000. Ministério das Relações Exteriores do Paraguai. Disponível em: <http://www.mre.gov.py/tratados/public_web/DetallesTratado.aspx?id=2su9OY4L8FfCN8c OJ4\%2fkjg\%3d\%3d\&em=lc4aLYHVB0dF+kNrtEvsmZ96BovjLlz0mcrZruYPcn8\%3d>. Acesso em: 25 ago.2016.

ACORDO QUADRO PARA A CRIAÇÃO DE UMA AREA DE LIVRE COMERCIO ENTRE O MERCOSUL E A REPUBLICA DA SIRIA. Foz do Iguaçu, 2010. Ministério das Relações Exteriores do Paraguai Disponível em: <http://www.mre.gov.py/tratados/public_web/DetallesTratado.aspx?id=5DB0UKH9iDy3ZL 
TLrBhB6A\%3d\%3d\&em=lc4aLYHVB0dF+kNrtEvsmZ96BovjLlz0mcrZruYPcn8\%3d>. Acesso em: 30 ago.2016.

ACORDO-QUADRO DE COMERCIO E COOPERAÇÃO ECONOMICA ENTRE O MERCOSUL E A ORGANIZAÇÃO PARA A LIBERTAÇÃO DA PALESTINA, EM NOME DA AUTORIDADE NACIONAL PALESTINA. Foz do Iguaçu, 2010. Ministério das Relações Exteriores do Paraguai. Disponível em: <http://www.mre.gov.py/tratados/public_web/DetallesTratado.aspx?id=oPyaaAg8zyIIWPR odz0LEA\%3d\%3d\&em=lc4aLYHVB0dF+kNrtEvsmZ96BovjLlz0mcrZruYPcn8\%3d>. Acesso em: 30 ago.2016.

ACORDO-QUADRO DE COMÉRCIO E COOPERAÇÃO ECONOMICA ENTRE O MERCOSUL E A REPÚBLICA DA TUNISIA. Paraná, 2014. Ministério das Relações Exteriores do Paraguai. Disponível em: <http://www.mre.gov.py/tratados/public_web/DetallesTratado.aspx?id=QRbSCoGLiQIRpq hyX1RE2Q\%3d\%3d\&em=lc4aLYHVB0dF+kNrtEvsmZ96BovjLlz0mcrZruYPcn8\%3d>. Acesso em: 30 ago.2016.

ACORDO-QUADRO DE COMÉRCIO ENTRE O MERCOSUL E O ESTADO DE ISRAEL. Montevidéu, 2005. Ministério das Relações Exteriores do Paraguai. Disponível em: <http://www.mre.gov.py/tratados/public_web/DetallesTratado.aspx?id=ElsoDxj6v2OCfJKrf 1HfsQ\%3d\%3d\&em=lc4aLYHVB0dF+kNrtEvsmZ96BovjLlz0mcrZruYPcn8\%3d>. Acesso em: 28 ago. 2016.

ACORDO-QUADRO DE COOPERAÇÃO ECONÔMICA ENTRE OS ESTADOS PARTES DO MERCOSUL E OS ESTADOS MEMBROS DO CONSELHO DE COOPERAÇÃO DOS ESTADOS ÁRABES DO GOLFO (CCG). Brasília, 2005. Ministério das Relações Exteriores do Paraguai. Disponível em: <http://www.mre.gov.py/tratados/public_web/DetallesTratado.aspx?id=DvuMcsykAIHW5P YUz27b8Q\%3d\%3d\&em=lc4aLYHVB0dF+kNrtEvsmZ96BovjLlz0mcrZruYPcn8\%3d>. Acesso em: 28 ago.2016.

ACORDO-QUADRO ENTRE O MERCOSUL E A REPUBLICA DA INDIA. Assunção, 2003. Ministério das Relações Exteriores do Paraguai. Disponível em: <http://www.mre.gov.py/tratados/public_web/DetallesTratado.aspx?id=VF+BuHgPVEMV HtUhg2P8ZA\%3d\%3d\&em=lc4aLYHVB0dF+kNrtEvsmZ96BovjLlz0mcrZruYPcn8\%3d>. Acesso em: 25 ago.2016.

ACORDO-QUADRO ENTRE O MERCOSUL E O REINO HASHEMITA DA JORDÂNIA. São Miguel de Tucuman, 2008. Ministério das Relações Exteriores do Paraguai. Disponível em:

<http://www.mre.gov.py/tratados/public_web/DetallesTratado.aspx?id=FzBIDYRunG4foMl MeX2U4g\%3d\%3d\&em=lc4aLYHVB0dF+kNrtEvsmZ96BovjLlz0mcrZruYPcn8\%3d>.

Acesso em: 30 ago.2016. 
ACORDO-QUADRO INTER REGIONAL DE COOPERAÇÃO ENTRE A COMUNIDADE EUROPEIA E SEUS ESTADOS MEMBROS, POR UMA PARTE, E O MERCADO COMUM DO SUL E SEUS ESTADOS PARTES, POR OUTRA. Madrid, 1995. Ministério das Relações Exteriores do Paraguai. Disponível em: <http://www.mre.gov.py/tratados/public_web/DetallesTratado.aspx?id=It969rctpjSJ8GA3B UZQvA\%3d\%3d\&em=lc4aLYHVB0dF+kNrtEvsmZ96BovjLlz0mcrZruYPcn8\%3d>.

Acesso em: 25 ago.2016.

ACORDO-QUADRO PARA O ESTABELECIMENTO DE UMA AREA DE LIVRE COMERCIO ENTRE O MERCOSUL E A REPUBLICA DA TURQUIA. São Miguel de Tucumán, 2008. Ministério das Relações Exteriores do Paraguai. Disponível em: <http://www.mre.gov.py/tratados/public_web/DetallesTratado.aspx?id=3sD3r8+x7J5Kmrjtu

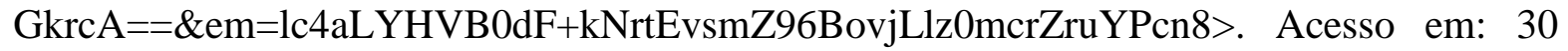
ago.2016.

ACORDO-QUADRO SOBRE COMÉRCIO ENTRE O MERCOSUL E O A REPÚBLICA ISLÂMICA DO PAQUISTÃO. Córdoba, 2006. Ministério das Relações Exteriores do Paraguai. $\quad$ Disponível Disponível em: <http://www.mre.gov.py/tratados/public_web/DetallesTratado.aspx?id=ZHrFFs5jWUxoSX P9jwzqcA\%3d\%3d\&em=lc4aLYHVB0dF+kNrtEvsmZ96BovjLlz0mcrZruYPcn8\%3d>. Acesso em: 28 ago.2016.

MEMORANDO DE ENTENDIMENTO DE COMÉRCIO E COOPERAÇÃO ECONÔMICA ENTRE O MERCOSUL E A REPÚBLICA DO LÍBANO. Paraná, 2014. Ministério das Relações Exteriores do Paraguai. Disponível em: <http://www.mre.gov.py/tratados/public_web/DetallesTratado.aspx?id=U2fUu9mphIV7Yn MHDG1cpw\%3d\%3d\&em=lc4aLYHVB0dF+kNrtEvsmZ96BovjLlz0mcrZruYPcn8\%3d>. Acesso em: 30 ago.2016.

MEMORANDO DE ENTENDIMENTO ENTRE O MERCOSUL E A REPÚBLICA COOPERATIVISTA DA GUIANA EM MATÉRIA DE COMÉRCIO E INVESTIMENTO. Rio de Janeiro, 1999. Ministério das Relações Exteriores do Paraguai. Disponível em: <http://www.mre.gov.py/tratados/public_web/DetallesTratado.aspx?id=9z8pG\%2faIwLLaB \%2fsNR54ADg\%3d\%3d\&em=lc4aLYHVB0dF+kNrtEvsmZ96BovjLlz0mcrZruYPcn8\%3d >. Acesso em: 25 ago.2016.

MEMORANDO DE ENTENDIMENTO ENTRE O MERCOSUL E A REPÚBLICA DE TRINIDAD E TOBAGO EM MATÉRIA DE COMÉRCIO E INVESTIMENTO. Rio de Janeiro, 1999. Ministério das Relações Exteriores do Paraguai. Disponível em: <http://www.mre.gov.py/tratados/public_web/DetallesTratado.aspx?id=fpP3xdc7Eu+Dpjybj 8cDAA\%3d\%3d\&em=lc4aLYHVB0dF+kNrtEvsmZ96BovjLlz0mcrZruYPcn8\%3d>.

Acesso em: 25 ago.2016.

MEMORANDO DE ENTENDIMENTO PARA O ESTABELECIMENTO DE UM GRUPO CONSULTIVO CONJUNTO PARA A PROMOCAO DE COMERCIO E 
INVESTIMENTOS ENTRE O MERCOSUL E A REPUBLICA DA COREIA. Assunção. 2009. Ministério das Relações Exteriores do Paraguai. Disponível em: <http://www.mre.gov.py/tratados/public_web/DetallesTratado.aspx?id=hGerkGNKcmFeUC EXf7f4zg\%3d\%3d\&em=lc4aLYHVB0dF+kNrtEvsmZ96BovjLlz0mcrZruYPcn8\%3d>.

Acesso em: 30 ago.2016.

MEMORANDO DE ENTENDIMENTO SOBRE COOPERAÇÃO EM COMÉRCIO E INVESTIMENTOS E PLANO DE AÇÃO ENTRE O MERCOSUL E A REPÚBLICA DE CINGAPURA. Nova Iorque, 2007. Ministério das Relações Exteriores do Paraguai. Disponível em: <http://www.mre.gov.py/tratados/public_web/DetallesTratado.aspx?id=wzisEu10M70GhX6 JCMFmeg\%3d\%3d\&em=lc4aLYHVB0dF+kNrtEvsmZ96BovjLlz0mcrZruYPcn8\%3d>. Acesso em: 30 ago.2016.

PROTOCOLO ADICIONAL AO TRATADO DE ASSUNÇÃO SOBRE ESTRUTURA INSTITUCIONAL DO MERCOSUL (PROTOCOLO DE OURO PRETO). Ouro Preto, 1994. Ministério das Relações Exteriores do Paraguai. Disponível em: <http://www.mre.gov.py/tratados/public_web/DetallesTratado.aspx?id=QvE8z5bllxmQDCf TQ9YVBA\%3d\%3d\&em=lc4aLYHVB0dF+kNrtEvsmZ96BovjLlz0mcrZruYPcn8\%3d>. Acesso em: 25 ago.2016.

PROTOCOLO DE ADESÃO DA REPÚBLICA BOLIVARIANA DA VENEZUELA. Caracas, 2006. Ministério das Relações Exteriores do Paraguai. Disponível em: <http://www.mre.gov.py/tratados/public_web/DetallesTratado.aspx?id=LTaMVymw\%2faY C9dXPH0uCXg\%3d\%3d\&em=lc4aLYHVB0dF+kNrtEvsmZ96BovjLlz0mcrZruYPcn8\%3d >. Acesso em: 28 ago.2016.

PROTOCOLO DE ADESÃO DO ESTADO PLURINACIONAL DA BOLÍVIA AO MERCOSUL. Brasília, 2015. Ministério das Relações Exteriores do Paraguai. Disponível em:

<http://www.mre.gov.py/tratados/public_web/DetallesTratado.aspx?id=wPEBvbgLt4cMYa xJfUrS\%2fw\%3d\%3d\&em=lc4aLYHVB0dF+kNrtEvsmZ96BovjLlz0mcrZruYPcn8\%3d>. Acesso em: 30 ago.2016.

PROTOCOLO DE COLONIA PARA PROMOCION Y PROTECCION RECIPROCA DE INVERSIONES EM EL MERCOSUR. Colônia, 1994. Ministério das Relações Exteriores do Paraguai. Disponível em: <http://www.mre.gov.py/tratados/public_web/DetallesTratado.aspx?id=QbqmyvQ17CGPrIu gK4Iltg\%3d\%3d\&em=lc4aLYHVB0dF+kNrtEvsmZ96BovjLlz0mcrZruYPcn8\%3d>. Acesso em: 19 ago. 2016.

PROTOCOLO DE CONTRATAÇÕES PÚBLICAS DO MERCOSUL. Córdoba, 2006. Ministério das Relações Exteriores do Paraguai. Disponível em: <http://www.mre.gov.py/tratados/public_web/DetallesTratado.aspx?id=\%2ff6EBn0v8Qqfg 
MpQ7Bc17A\%3d\%3d\&em=lc4aLYHVB0dF+kNrtEvsmZ96BovjLlz0mcrZruYPcn8\%3d>. Acesso em: 30 ago.2016.

PROTOCOLO DE CONTRATAÇÕES PÚBLICAS DO MERCOSUL. Montevidéu, 2003. Ministério das Relações Exteriores do Paraguai. Disponível em: <http://www.mre.gov.py/tratados/public_web/DetallesTratado.aspx?id=FMiD4ao0UW5sfv Mu2KT2vQ\%3d\%3d\&em=lc4aLYHVB0dF+kNrtEvsmZ96BovjLlz0mcrZruYPcn8\%3d>. Acesso em: 25 ago.2016.

PROTOCOLO DE CONTRATAÇÕES PÚBLICAS DO MERCOSUL. Montevidéu, 2004. Ministério das Relações Exteriores do Paraguai. Disponível em: <http://www.mre.gov.py/tratados/public_web/DetallesTratado.aspx?id=iiS0dzteoNUIZtx4t RaU2Q\%3d\%3d\&em=lc4aLYHVB0dF+kNrtEvsmZ96BovjLlz0mcrZruYPcn8\%3d>. Acesso em: 28 ago.2016.

PROTOCOLO DE HARMONIZAÇÃO DE NORMAS SOBRE PROPRIEDADE INTELECTUAL NO MERCOSUL EM MATÉRIA DE MARCAS, INDICAÇÕES DE PROCEDÊNCIA E DENOMINAÇÕES DE ORIGEM. Assunção, 1995. Ministério das Relações Exteriores do Paraguai. Disponível em: <http://www.mre.gov.py/tratados/public_web/DetallesTratado.aspx?id=2ooBwPZqYBYDy $\mathrm{HTjMx}+\mathrm{HmQ} \% 3 \mathrm{~d} \% 3 \mathrm{~d} \& \mathrm{em}=\mathrm{lc4aLYHVB0dF}+\mathrm{kNrtEvsmZ96BovjLlz0mcrZruYPcn8 \% 3d>.}$ Acesso em: 25 ago.2016.

PROTOCOLO DE MONTEVIDÉU SOBRE O COMÉRCIO DE SERVIÇOS DO MERCOSUL. Montevidéu, 1995. Ministério das Relações Exteriores do Paraguai. Disponível em: <http://www.mre.gov.py/tratados/public_web/DetallesTratado.aspx?id=1RzZPEFh9pQPgh DrS5IZow\%3d\%3d\&em=lc4aLYHVB0dF+kNrtEvsmZ96BovjLlz0mcrZruYPcn8\%3d>. Acesso em: 25 ago.2016.

PROTOCOLO RELATIVO AO CÓDIGO ADUANEIRO DO MERCOSUL. Ouro Preto, 1994. Ministério das Relações Exteriores do Paraguai. Disponível em: <http://www.mre.gov.py/tratados/public_web/DetallesTratado.aspx?id=Q3fTVDNdHPrY\% 2fWGSfN2PwQ\%3d\%3d\&em=lc4aLYHVB0dF+kNrtEvsmZ96BovjLlz0mcrZruYPcn8\%3d >. Acesso em: 25 ago.2016.

PROTOCOLO SOBRE PROMOCAO E PROTECAO DE INVESTIMENTOS PROVENIENTES DE ESTADOS NÃO PARTES DO MERCOSUL. Buenos Aires, 1994. Ministério das Relações Exteriores do Paraguai. Disponível em: <http://www.mre.gov.py/tratados/public_web/DetallesTratado.aspx?id=MzFrhVNTCm7X+ Ji9lTDZ0Q\%3d\%3d\&em=lc4aLYHVB0dF+kNrtEvsmZ96BovjLlz0mcrZruYPcn8\%3d>. Acesso em: 25 ago.2016. 
TRATADO DE LIVRE COMERCIO ENTRE MERCOSUL E O ESTADO DA PALESTINA. Montevidéu, 2011. Ministério das Relações Exteriores do Paraguai. Disponível em: <http://www.mre.gov.py/tratados/public_web/DetallesTratado.aspx?id=Da0viY0XRJ9TahV 9+XJw7Q\%3d\%3d\&em=lc4aLYHVB0dF+kNrtEvsmZ96BovjLlz0mcrZruYPcn8\%3d>. Acesso em: 30 ago.2016.

TRATADO DE LIVRE COMÉRCIO ENTRE O MERCOSUL E A REPUBLICA ARABE DO EGITO. San Juan, 2010. Ministério das Relações Exteriores do Paraguai. Disponível em: <http://www.mre.gov.py/tratados/public_web/DetallesTratado.aspx?id=+8CsSy3sFmfNH1c 84fIBCg\%3d\%3d\&em=lc4aLYHVB0dF+kNrtEvsmZ96BovjLlz0mcrZruYPcn8\%3d>.

Acesso em: 30 ago.2016.

TRATADO DE LIVRE COMÉRCIO ENTRE O MERCOSUL E O ESTADO DE ISRAEL. Montevidéu, 2007. Ministério das Relações Exteriores do Paraguai. Disponível em: $<$ http://www.mre.gov.py/tratados/public_web/DetallesTratado.aspx?id=EMs9YVOPyafhQK DNGWZcqg==\&em=lc4aLYHVB0dF+kNrtEvsmZ96BovjLlz0mcrZruYPcn8=>. Acesso em: 16 abr. 2016.

TRATADO PARA CONSTITUIÇÃO DE UM MERCADO COMUM (TRATADO DE ASSUNÇÃO). 1991. Ministério das Relações Exteriores do Paraguai. Disponível em: <http://www.mre.gov.py/tratados/public_web/DetallesTratado.aspx?id=0GXnoF+V0qWCz +EoiVAdUg\%3d\%3d\&em=lc4aLYHVB0dF+kNrtEvsmZ96BovjLlz0mcrZruYPcn8\%3d>. Acesso em: 19 ago.2016. 


\section{ANEXO}

\section{Entrevistas Realizadas}

\section{Entrevista Doutor Fernando Magalhães Furlan, antigo secretário-executivo do} MDIC.

1. Qual a opinião pessoal de V. Exa. com relação ao desempenho da OMC nos últimos 20 anos, bem como os prognósticos para o futuro próximo? Como o Brasil se tem desempenhado vis-à-vis à OMC, no passado recente e quais os possíveis prognósticos para o futuro?

R: Creio que a OMC cumpriu um papel crucial de referência em legislação, melhores práticas e especialmente em solução de controvérsias. Não fosse a OMC, certamente as trocas internacionais sofreriam muito pela falta de referencial normativo. Muito foi alcançado e é digno de louvor o engajamento de muitos membros ao longo dos anos. Com a utilização do método do "single undertaking", certamente muitas negociações não avançaram e parece que agora a OMC passa por uma certa crise de identidade. Pude sentir isso na Conferência de Nairóbi, da qual participei na qualidade de vice-ministro do Comércio do Brasil. Principalmente por conta da intransigência indiana, muito pontos não avançaram e uma crise institucional se instalou silenciosamente.

A OMC está frente a uma escolha entre o "single undertaking" e as acordos temáticos e voluntários, em que se escolhem os temas a negociar e a participação é voluntária. Algo como o recente TISA (Trade in Services Agreement), por exemplo.

O Brasil é reconhecido por todos os membros da OMC e pelo Secretariado, como um país de tem contribuído sobremaneira para a consolidação do sistema de solução de controvérsias, para as negociações em razão de sua posição de destaque entre os "países em desenvolvimento", especialmente quanto a temas como acesso a mercados agrícolas, fim de subsídios à exportação e de apoio interno, dentre outros.

Entendo que o futuro da OMC depende de como a organização se posicionará perante a comunidade comercial internacional, mas com certeza ela poderá se manter como uma 
referência de melhores práticas internacionais, ponto de convergência em questões de conteúdo e órgão de solução de controvérsias.

2. Quais foram as principais mudanças na área do comércio internacional, levadas a cabo pelo atual Governo federal? Qual sua opinião pessoal sobre tais mudanças.

R: Desde a gestão do então ministro Armando Monteiro Neto (2015-2016) foi concebido e implementado o Plano Nacional de Exportações, incluindo avanços como o "Portal Único de Comércio Exterior", digitalizando 100\% das operações de exportação e importação e reduzindo em até 50\% o tempo gasto. Além disso, foram definidos o mercados-alvo para o período 2015-2018; foi definido um novo modelo de tratados de proteção de investimentos, o Acordo de Cooperação e Facilitação de Investimentos (ACFIs), um novo paradigma internacional em que se opta por uma modelo Estado-Estado, em contraposição ao modelo utilizado pelo países desenvolvidos de tratados Estado - Investidor; foram assinados ou expandidos acordos preferenciais de comércio com vários países sulamericanos (Chile, Peru, Colômbia, Paraguai, Argentina, etc.); foi assinado o primeiro acordo bilateral de Compras Governamentais com o Peru, em 2016, etc.

A CAMEX sofreu mudanças desnecessárias desde a posse de Michel Temer, a partir de pressões do chanceler José Serra. Depois de alguns meses, o Governo alterou novamente a estrutura da CAMEX que passou a ser chefiada não mais pelo presidente da República, mas pelo Ministro-Chefe da Casa Civil. Ocorre que, com isso, uma situação estranha se instalou na CAMEX: ela é chefiada pelo ministro-chefe da Casa Civil, mas sua secretariaexecutiva está subordinada ao ministro das Relações Exteriores.

3. O que se pode dizer do desempenho, nos últimos 20 anos, da OMC, da ALADI e do MERCOSUL e quais os prognósticos para o futuro próximo?

R: Quanto à OMC, creio ter respondido, ainda que brevemente, na resposta acima. Quanto à ALADI, creio que é um tratado econômico-comercial multilateral de grande importância e que funciona como um grande "guarda-chuva", inclusive para o Mercosul. Este, o Mercosul, infelizmente sofre há anos de "paralisia decisória" em razão da fórmula intergovernamental de suas decisões e o espaço dado a questões ideológicas, de lado a lado. 
Com o impasse atual com a Venezuela, e o desgaste do Brasil em relação ao Uruguai, o Mercosul sofrerá ainda mais em sua governança e nos resultados a serem demonstrados.

4. O que se pode dizer da participação, nos últimos 20 anos do Brasil na OMC, na ALADI e no MERCOSUL e quais os prognósticos para o futuro próximo?

R: Creio que o Brasil tem sido reconhecido como uma das referências entre países em desenvolvimento membros da OMC, conforme descrito acima. Quanto ao Mercosul, entendo que o Brasil deveria investir mais na institucionalidade do bloco, diminuindo o espaço para interferências políticas e ideológicas.

5. Qual o papel do Ministério da Indústria, Comércio Exterior e Serviços e do MRE no comércio internacional do Brasil? Como vê as mudanças que o atual Governo federal vem imprimindo? Quais poderiam ser os prognósticos possíveis?

R: Vejo com certo receio a confusão entre diplomacia de Estado e diplomacia comercial. Ambas são complementares, embora não devam imiscuir-se, sob pena de estorvo recíproco. Entendo que a CAMEX deva ser chefiada e secretariada pela Casa Civil. Creio que a Apex-Brasil poderá se beneficiar com ganhos de escopo em relação aos Setores de Promoção Comercial (SECOM's) das legações brasileiras no exterior.

\section{Entrevista Professor Welber Barral, antigo Secretário de Comércio Exterior do} MDIC.

1. Qual foi o desempenho da OMC nos últimos 20 anos e quais os prognósticos possíveis para o futuro próximo? Como o Brasil se tem desempenhado vis-à-vis à OMC, no passado recente e quais os possíveis prognósticos para o futuro próximo?

R.: A Rodada Uruguai consolidou um momento especifico de concessões que permitiram enormes resultados, que eram impensáveis quando a Rodada se iniciou. Este 
momentum não voltou a ocorrer desde então. A tentativa de agenda em Doha, em 2001, acabou fracassada, e mesmo evoluções pequenas (como o acordo de facilitação de comercio), somente foram obtidas com muita dificuldade.

O Brasil conseguiu protagonismo, ao liderar os países em desenvolvimento durante a Rodada, mas não consegue avançar em negociações multilaterais relevantes em a concordância de EUA e EU.

2. Idem com referência à ALADI

R.: A Aladi continua a existir como o registro dos ACE's que envolvem parte importante dos países latino-americanos. Entretanto, sua relevância corre risco, na medida em que esses países negociam acordos extra regionais de segunda geração.

3. Idem relativamente ao MERCOSUL

R.: Mercosul teve relevância política inegável no Cone Sul, mas sofreu uma "estagnação institucional" desde a crise argentina de 2001. Sua evolução futura depende, fundamentalmente, da conjunção política e econômica entre Brasil e Argentina.

4. Quais foram as principais mudanças na área do comércio internacional, levadas a cabo pelo atual Governo federal? Qual o prognóstico sobre tais mudanças?

R.: O Brasil continua uma economia relativamente fechada, com baixa taxa de participação do comércio exterior em seu PIB total.

Há promessas de abertura por parte de sucessivos governos, normalmente por meio de acordos comerciais. Estas promessas, entretanto, acabam não se concretizando em razão da conjuntura internacional (crise econômica e/ou maior protecionismo).

De qualquer forma, e independentemente de acordos regionais ou bilaterais, o Brasil tem enorme tarefa a realizar, no que se refere à competitividade de sua produção industrial, afetada por distorções tributárias, altos custos logísticos e excesso de burocracia. 
5. Qual o papel no passado recente e no futuro próximo do Ministério das Relações Exteriores e do Ministério da Indústria, Comércio Exterior e Serviços no comércio internacional do Brasil? Quais os prognósticos possíveis?

R.: No atual governo, o papel do MDIC foi reduzido, com a transferência da Apex e Camex para o MRE, além do BNDES para o MPOG.

Esta não é a tendência da maioria dos governos atuais, que têm criado estruturas de comércio exterior independentes da estrutura de política externa. Serão necessários alguns anos para avaliar se esta nova estrutura aumenta a eficácia das ações do governo brasileiro.

III. Entrevista Embaixador Santiag Irazabal Mourão, Subsecretário-Geral de Cooperação Internacional, Promoção Comercial e Temas Culturais do MRE.

1. Qual foi o desempenho da OMC nos últimos 20 anos e quais os prognósticos possíveis para o futuro próximo? Como o Brasil se tem desempenhado vis-à-vis à OMC, no passado recente e quais os possíveis prognósticos para o futuro próximo?

R.: A Organização Mundial do Comércio (OMC) é a sucessora do Acordo Geral de Tarifas e Comércio (GATT, na sigla em inglês) e foi fundada após a conclusão da Rodada Uruguai (1986-1994) com a assinatura do Tratado de Marraquexe no dia 15 de abril de 1994. A nova estrutura institucional e os novos acordos que ampliam o escopo da organização passam a vigorar a partir do dia 1o de janeiro de 1995.

A dinâmica consagrada com a criação da OMC tem como principal objetivo a contínua liberalização comercial e divide-se em três pilares: o pilar negociador, em que os países-membros continuam discutindo novos acordos para aumentar o nível dos compromissos representados pelos Acordos abarcados, em sucessivas rodadas de negociação de aprofundamento das obrigações, atualmente representado pela Rodada Doha, iniciada em 2001; o pilar de monitoramento mútuo do cumprimento das obrigações assumidas, consubstanciado nas sucessivas revisões de política comercial com fundamento no Mecanismo de Revisão das Políticas Comerciais (Anexo III do Acordo de Marraquexe); e, finalmente, o pilar de solução de 
controvérsias, talvez o mais conhecido, baseado no Entendimento sobre Solução de Controvérsias (Anexo II do Acordo de Marraquexe).

Com a demora excessiva para a conclusão da Rodada Doha, a mais alongada da história das rodadas de negociação, atualmente com mais de 15 anos, é comum críticos apontarem a falência da Organização Mundial do Comércio como instrumento hábil para a contínua liberalização comercial. Esse entendimento decorre, talvez, de conhecimento limitado acerca do funcionamento da organização. Os dois outros pilares (monitoramento e solução de controvérsias) funcionam com regularidade e dão resultados palpáveis em termos de ganhos comerciais e de cumprimento das obrigações já assumidas. Mesmo o pilar negociador, apesar de não ter sido possível cumprir a contento o mandato da Rodada Doha, entrega resultados práticos, de que é exemplo a conclusão do Acordo de Facilitação de Comércio, no presente em fase de depósito das ratificações para entrada em vigor.

O Embaixador brasileiro Roberto Azevêdo é o atual Diretor-Geral da OMC (quadriênio 2013-2017) e poderá concorrer à reeleição para um segundo período à frente da organização para o quadriênio subsequente. A recondução do Embaixador é dada como praticamente certa e até o momento não existe sequer indicação de que haja concorrente, fato que denota a excelência do trabalho desempenhado no período.

Os principais temas a serem tratados na agenda futura da organização refletem certa tensão presente entre países desenvolvidos e países em desenvolvimento. Enquanto estes entendem que algumas "dívidas" históricas da organização ainda precisam ser pagas, notadamente na liberalização do comércio de produtos agrícolas, aqueles tentam avançar os chamados "novos temas", como aprofundamento de obrigações relacionadas a propriedade intelectual e comércio eletrônico.

2. Qual foi o desempenho da ALADI nos últimos 20 anos e quais os prognósticos possíveis para o futuro próximo? Como o Brasil se tem desempenhado vis-à-vis à ALADI, no passado recente e quais os possíveis prognósticos para o futuro próximo?

R.: A ALADI é o arcabouço jurídico institucional dos acordos econômicocomerciais da América Latina. Desde a década de 1990, as negociações no âmbito da ALADI estão centradas não em amplas rodadas multilaterais, como ocorre na 
OMC, mas em acordos bilaterais ou plurilaterais de alcance parcial, sobretudo os chamados Acordos de Complementação Econômica (ACE's), que liberalizam o comércio entre alguns países membros, como é o caso do próprio MERCOSUL (ACE-18).

O Brasil tem sido protagonista nesse processo, tendo celebrado, nos últimos vinte anos, importantes acordos com Chile (1996), Bolívia (1996), México (2002), Colômbia (2004), Equador (2004), Venezuela (2004 e 2012), Peru (2005) e Cuba (2006). Em virtude desses acordos, o Brasil já possui, individualmente ou em conjunto com o MERCOSUL, uma ampla rede de preferências comerciais na América Latina. Com Chile e Bolívia, já há 100\% de preferência tarifária (tarifa zero) para todo o universo tarifário. Com os demais países da América do Sul, à exceção de Guiana e Suriname, já estão em curso os cronogramas de desgravação tarifária, que levarão à conformação de uma virtual área de livre comércio até 2019. Segundo estudo da Secretaria-Geral da ALADI, apenas 5,9\% do total do universo tarifário não conta com tarifas preferenciais ou tarifa zero nas exportações do Brasil para os países da ALADI.

Inicialmente restritos a temas tarifários, ao longo dos anos 1990 e 2000 os acordos no âmbito da ALADI passaram a incorporar temas como integração física, cooperação aduaneira e, em alguns casos, serviços. Já nos últimos anos, é possível vislumbrar uma nova geração de acordos, com temas ainda mais diversificados, cujo principal exemplo é o recente acordo firmado pelo Brasil com o Peru (investimentos, serviços e compras governamentais) e a negociação em curso entre Brasil e México, que inclui também temas como propriedade intelectual, coerência regulatória, facilitação do comércio, entre outros.

Tendo em vista o estado avançado da liberalização tarifária na região, tende a assumir importância cada vez maior a discussão de temas conexos, como a facilitação do comércio e a promoção comercial. Destaque-se, por exemplo, o projeto de Certificação de Origem Digital, cujo objetivo é implementar um sistema digital para emissão, assinatura e transmissão dos certificados de origem, dispensando o uso do papel. Outra iniciativa recente de grande êxito é a EXPO ALADI, macro rodada de negócios envolvendo empresários dos países da 
Associação e empresas convidadas da América Central e do Caribe, realizada desde 2014.

Outro traço da ALADI nos últimos vinte anos é a sua expansão numérica, passando de onze para treze países-membros, com a adesão de Cuba (1999) e do Panamá (2012). Atualmente, está em curso o processo de adesão da Nicarágua.

3. Qual foi o desempenho da MERCOSUL nos últimos 20 anos e quais os prognósticos possíveis para o futuro próximo? Como o Brasil se tem desempenhado vis-à-vis à MERCOSUL, no passado recente e quais os possíveis prognósticos para o futuro próximo?

R.: O MERCOSUL foi lançado no início dos anos noventa, na esteira da aproximação havida entre Brasil-Argentina, na década precedente, em contexto de redemocratização, reforma econômica e superação das hipóteses de conflito, em especial no campo nuclear. Paraguai e Uruguai somaram-se às duas maiores economias da região para conformar, em 1991, o Mercado Comum do Sul.

Os acordos fundamentais do Bloco são o Tratado de Assunção (23/3/1991) e o Protocolo de Ouro Preto (17/12/1994). O Tratado de Assunção determinou a conformação de um Mercado Comum em 31 de dezembro de 1994. O Protocolo de Ouro Preto definiu a estrutura institucional dos principais órgãos do MERCOSUL, as atribuições específicas de cada um e seu sistema de tomada de decisões. Adicionalmente, atribuiu personalidade jurídica de Direito Internacional ao bloco.

O MERCOSUL é a mais abrangente iniciativa de integração já empreendida na região latino-americana. É parte essencial do projeto de desenvolvimento nacional brasileiro. Contribui significativamente para a paz, a estabilidade, a cooperação e a prosperidade na região.

Entre 2006 e 2015, o comércio com os sócios do MERCOSUL foi responsável por US\$ 87 bilhões dos US\$ 224 bilhões de superávit comercial acumulados pelo Brasil no período. O bloco é, portanto, fonte importante de divisas para o país. 
O MERCOSUL combina a liberalização do comércio dentro do bloco, com a adoção de um modelo de negociação e da execução de uma agenda de projetos que privilegiam o desenvolvimento socioeconômico e a diversificação produtiva.

Recentemente, o MERCOSUL passou por um necessário processo de reavaliação por todos os seus Membros. O consenso fundamental é o de que é necessário revitalizar a integração econômica e comercial e promover maior liberalização e abertura, tanto do mercado interno quanto do mercado externo.

No comércio intrabloco, o foco está na eliminação das barreiras não tarifárias remanescentes e na expansão do MERCOSUL em novas áreas, como compras governamentais. Igualmente, deve ser concluída em breve a negociação de um acordo de facilitação de investimentos.

A intenção dos sócios é estimular a mobilidade de capitais entre os países do MERCOSUL, promover a alocação mais eficiente desses recursos e tornar o ambiente de negócios mais favorável aos empreendedores.

Paralelamente, os Estados Parte tencionam acelerar as negociações comerciais extra regionais, de forma a ampliar suas exportações e atrair capitais para setores-chave de suas economias.

4. Quais foram as principais mudanças na área do comércio internacional, levadas a cabo pelo atual Governo federal? Qual o prognóstico sobre tais mudanças?

R.: Em seu discurso de posse, o Ministro das Relações Exteriores, José Serra, apresentou dez diretrizes para a nova política externa brasileira. Como ponto de partida conceitual, já na primeira diretriz, se estabeleceu um contraponto à visão que orientou a política anterior, de caráter mais ideológico. No novo modelo, acentuouse o peso dos interesses econômicos na definição das estratégias externas adotadas pelo País. Não por acaso, das dez diretrizes apresentadas pelo novo Chanceler, seis são voltadas à política comercial.

Nesse cenário, um ponto de inflexão importante está relacionado com o Mercosul. A nova gestão trabalha no sentido da renovação do agrupamento regional, fortalecendo-o no que diz respeito ao livre-comércio entre seus países-membros, buscando eliminar entraves internos. Atualmente, chegam a 80 as barreiras de 
comércio dentro do bloco. Além disso, a nova política comercial tem defendido maior agressividade nos acordos bilaterais do Mercosul.

Na busca por uma inserção comercial mais pragmática no cenário mundial, o Brasil deixou para trás a prioridade que dava aos esforços no âmbito do multilateralismo da $\mathrm{OMC}$, passando à ênfase na necessidade de avançar em acordos preferenciais de comércio.

Outro ponto de inflexão da política comercial brasileira parece refletir novo ânimo para a abertura econômica, como no uso da vantagem de acesso ao mercado interno como instrumento de obtenção de concessões negociadas na base da reciprocidade equilibrada. Um bom exemplo disso é a negociação entre o Mercosul e a União Europeia, onde os europeus pedem uma navegação de cabotagem mais aberta aos parceiros sul-americanos. É possível ceder nessa área, desde que o lado europeu ofereça uma contraproposta proporcional.

5. Qual o papel no passado recente e no futuro próximo do Ministério das Relações Exteriores e do Ministério da Indústria, Comércio Exterior e Serviços no comércio internacional do Brasil? Quais os prognósticos possíveis?

R.: Nenhuma outra instituição brasileira, pública ou privada, conta com estrutura de promoção comercial no exterior tão ampla quanto a do Itamaraty, o que demonstra o papel do Ministério na estratégia comercial brasileira - tanto no aspecto político, mediante realização de contatos governamentais e empresariais, quanto no operacional, por meio da produção de informações para subsidiar a promoção do comércio exterior.

O Ministério das Relações Exteriores contribui para atrair capital estrangeiro e internacionalizar empresas brasileiras; realiza gestões junto a Governos estrangeiros sobre interesses comerciais específicos do empresário nacional; produz estudos de inteligência comercial; e contribui para os debates acerca da estratégia de promoção das exportações brasileiras. O Itamaraty também organiza missões comerciais, das quais, muitas vezes, participam autoridades governamentais, em nível presidencial ou ministerial. Eventos de promoção comercial resultam em ações diretas e imediatas de divulgação dos produtos, das empresas e do turismo brasileiros no exterior. 
O Itamaraty, entretanto, não atua isoladamente na elaboração e na execução da estratégia de promoção comercial brasileira, mas desenvolve suas iniciativas em coordenação e cooperação com outros órgãos do Governo brasileiro envolvidos com o tema. Destacam-se, nesse contexto, os esforços empreendidos conjuntamente com o Ministério da Indústria, Comércio Exterior e Serviços (MDIC). A manutenção de ações de complementaridade entre as duas pastas fortalece as ações de política externa, em especial no âmbito das negociações dos acordos comerciais internacionais.

Vale destacar, por oportuno, que a inserção da Apex-Brasil no Ministério das Relações Exteriores - a agência era anteriormente supervisionada pelo MDIC -, oferece ao Itamaraty maior capilaridade interna, que contribui para uma melhor articulação externa dos interesses nacionais, e ajuda a criar sinergias para o desenvolvimento de estratégias de negócios, com maior aderência das negociações comerciais às demandas dos setores privados. 